\title{
Radioisotope Power System Dose Estimation Tool (RPS-DET) User Manual
}

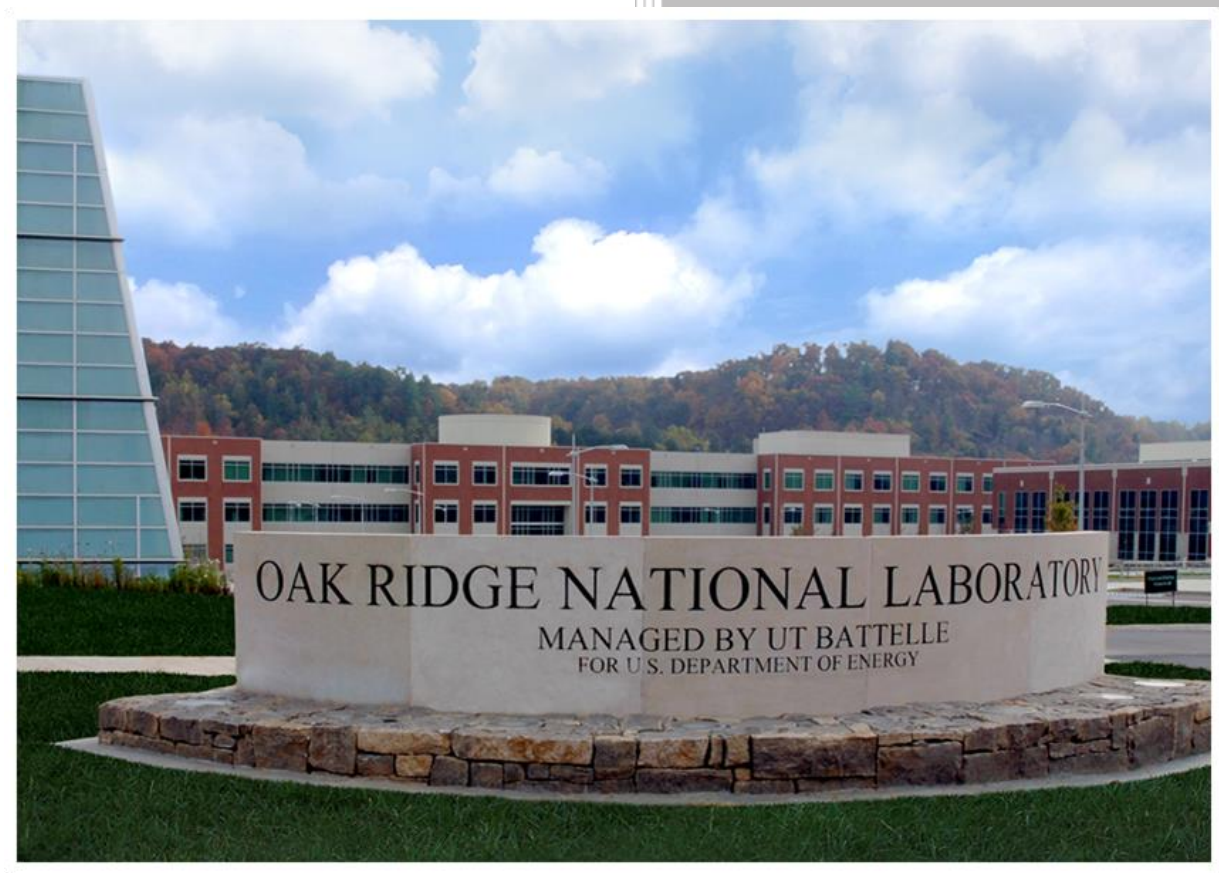

\section{Approved for public release.} Distribution is unlimited.

Michael B. R. Smith Douglas E. Peplow Robert A. Lefebvre William A. Wieselquist

August 24, 2019 


\section{DOCUMENT AVAILABILITY}

Reports produced after January 1, 1996, are generally available free via US Department of Energy (DOE) SciTech Connect.

Website www.osti.gov

Reports produced before January 1, 1996, may be purchased by members of the public from the following source:

National Technical Information Service

5285 Port Royal Road

Springfield, VA 22161

Telephone 703-605-6000 (1-800-553-6847)

TDD 703-487-4639

Fax 703-605-6900

E-mail info@ntis.gov

Website http://classic.ntis.gov/

Reports are available to DOE employees, DOE contractors, Energy Technology Data Exchange representatives, and International Nuclear Information System representatives from the following source:

Office of Scientific and Technical Information

PO Box 62

Oak Ridge, TN 37831

Telephone 865-576-8401

Fax 865-576-5728

E-mail reports@osti.gov

Website http://www.osti.gov/contact.html

This report was prepared as an account of work sponsored by an agency of the United States Government. Neither the United States Government nor any agency thereof, nor any of their employees, makes any warranty, express or implied, or assumes any legal liability or responsibility for the accuracy, completeness, or usefulness of any information, apparatus, product, or process disclosed, or represents that its use would not infringe privately owned rights. Reference herein to any specific commercial product, process, or service by trade name, trademark, manufacturer, or otherwise, does not necessarily constitute or imply its endorsement, recommendation, or favoring by the United States Government or any agency thereof. The views and opinions of authors expressed herein do not necessarily state or reflect those of the United States Government or any agency thereof. 
Reactor and Nuclear Systems Division

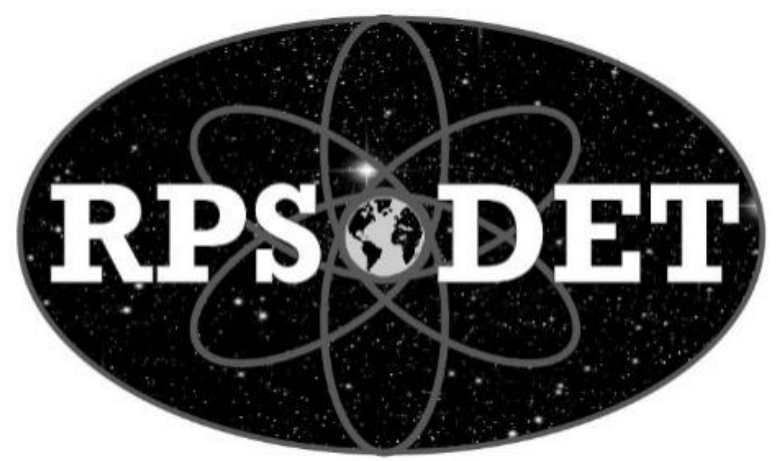

\section{THE RADIOISOTOPE POWER SYSTEM DOSE ESTIMATION TOOL (RPS-DET) USER MANUAL}

Michael B. R. Smith

Douglas E. Peplow

Robert A. Lefebvre

William A. Wieselquist

August 24, 2019

Prepared by

OAK RIDGE NATIONAL LABORATORY

Oak Ridge, TN 37831-6283

managed by

UT-BATTELLE, LLC

for the

US DEPARTMENT OF ENERGY

under contract DE-AC05-00OR22725 



\section{CONTENTS}

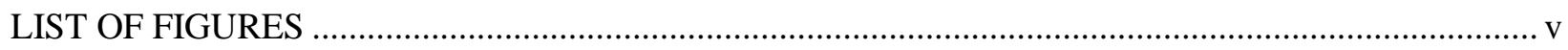

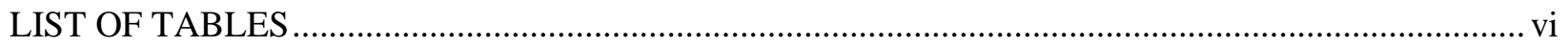

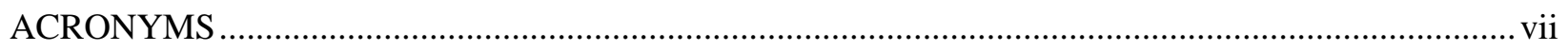

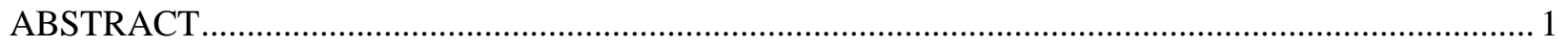

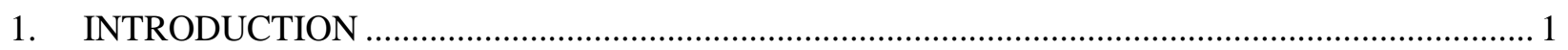

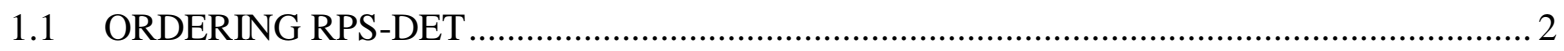

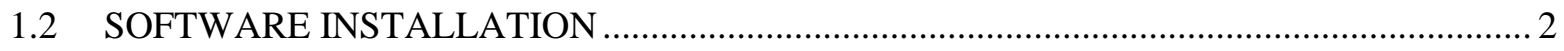

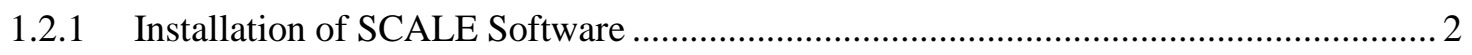

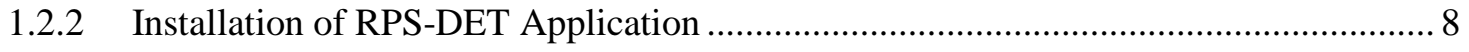

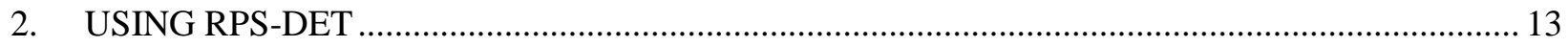

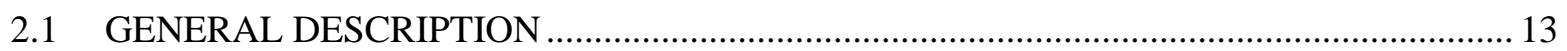

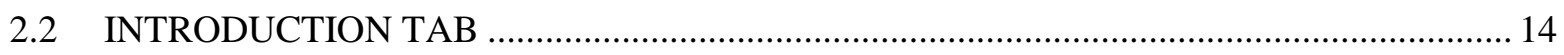

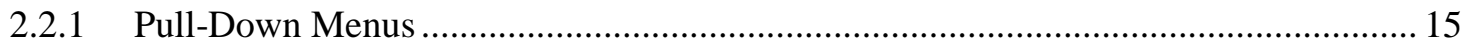

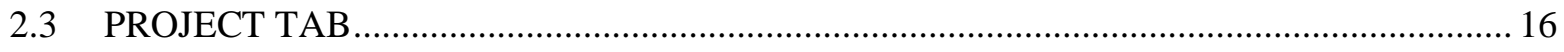

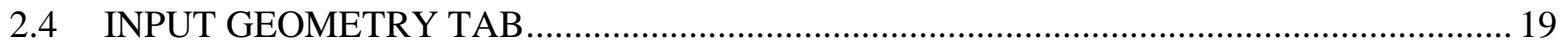

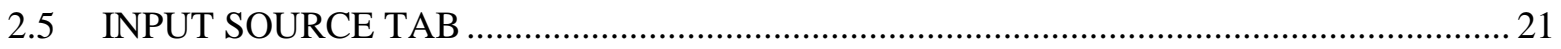

2.5.1 Custom Settings for Fuel and Impurity Values....................................................... 24

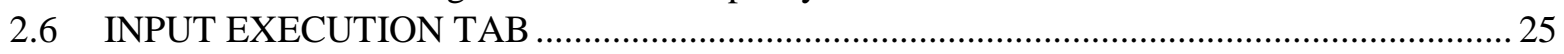

2.6.1 Considerations for Selecting Simulation Runtime and/or Number of Particles...........28

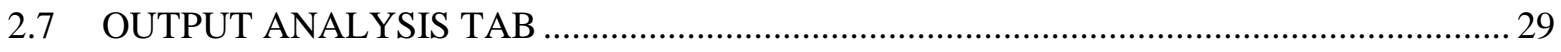

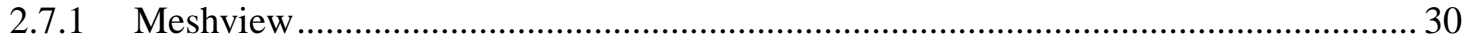

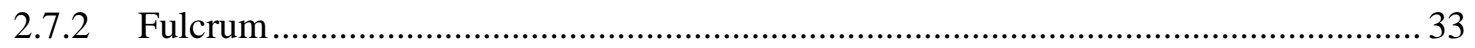

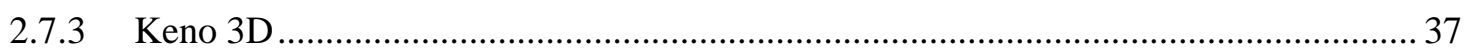

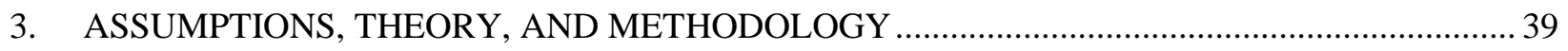

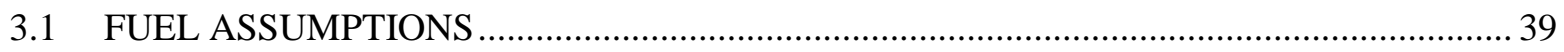

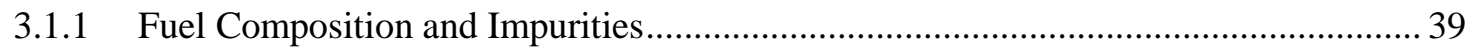

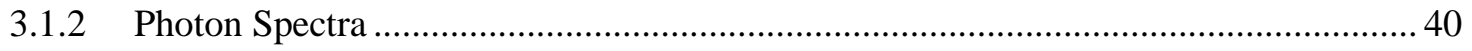

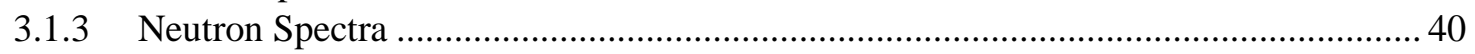

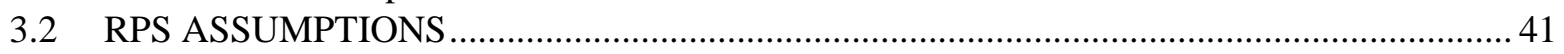

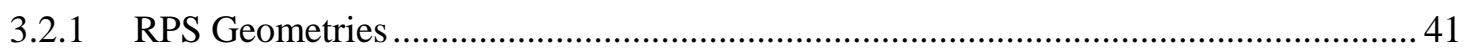

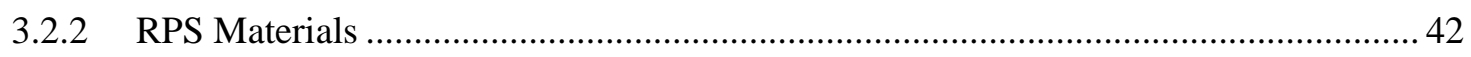

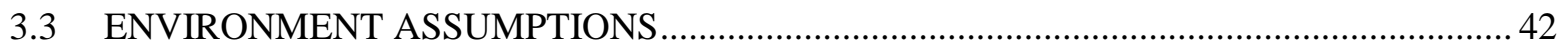

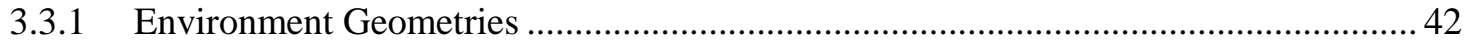

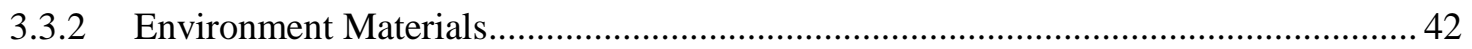

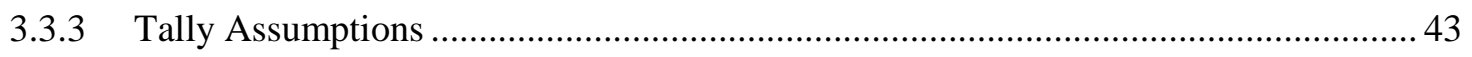

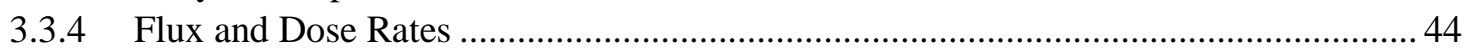

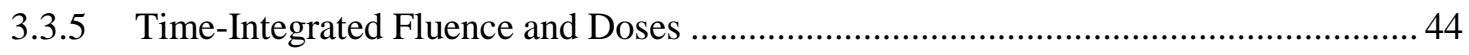

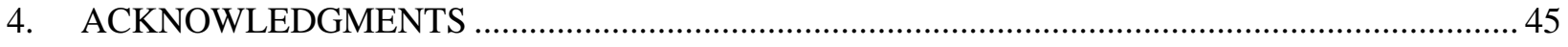

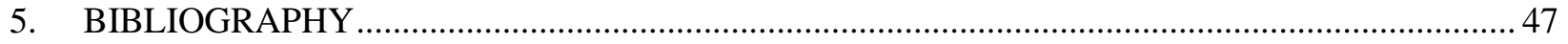

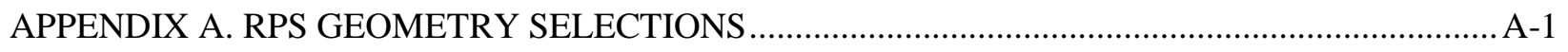

APPENDIX B. ENVIRONMENT GEOMETRY SELECTIONS ….................................................. B-1

APPENDIX C. LOWER ENERGY PHOTON THRESHOLD .........................................................

APPENDIX D. RPS-DET SIMULATION COMPARISONS TO MMRTG MEASUREMENT ............. D-1 


\section{LIST OF FIGURES}

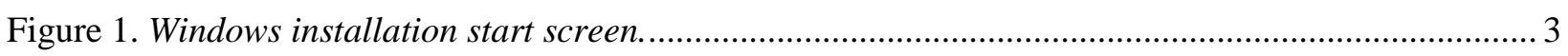

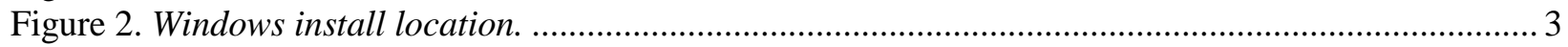

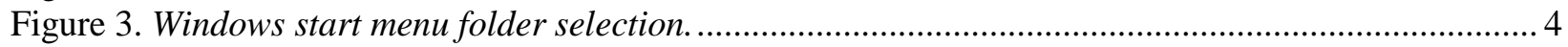

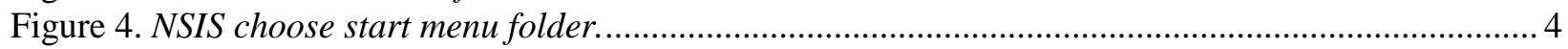

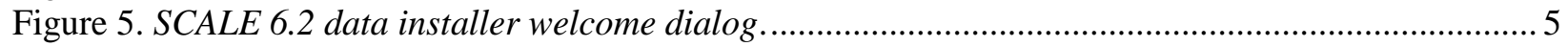

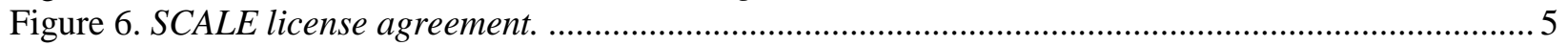

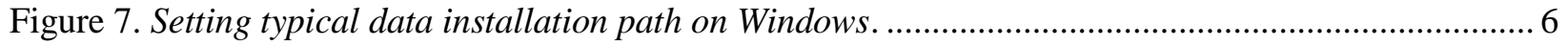

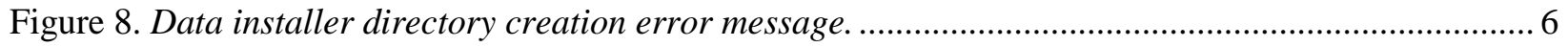

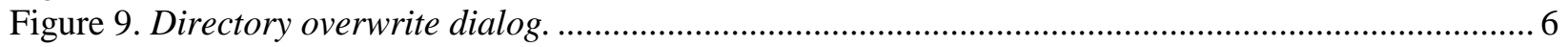

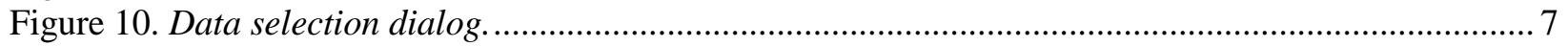

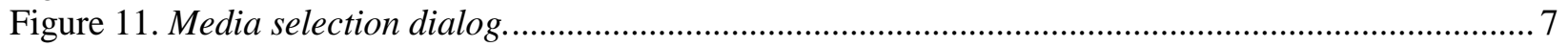

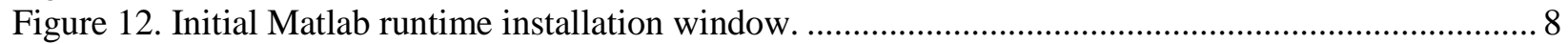

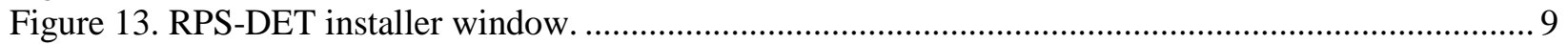

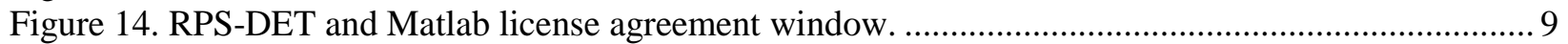

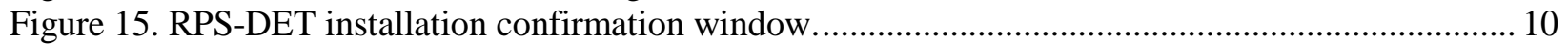

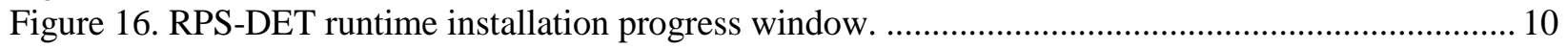

Figure 17. RPS-DET and Matlab runtime installation complete window. ............................................. 11

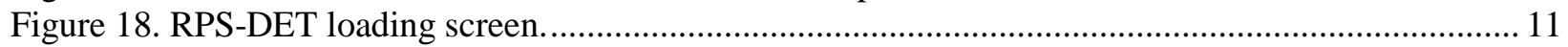

Figure 19. Configuration GUI at first-time installation. ................................................................... 12

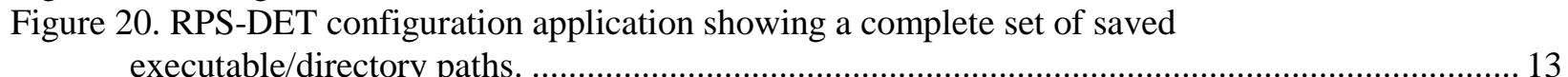

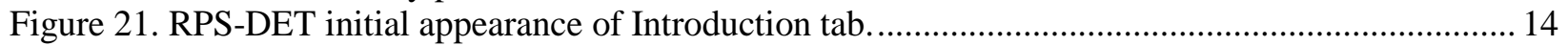

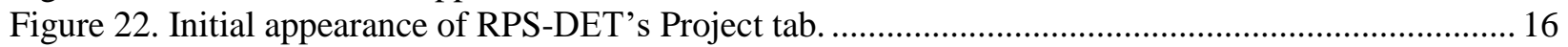

Figure 23. Simulation tab with Beginning New Simulation button selected, and a title and

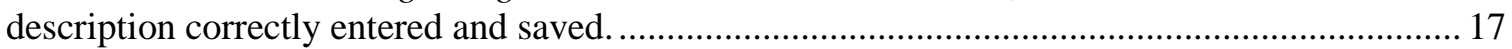

Figure 24. Sequence of events for Loading Saved Simulation button usage. .......................................... 18

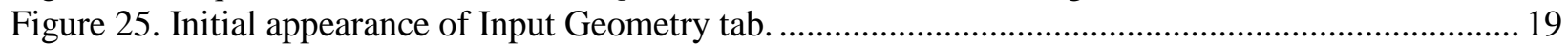

Figure 26. RPS, Environment, and rotation selection process.......................................................... 20

Figure 27. Rendering a geometry selection with Keno 3D application............................................... 20

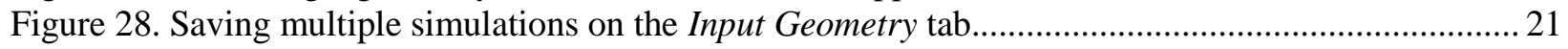

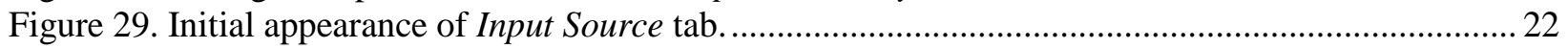

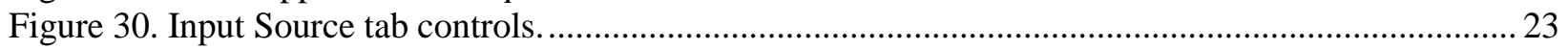

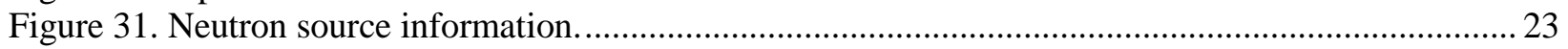

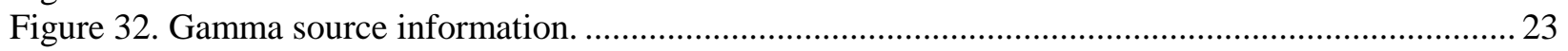

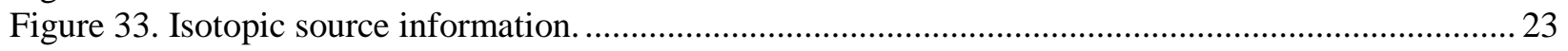

Figure 34. Example of integration scheme for 5-10-year integrated source selections in RPS-

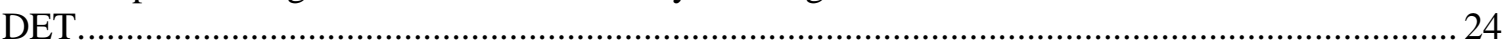

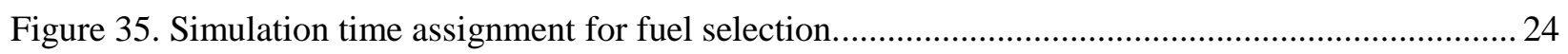

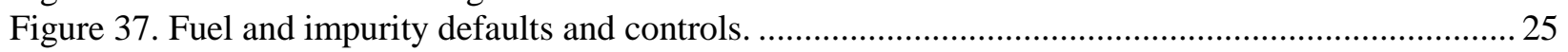

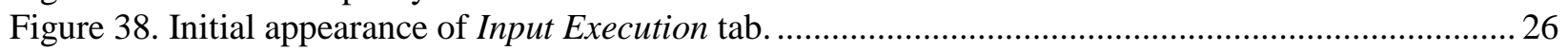

Figure 39. Selection for number of particles or computer runtime.................................................. 27

Figure 40. Logic and sequence for starting/stopping simulations with RPS-DET. ............................... 28

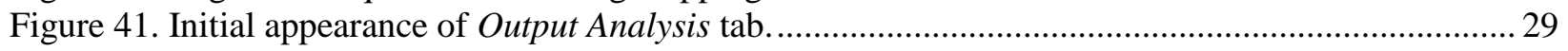

Figure 42. Output Analysis tab, controls, and button logic.............................................................. 30

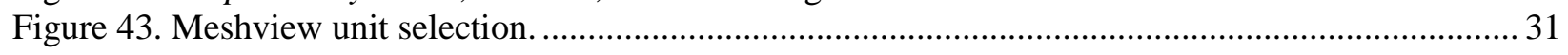

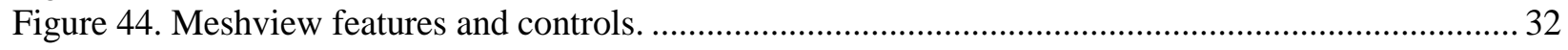

Figure 45. Loading RPS-DET simulation in Fulcrum and visualizing geometry.................................... 33

Figure 46. Loading RPS-DET simulation results in Fulcrum and overlaying on geometry..................... 34 
Figure 47. Various features of other Fulcrum data inspection capabilities............................................ 36

Figure 48. Controls and appearance of Keno 3D application for RPS-DET geometries.......................... 38

Figure 49. Fueled clad (FC) geometry: full example (top) and cutaway (bottom). ................................ 41

Figure 50. GPHS geometry: full example (top) and cutaway (bottom) .................................................. 41

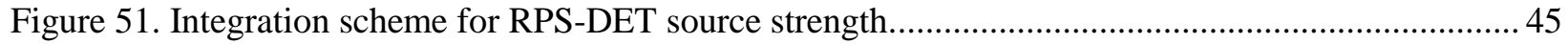

\section{LIST OF TABLES}

Table 1. Configuration names, starting search locations, expected executable/directory locations, and names

Table 2. Example of single RPS-DET simulation performance.

Table 3. Brief descriptions of relevant Meshview controls for inspecting RPS-DET results. All labels in this table reference Figure 44 below

Table 4. Description of .3dmap file generated by RPS-DET simulations.

Table 5. Material information and assumptions regarding planetary regolith and atmospheric assumptions 


\section{ACRONYMS}

$\begin{array}{ll}\text { ASRG } & \text { Advanced Stirling Radioisotope Generator } \\ \text { CSV } & \text { comma-separated value } \\ \text { DOE } & \text { US Department of Energy } \\ \text { EAR } & \text { Export Administration Regulations } \\ \text { EULA } & \begin{array}{l}\text { end-user license agreement } \\ \text { fueled clad }\end{array} \\ \text { FC } & \text { general-purpose heat source } \\ \text { GPHS } & \text { graphical user interface } \\ \text { GUI } & \text { International Commission on Radiation Units } \\ \text { ICRU } & \text { Idaho National Laboratory } \\ \text { INL } & \text { International Traffic and Arms Regulations } \\ \text { ITAR } & \text { Multi-Mission Radioisotope Thermoelectric Generator } \\ \text { MMRTG } & \text { Mars Science Laboratory } \\ \text { MSL } & \text { National Aeronautics and Space Administration } \\ \text { NASA } & \text { Nullsoft Scriptable Install System } \\ \text { NSIS } & \text { Oak Ridge National Laboratory } \\ \text { ORNL } & \text { Radioisotope Power System } \\ \text { RPS } & \text { RPS Dose Estimation Tool } \\ \text { RPS-DET } & \text { RPS Program Office } \\ \text { RPSPO } & \text { Radiation Safety Information Computational Center } \\ \text { RSICC } & \text { R }\end{array}$




\begin{abstract}
Radioisotope power systems (RPSs) convert decay heat from radioactive materials to electrical power. The National Aeronautics and Space Administration (NASA) uses RPSs for certain orbiters, landers, rovers, and probes that cannot rely on solar or chemical power. Most of the emitted charged particles in RPS fuels are locally absorbed, and the particles' kinetic energy is converted into thermal energy as they slow down in the surrounding materials. This heat is subsequently converted into electricity through some form of energy conversion process (e.g., thermoelectric, heat engine, thermionic). While nearly all the charged particles are stopped locally, a non-trivial portion of the emitted neutral particles (neutrons and photons) escape the fuel and are free to interact with surrounding materials. This escaping radiation field can be operationally problematic for certain instruments, materials, electronics, etc., and can cause problems during terrestrial shipping, integration, testing for personnel, instrumentation, etc. Furthermore, the fuel's emission spectrum evolves over time as the parent isotopes decay away and daughter products accumulate. This changing fuel composition alters characteristics of the ambient radiation field over time, which is further affected by RPS orientation and the surrounding environment.

Tools that can rapidly estimate the radiation characteristics of RPSs with various fuel compositions, fuel ages, various RPS orientations, and in/on different spaceflight and planetary scenarios provide researchers with an opportunity to quickly estimate the radiation implications of a given RPS scenario.

The RPS dose estimation tool (RPS-DET) provides engineers, scientists and analysts who are not trained in the art of particle transport software with a solution for quickly building, simulating, and analyzing the radiation impacts of various RPS designs in relevant spaceflight and terrestrial environments.
\end{abstract}

\title{
1. INTRODUCTION
}

RPS-DET is a MATLAB-based graphical user interface (GUI) and collection of data-handling algorithms that builds, executes, and allows simple inspection of SCALE/ORIGEN decay calculations and SCALE/MAVRIC particle transport simulations for RPS spaceflight scenarios. While there is no substitute for building a particle transport simulation from the ground up and having intimate knowledge of every detail of its construction, RPS-DET endeavors to lay the groundwork in simulating radiation from an RPS by collecting the general assumptions regarding RPS geometries, RPS materials, spaceflight geometric environments, spaceflight materials, fuel compositions, fuel aging characteristics, resulting radiation spectra, particle tallies, and response functions. These capabilities will ultimately allow a user to easily customize the inter-combination of all these assumptions, run simulations, and analyze the results - all in one easy-to-use application.

Having these assumptions collocated in a single application will provide a researcher/analyst with the tools necessary to either perform every calculation needed without any alteration or to provide a foundation so that only a small portion of the simulation would require tailoring to their specific area of interest. Either way, the intent is for a large portion of the simulation creation, execution, and analysis to be simplified by using RPS-DET.

Please do not hesitate to contact the developers with questions, comments, or clarification at any time at rpsdethelp@ornl.gov. 


\subsection{ORDERING RPS-DET}

Contact the RPS Program Office (RPSPO) first to inquire about eligibility for gaining access to RPS-DET (rps@ nasa.gov). Upon approval from RPSPO, Oak Ridge National Laboratory (ORNL) will be notified. The Radiation Safety Information Computational Center (RSICC), which is located at ORNL, is tasked with maintaining, controlling, and distributing RPS-DET, along with many of the nation's other nuclearrelated code packages. As access to SCALE and RPS-DET is restricted to users from certain nuclearsensitive countries, the user will be required to apply online at the RSICC website (https://rsicc.ornl.gov/) to disclose the intended use, the end-user's nationality, and professional/research affiliations. RSICC will verify this information prior to issuing the software. An administrative/handling fee required prior to SCALE/RPS-DET distribution. The user is encouraged to review the RSICC website and/or contact the RSICC office for clarification on current fee structures. Upon approval and fee payment, the user may request CD-ROM hard-copy distributions or online downloads of the software, install, and use at will.

The end-user is the only user licensed for the distributed code. Deliberate and/or accidental sharing of these codes with other individuals is a breach of the end-user license agreement (EULA) and can also be a violation of export control laws, as RPS-DET is subject to Export Administration Regulations (EAR), specifically EAR 99. The user is also cautioned that the SCALE software, which is assumed to be installed on the same machine as RPS-DET, is also export controlled. The RSICC office can provide details about any/all requirements for end-users on the correct handling of export-controlled software domestically, but the user is advised at this time that SCALE and RPS-DET are both prohibited from being transported on disc, flash-drive, desktop, laptop computer, or any other format outside of the United States of America, and violation of this is a crime.

\subsection{SOFTWARE INSTALLATION}

The RPS-DET application can be thought of as a wrapper for the SCALE software suite, providing a simplified library-based approach to RPS particle transport simulations. As such, while RPS-DET includes many RPS and spaceflight geometries and materials, planetary science materials, and nuclear fuel compositions, no actual particle transport can be performed without correct, complete installation of the SCALE software first. The following two sections provide the steps required to install the SCALE software, followed by instructions for installation of the RPS-DET application.

\subsubsection{Installation of SCALE Software}

For convenience, the RPS-DET User Manual provides a brief overview of the SCALE installation process, but users are encouraged to reference the SCALE User Manual [1] for more detailed installation instructions (https://www.ornl.gov/sites/default/files/SCALE 6.2.3.pdf); users can contact the SCALE User Forum (SCALE User Group) or help line (scalehelp@ornl.gov) if issues occur during the SCALE installation. The RPS-DET application is currently only available for Windows operating systems, so most of the SCALE excerpts presented here specifically reference Windows installations and omit or skip information regarding UNIX/LINUX -based installations, as denoted by ellipsis points: ... .Text in this section formatted with italics is quoted directly from the SCALE 6.2.3 manual [1] (pages 38-49) and is presented here for convenience.

The SCALE 6.2.3 installation has been divided into three components: 64-bit precompiled binaries, source code, and the data. The precompiled binaries are available in platform-familiar installers: [Nullsoft Scriptable Install System] NSIS on Windows, Drag-N-Drop bundle on Mac, and TarGZip on Linux. For deployments that include source code, it is available as a zip file, and the data are available as a self-extracting IzPack installer. Other systems may require a custom build of SCALE from source code using the build instructions provided below. 
Note: After the Binaries are installed, the nuclear data still must be installed. After completing the binary installation according to the instructions in this section, please follow the instructions for SCALE 6.2 Data.

Double-click the Windows installation file "SCALE-6.2.3-setup.exe", agree to the terms, and the following "Welcome" dialog will be shown [Figure 1].

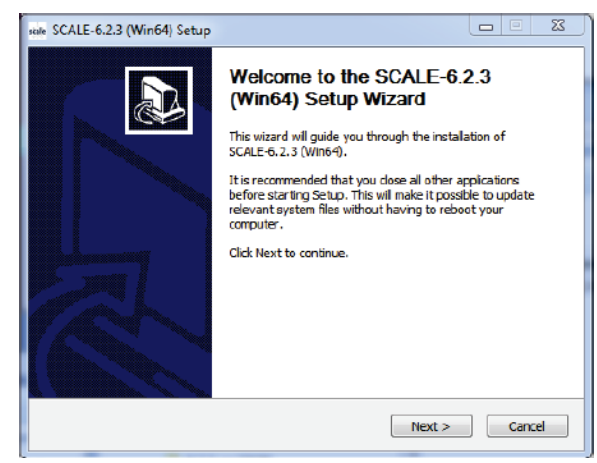

Figure 1. Windows installation start screen.

Follow the prompts through the install. There are two user decisions. The first is regarding the install location, as shown below. Generally, the "C:USCALE-6.2.3" is sufficient. (Do not install SCALE to the "Program Files" directory as it has insufficient default privileges.) [Figure 2].

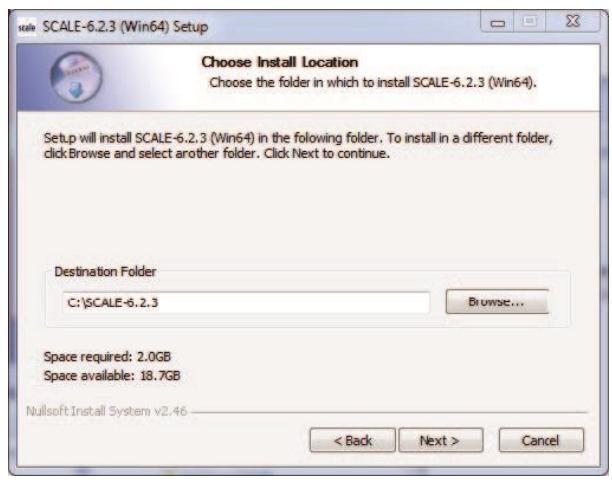

Figure 2. Windows install location.

The next is the name of the SCALE 6.2.3 application folder within the Windows start menu. The default is "SCALE 6.2.3 (Win64)" but changing this name will not affect the installation in any way. [Figure 3]. 


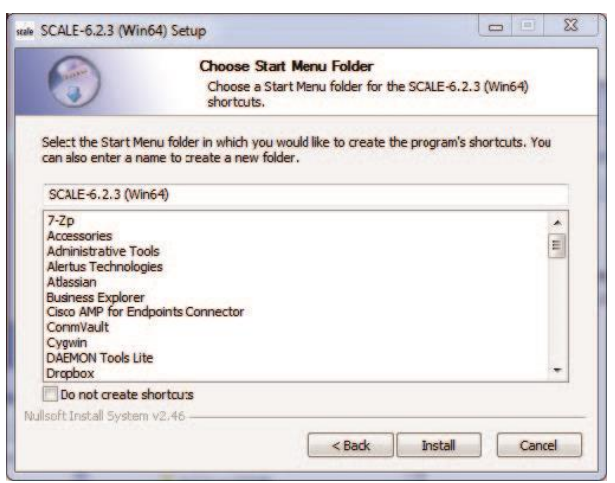

Figure 3. Windows start menu folder selection.

Next, the "Choose Start Menu Folder" is prompted. This defaults to installing Start Menu shortcuts. You may click "Do not create shortcuts" to disable Start Menu shortcuts. Desktop shortcuts are always installed. Clicking "Install” will continue [Figure 4].

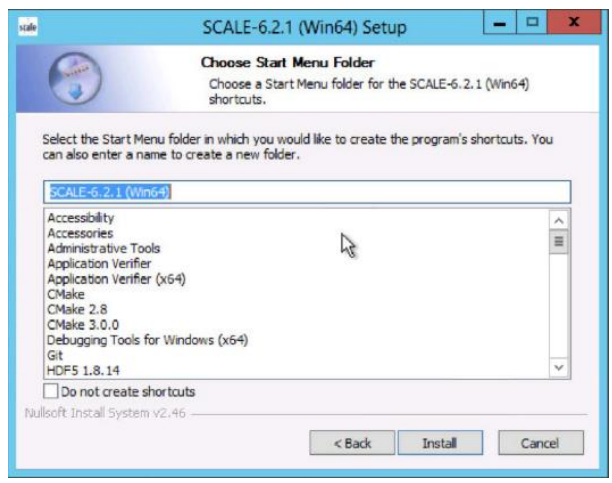

Figure 4. NSIS choose start menu folder.

The installation can take several minutes. Note that Norton Antivirus on Windows requires an exception for the SCALE Runtime Environment program, scalerte.exe. If using Norton Antivirus, please establish this exception prior to testing or SCALE 6.2.3 will not be able to execute. Once installation is complete, follow the instructions given below to install SCALE 6.2 Data.

\section{SCALE Data Installation}

Note that if you have SCALE 6.2 data installed from a prior SCALE 6.2 installation, you can copy or link the data into the SCALE 6.2.3 directory. To link preinstalled SCALE 6.2 data, open a command prompt and change the directory to the SCALE 6.2.3 installation directory: (C:ISCALE-6.2.3, /Applications/SCALE 6.2.3/Contents/Resources, etc.). On Windows, the following will link the SCALE 6.2 data into the SCALE 6.2.3 installation. (This may require administrative privileges.) mklink /D data C: SCALE-6.2 ldata.

To begin installation of SCALE 6.2 data, copy the scale-6.2-data-setup.jar to your local disk. Double-click this jar file. If the installer does not start, then bring up a command prompt or terminal window and issue the following command: java-jar scale-6.2-data-setup.jar in the location where the installer jar file was copied. 
After launching the installer, a dialog should appear as shown below [Figure 5].

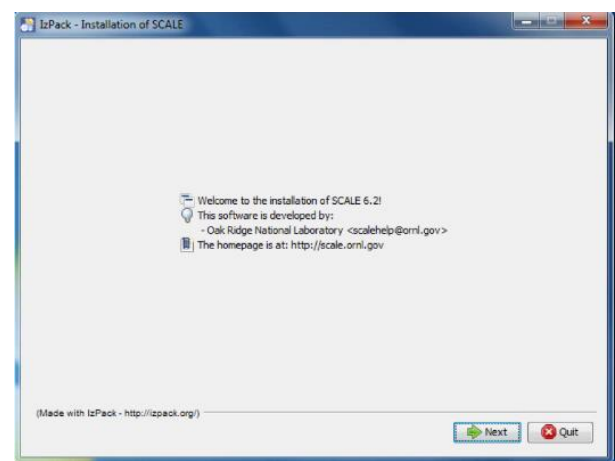

Figure 5. SCALE 6.2 data installer welcome dialog.

Continue by pressing "Next".

You will be prompted to review and accept the terms of the license agreement [Figure 6].

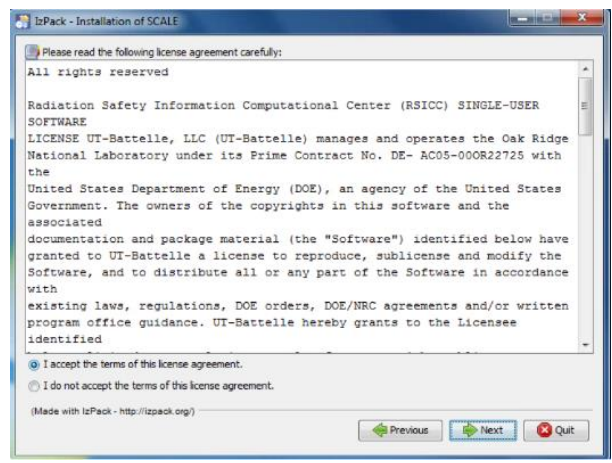

Figure 6. SCALE license agreement.

To proceed, check that you accept the terms and press next.

You will be prompted to choose the destination of your installation.

For Windows users, the recommended installation path is inside your SCALE-6.2.3 directory: c: SCALE-6.2.3 [Figure 7]. 


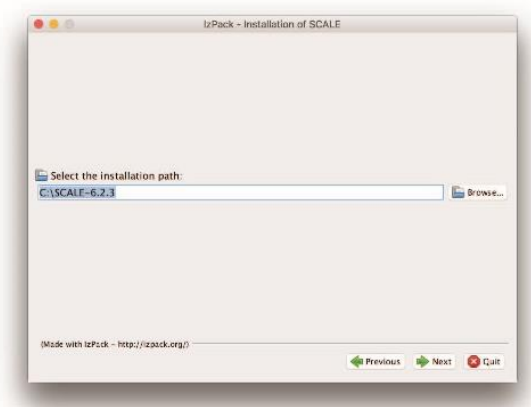

Figure 7. Setting typical data installation path on Windows.

For some systems, the installer will not be allowed to create a new directory. If you encounter a message like the one shown below, simply create the directory manually (e.g. using Windows Explorer) then return to the installer and continue [Figure 8].

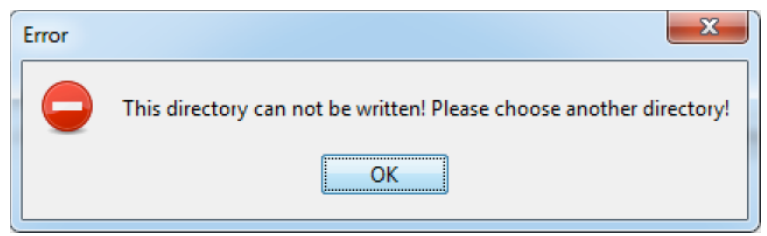

Figure 8. Data installer directory creation error message.

In most cases, the installer will present a prompt to confirm the creation of a new directory; if that target directory is correct, you can simply press $O K$.

If the directory was manually created, the installer will notify you that it is about to overwrite any previous contents. Press Yes to continue [

Figure 9].

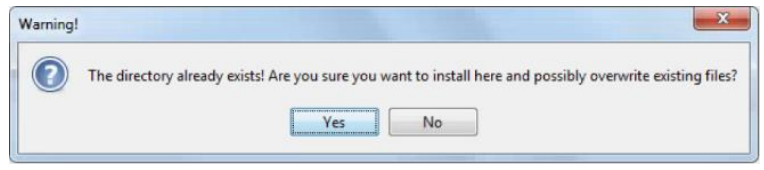

Figure 9. Directory overwrite dialog.

The installer then presents a dialog for available data sets you may wish to install [Figure 10]. 


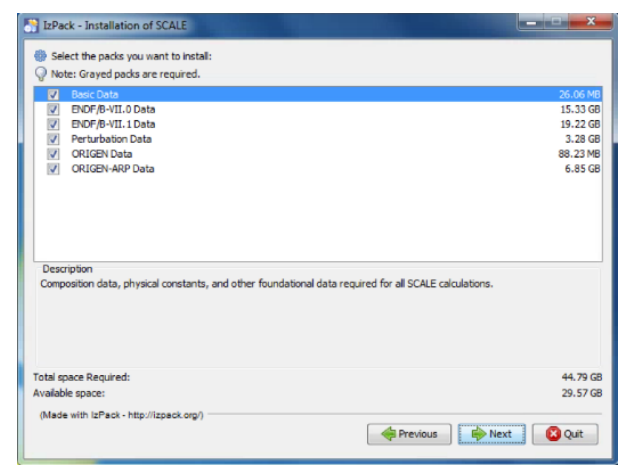

Figure 10. Data selection dialog.

Please install all data packages.

Next, the installer may ask for the location of the data .pak files that are unpacked during the installation process. Please direct the installer to the location of these data files, which are part of the SCALE distribution and may be on the distribution media or copied to a local directory as shown below. [Figure 11].

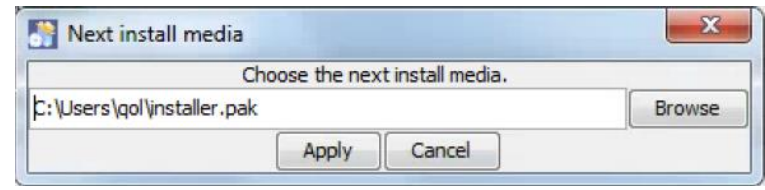

Figure 11. Media selection dialog.

The installer will display the progress of the installation. If installing from a DVD set,

part way through the installation, you will be prompted for installer.pak.1.

Please insert the PAK.1 disk and click Apply.

The installation from PAK.1 will complete and prompt for installer.pak.2.

Please insert the PAK.2 disk and click Apply.

PAK.2 will finish. Proceed with all DVDs or files in the delivery until you have completed your installation of SCALE 6.2 data. 


\subsubsection{Installation of RPS-DET Application}

Once SCALE has been successfully installed, the RPS-DET application should be installed as follows.

The RPS-DET installation begins either by loading your CD(s) into your local computer or, if RPS-DET was downloaded, by navigating to your downloaded .zip folder and extracting into a desired location titled RPSDET.

The unzipped file structure should resemble the following:

- ...VPPSDET

- User Manuals

- RPS-DET.pdf

- SCALE.pdf

- Fulcrum.pdf

- Keno3d.pdf

- Meshview.pdf

○ MCR_R2018a_win64_installer.exe

- RPSDET.exe

- customResponses.txt

RPS-DET was developed using Matlab version 2018a. If the machine on which RPS-DET is being installed does not have or has never had an installation of Matlab, then Matlab "runtime" is required and is included in this distribution. If Matlab is or was previously installed on the computer where RPS-DET will be installed, Matlab 2018a runtime may still need to be installed to ensure proper functionality of RPS-DET.

There are two separate ways to install the required Matlab runtime:

○ MCR_R2018a_win64_installer.exe

- Execute the included installer package.

Or

○ https://www.mathworks.com/products/compiler/matlab-runtime.html

- Navigate to the Matlab (Mathworks ${ }^{\text {TM }}$ link above and download the same installer package (2018a).

Navigate to the runtime installer (...RPSDET

$\left.M C R \_R 2018 a \_w i n 64 \_i n s t a l l e r . e x e\right)$ and execute. An installation/extractor window will appear (Figure 12). This window will close after completion, and then the RPS-DET Installer wizard will open (Figure 13). You will then be guided through the installation process. After reading the information on this window, press the Next button.

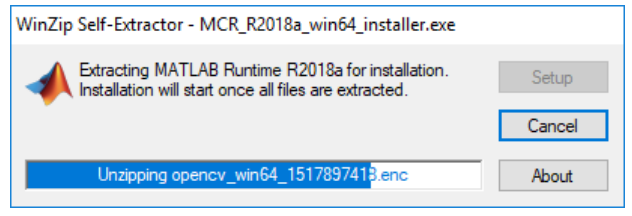

Figure 12. Initial Matlab runtime installation window. 


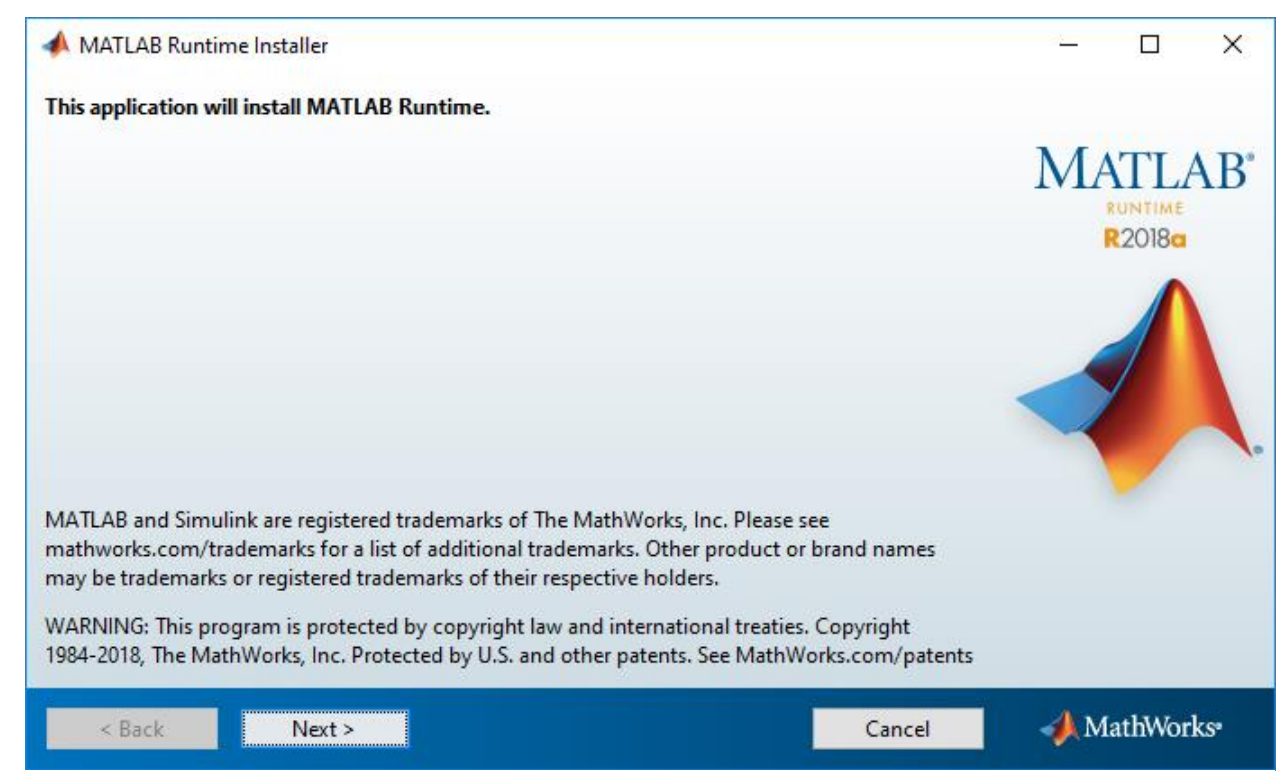

Figure 13. RPS-DET installer window.

Pressing Next will present the License Agreement window, where you must agree to the licensing terms to continue. After reading the agreement, select Yes if you agree, and then press the Next button to continue (Figure 14).

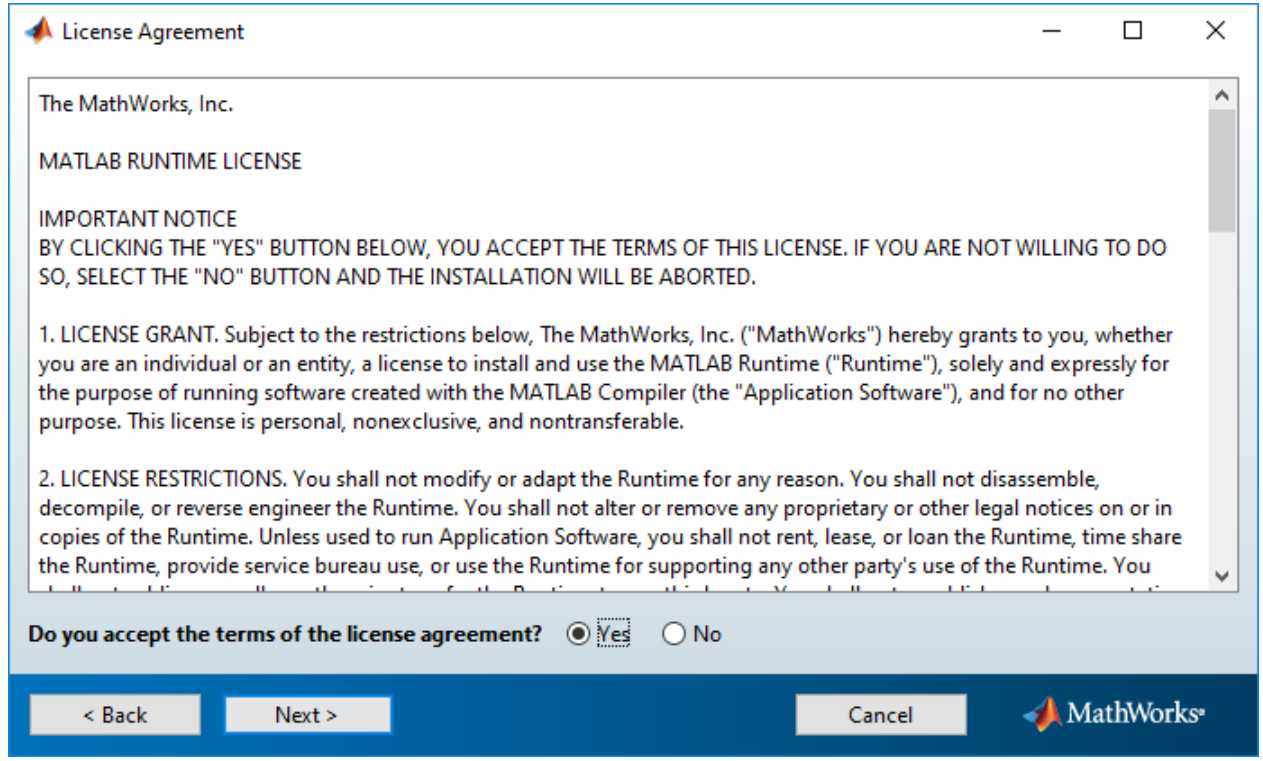

Figure 14. RPS-DET and Matlab license agreement window.

Pressing Next will present the final RPS-DET installation confirmation page. If all locations, versions, and file sizes are correct, press the Install button to begin installation (Figure 15). 


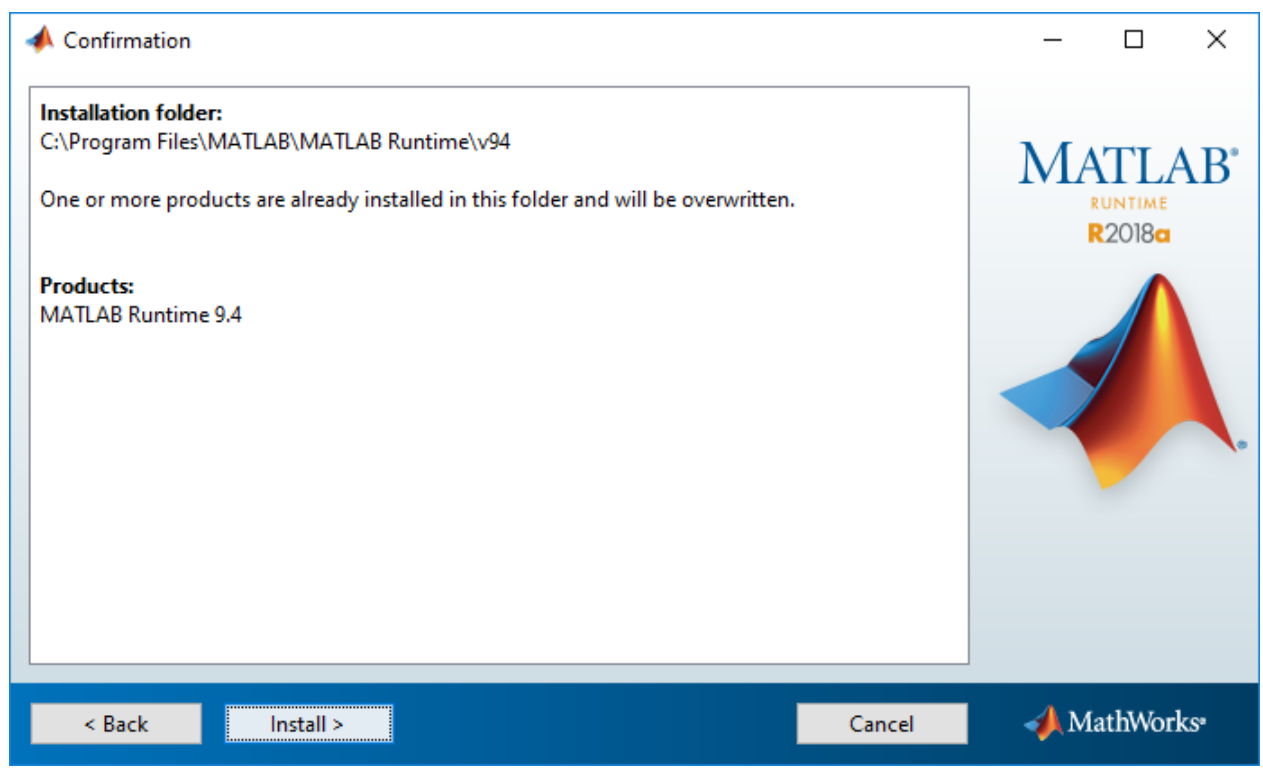

Figure 15. RPS-DET installation confirmation window.

Pressing Install will begin the installation process and present the installation window as depicted in Figure 16.

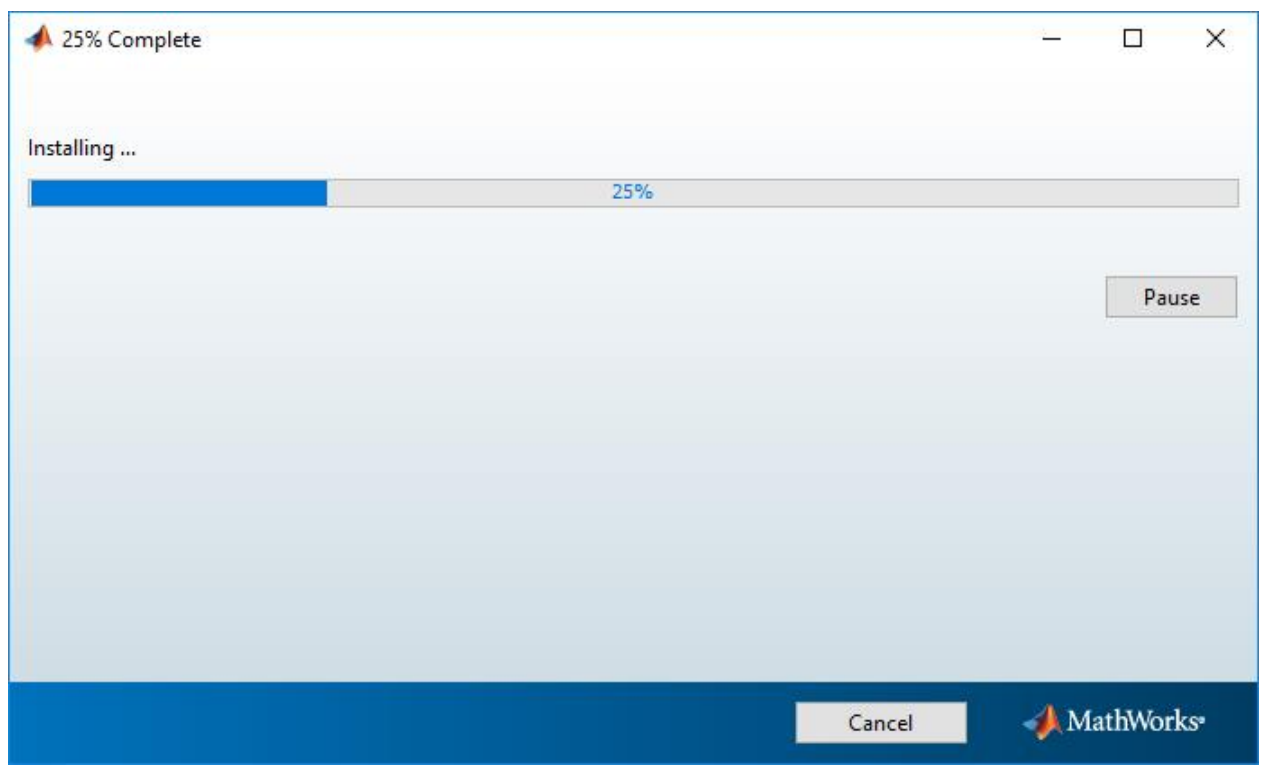

Figure 16. RPS-DET runtime installation progress window.

Once installation is complete, the Installation Complete window will appear. Press Finish to complete the RPS-DET Matlab runtime installation process (Figure 17). 


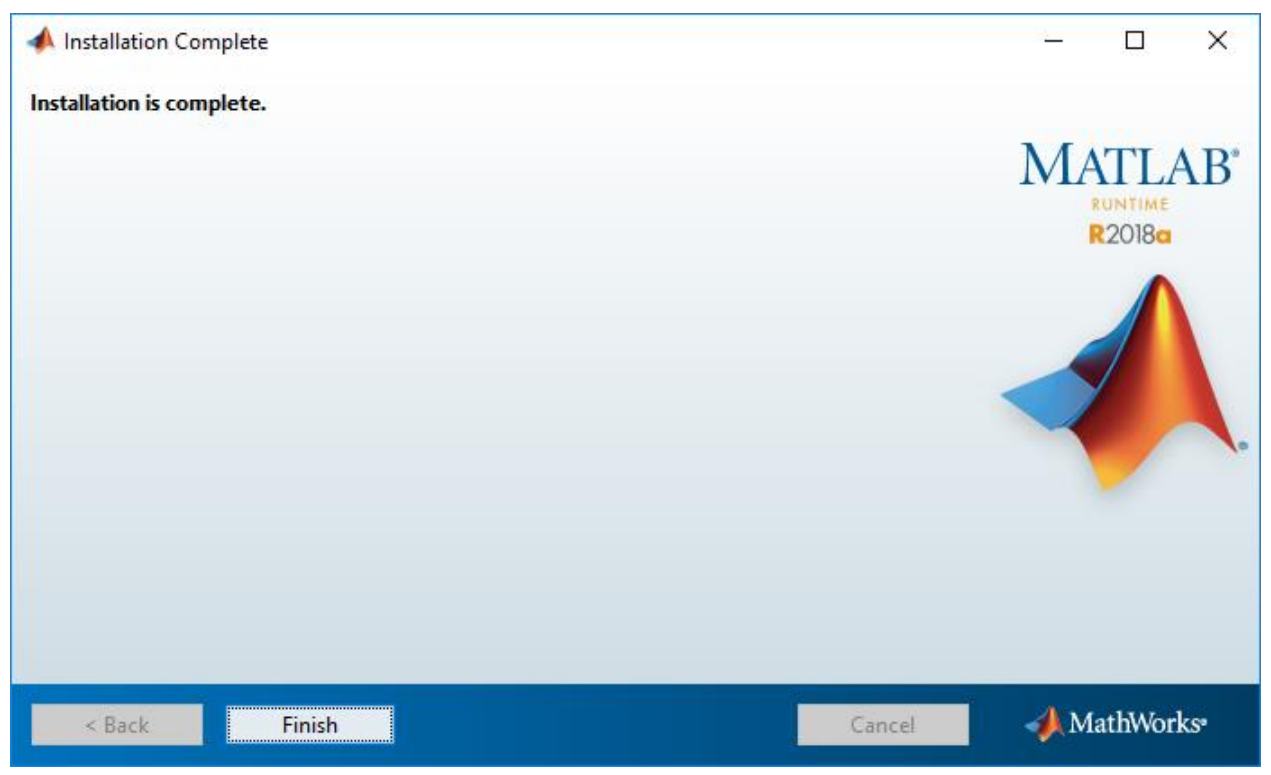

Figure 17. RPS-DET and Matlab runtime installation complete window.

After the RPS-DET and Matlab runtime installation is complete, navigate to the RPS-DET executable (RPSDET.exe) and open the file (execute, invoke, etc.). Upon successful launch of RPS-DET, you will be presented with the RPS-DET application loading screen shown below (Figure 18). This process typically takes a few minutes to complete, depending on the user's computer performance. Please be patient and allow RPS-DET to initiate. The first time this application is invoked on a given machine it may take longer than subsequent executions.

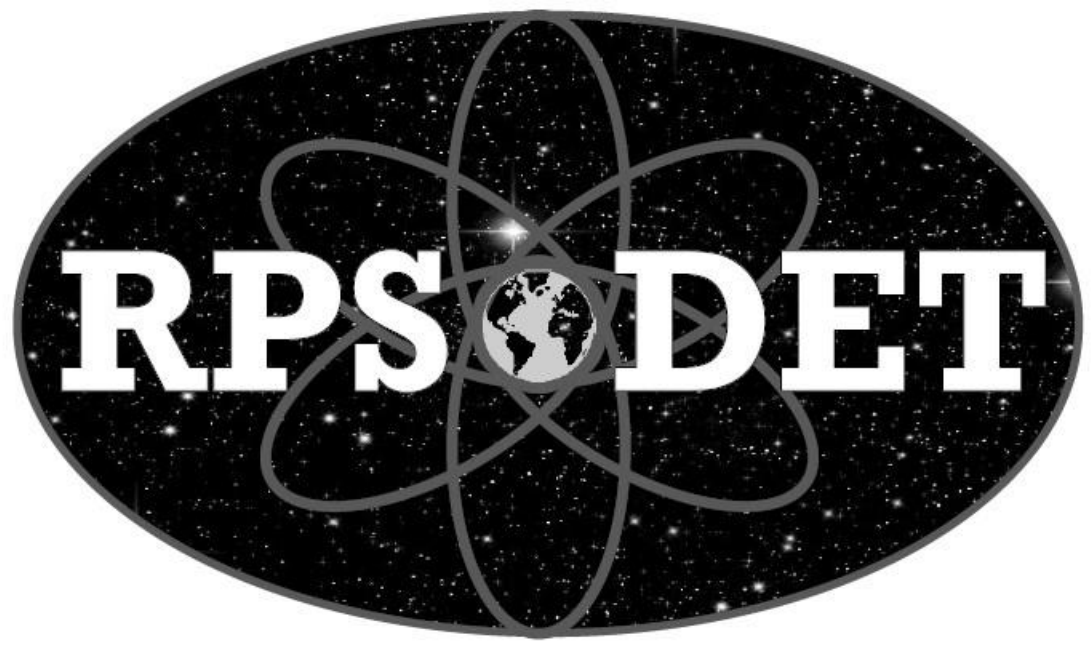

Figure 18. RPS-DET loading screen.

The first time the RPS-DET application is launched on a new computer, the configuration GUI will automatically be displayed (Figure 19). This GUI requires the user to select two separate paths leading to the RPS-DET home directory and the SCALE home directory. 


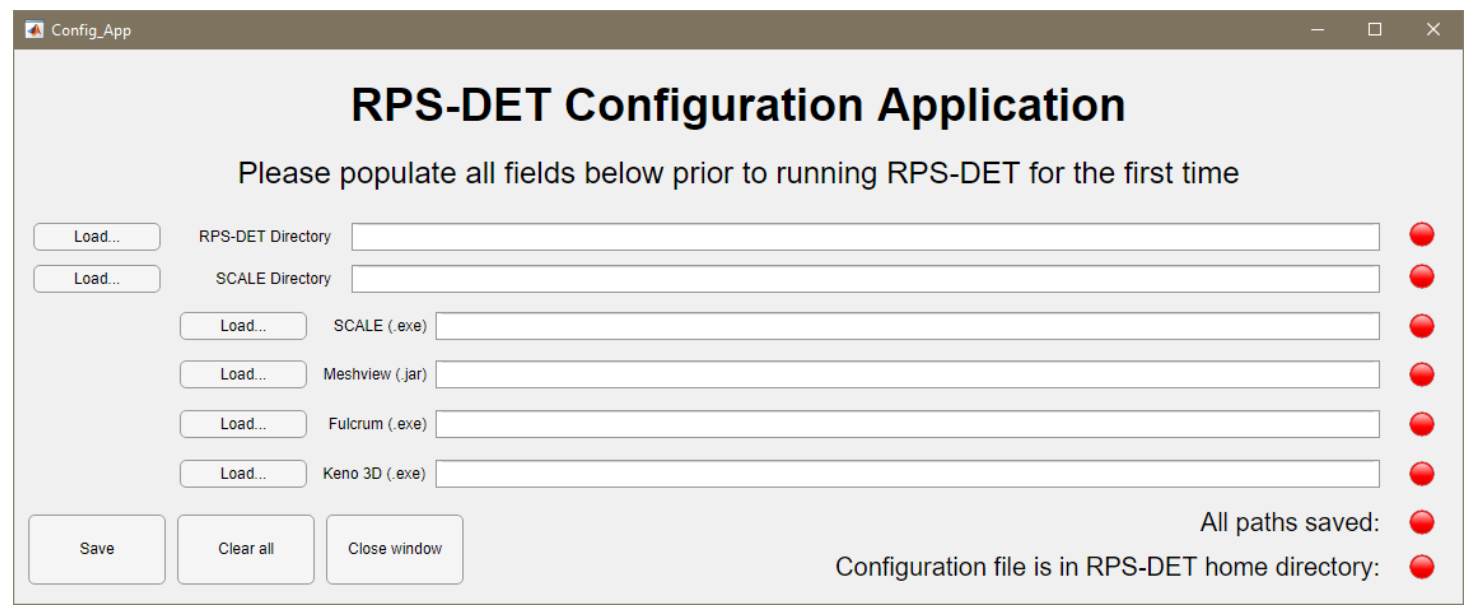

Figure 19. Configuration GUI at first-time installation.

Each of the two directory paths (RPS-DET Directory and SCALE Directory) has a corresponding Load button. Upon pressing either Load button, a directory search window will appear, and the specific location is prepopulated in the search criteria as specified in Table 1 below. The actual location of the SCALE applications will depend on the chosen location of the SCALE installation but loading the SCALE Directory correctly should auto-populate all subsequent SCALE executables. If this does not occur automatically, you may individually select each of the remaining executables by using their corresponding Load buttons.

Table 1. Configuration names, starting search locations, expected executable/directory locations, and names

\begin{tabular}{|c|c|c|}
\hline $\begin{array}{l}\text { Configuration } \\
\text { displayed name }\end{array}$ & $\begin{array}{c}\text { Starting search } \\
\text { location }\end{array}$ & Expected location/name* \\
\hline RPS-DET Directory & $\mathrm{C}: \mathrm{I}$ & Select the top-level directory RPS-DET directory $(C: \backslash \ldots \vee R P S D E T \backslash)$ \\
\hline SCALE Directory & $C: 1$ & Select the top-level SCALE directory (C:L..LSCALE-6.2.3\) \\
\hline SCALE* & $C: 1$ & C:1...ISCALE-6.2.3\binlscalerte.exe \\
\hline Meshview* & $C: 1$ & C:I...ISCALE-6.2.3\Meshview\meshview.jar \\
\hline Fulcrum* & $C: 1$ & C:I...ISCALE-6.2.3 \bin \Fulcrum.exe \\
\hline Keno 3D* & $C: 1$ & C:I...ISCALE-6.2.3\Keno3dlkeno3d.exe \\
\hline
\end{tabular}

*These executables should be automatically populated upon selection of the SCALE Directory. If they do not populate
automatically, use the individual Load buttons to assign the correct paths.

NOTE: All examples here assume a SCALE installation of 6.2.3. The user should assume that this same or similar expected path will apply to their installation if the SCALE version is not 6.2.3.

Upon selecting all executables/directories and pressing the Save button, the GUI should present a fully populated set of text fields with confirmatory green indicator lamps showing that this portion of the installation is complete (Figure 20). Once the Save button has been pressed, a specifically formatted configuration text file (ASCII) is written into the home directory entitled RPS_DET_Config.txt. Once written, incorrect formatting or text changes to this file can disrupt the performance of RPS-DET. (Do not edit this file). Upon saving, if any errors are noticed in the installation paths, then the Clear All button may be pressed to restart. Alternatively, if all installation paths are correct, then the Close Window button may be pressed to exit this section of the application. 


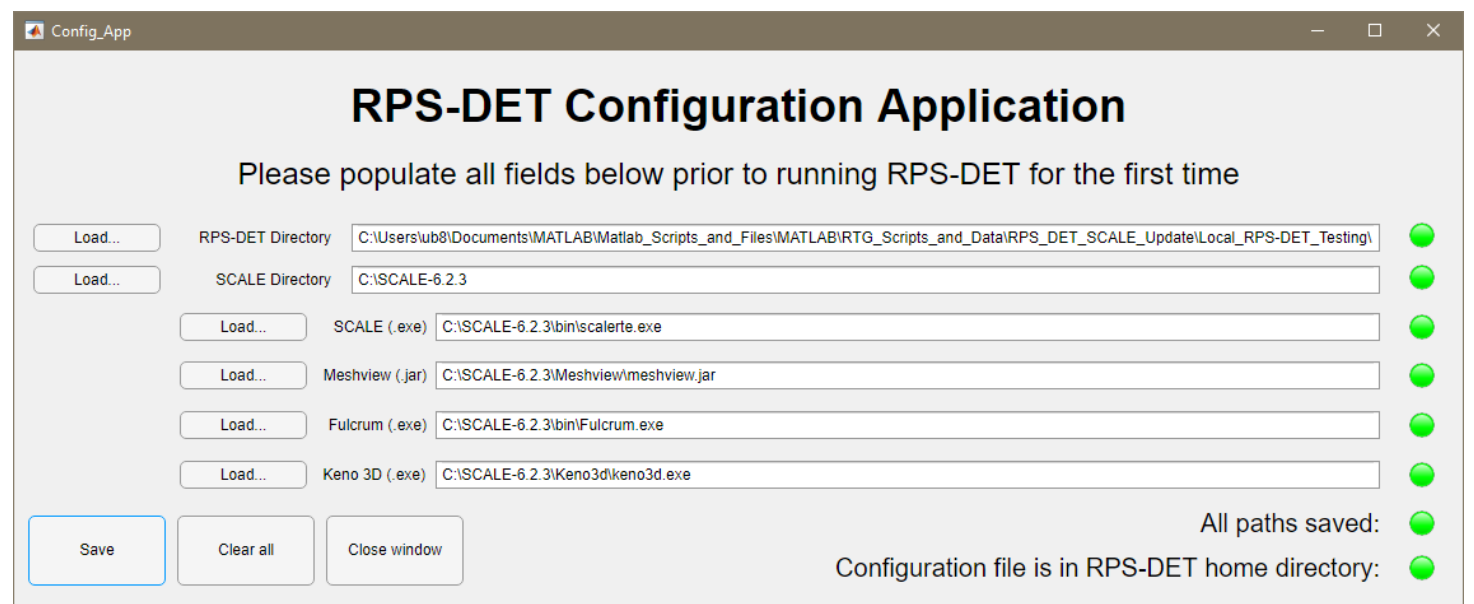

Figure 20. RPS-DET configuration application showing a complete set of saved executable/directory paths.

Once the configuration window has closed, the RPS-DET GUI will be present on the first tab of the GUI, and RPS-DET is ready to use (Figure 21).

\section{USING RPS-DET}

\subsection{GENERAL DESCRIPTION}

The RPS-DET GUI is designed to be navigated in a successive progression so that certain features of the GUI are not enabled until the user correctly completes all previously required operations. The RPS-DET GUI is subdivided into six tabs that describe and control various aspects of building and analyzing RPSDET simulations. The tabs are designed for the user to advance through them in the following progression, with brief descriptions of each presented below:

1. Introduction Tab:

- This tab provides a description of the GUI's high-level functionality, government sponsors/developers, and export control information. This tab only includes information, so there are no user-control options on this tab.

2. Simulation Tab:

- This tab allows the user to either begin a new simulation(s) or load a previously developed simulation(s). If developing a new simulation, this tab allows the user to assign a title and description, which builds a pre-defined directory structure and configuration files. If loading a previously built simulation, then the user will be prompted to select the previous simulation of choice, and relevant information about it will be presented in the text fields.

3. Input Geometry Tab:

- If developing a new simulation, this tab is where the user can build the geometry, choosing from libraries of pre-written RPSs, environments, and RPS rotations in certain permitted environments. The RPS-DET structure allows for three separate simulations to be built during a single session.

4. Input Source Tab:

- This tab allows the user to define the RPS fuel by either assuming a default fuel specification or a custom plutonium assay and impurity assignment. Furthermore, the user can specify the age of the fuel from 0-100 years and choose to either simulate a 
dose/flux rate at a specific point in time, or the user can choose a range of years (in integer years) over which to integrate for cumulative dose/fluence values.

5. Input Execution Tab:

- This tab is where the user invokes the SCALE software to perform the Monte-Carlo particle transport simulations. The user can specify to either end the simulation based on the total number of particles transported or based on CPU time. Information updates provide the user with estimates of simulation run-times based on the user's selections, along with color-coded indicator lamps to signal successful or unsuccessful simulation creation, execution, and completion.

6. Output Analysis Tab:

- This tab provides the user with simulation information for up to three separate options for geometry visualization, as well as particle transport results and data inspection. Simulations generate three-dimensional (3D) mesh tallies of neutron and gamma fluxes/fluences, along with chosen response functions representing flux-to-dose conversion values; features in the visualization software allow $1 \mathrm{D}, 2 \mathrm{D}$, and $3 \mathrm{D}$ inspection and interaction with the resulting data.

The following sections describe the detailed navigation and utility of each tab in the RPS-DET GUI. It is recommended that the user follow along with the user manual in a sequential order to become comfortable building and executing simulations with the RPS-DET GUI. If issues, bugs, or errors are identified in the RPS-DET application, please contact the RPS-DET development team at rpsdethelp@ornl.gov.

\subsection{INTRODUCTION TAB}

The RPS-DET Introduction Tab notifies the user of the export control concerns associated with RPS-DET and gives a brief description of the applications' general functions. While this specific tab has no controls for the user, general GUI pulldown menus such as "Help" and "Options" are available while interacting with any/all tabs, and their functionalities are described here.

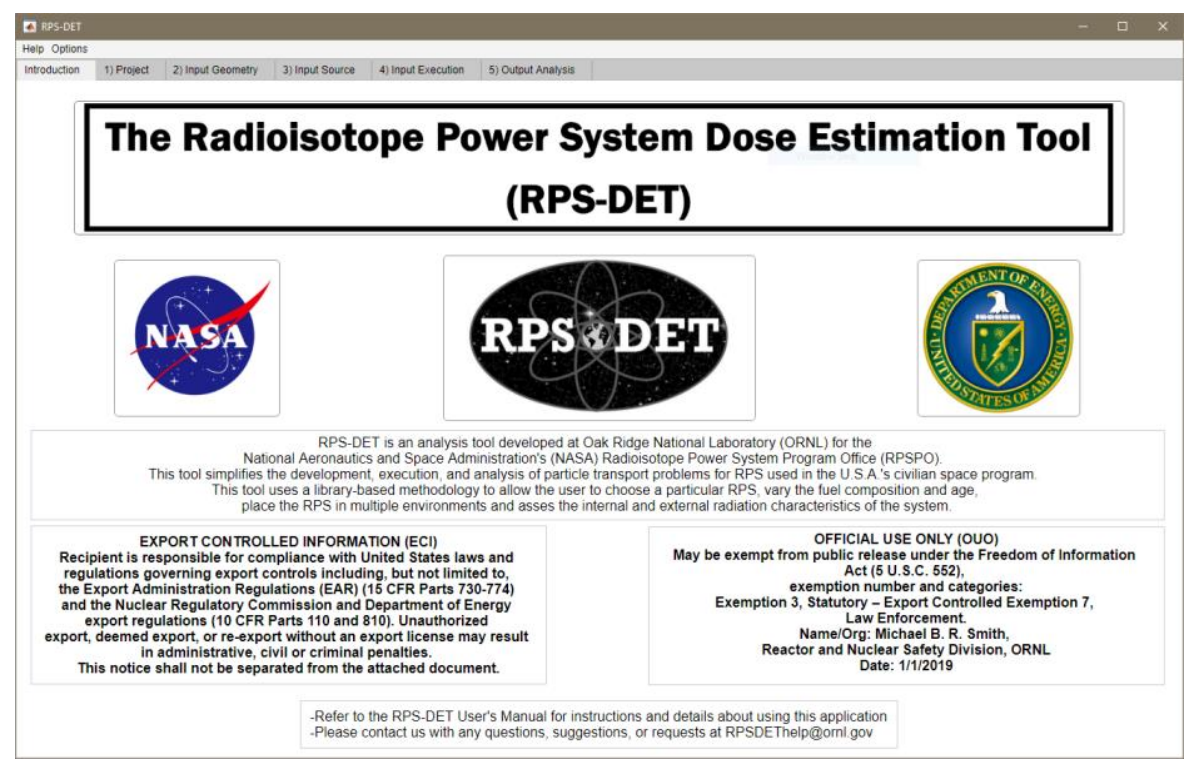

Figure 21. RPS-DET initial appearance of Introduction tab. 


\subsubsection{Pull-Down Menus}

There are two pulldown menus available at any time during use of the RPS-DET GUI: Help and Options. They are located in the top-left portion of the GUI.

\subsubsection{Help Menu}

The Help Menu has three selection choices:

- About: Selecting this option presents a window explaining the RPS-DET origin, version, and developing institution (ORNL).

- User Manuals: Selecting this will present a second pull-down menu with links to relevant user manuals for the following software/applications; this will load the desired document with your computer's preferred .pdf reader.

○ RPS-DET

- SCALE

- Fulcrum

- Meshview

- Keno 3D

- Contact: Selecting this will present a window describing various RPS-DET contacts.

\subsubsection{Options Menu}

The Options Menu has one selection

- Configuration Manager...: Selecting this presents the Configuration Manager application that was shown at the initial installation. Once the configuration has been set from the original (or subsequent) installations, all text fields in this application should automatically populate upon launching. If a user must reinstall any supporting SCALE software, reimage a hard drive, etc., then the Configuration Manager can be launched to update the RPS-DET configuration file with the new paths. 


\subsection{PROJECT TAB}

The Project Tab is the first RPS-DET tab with user controls and input/output. The Project Tab should appear as shown in Figure 22 the first time it is presented in every launching of RPS-DET.

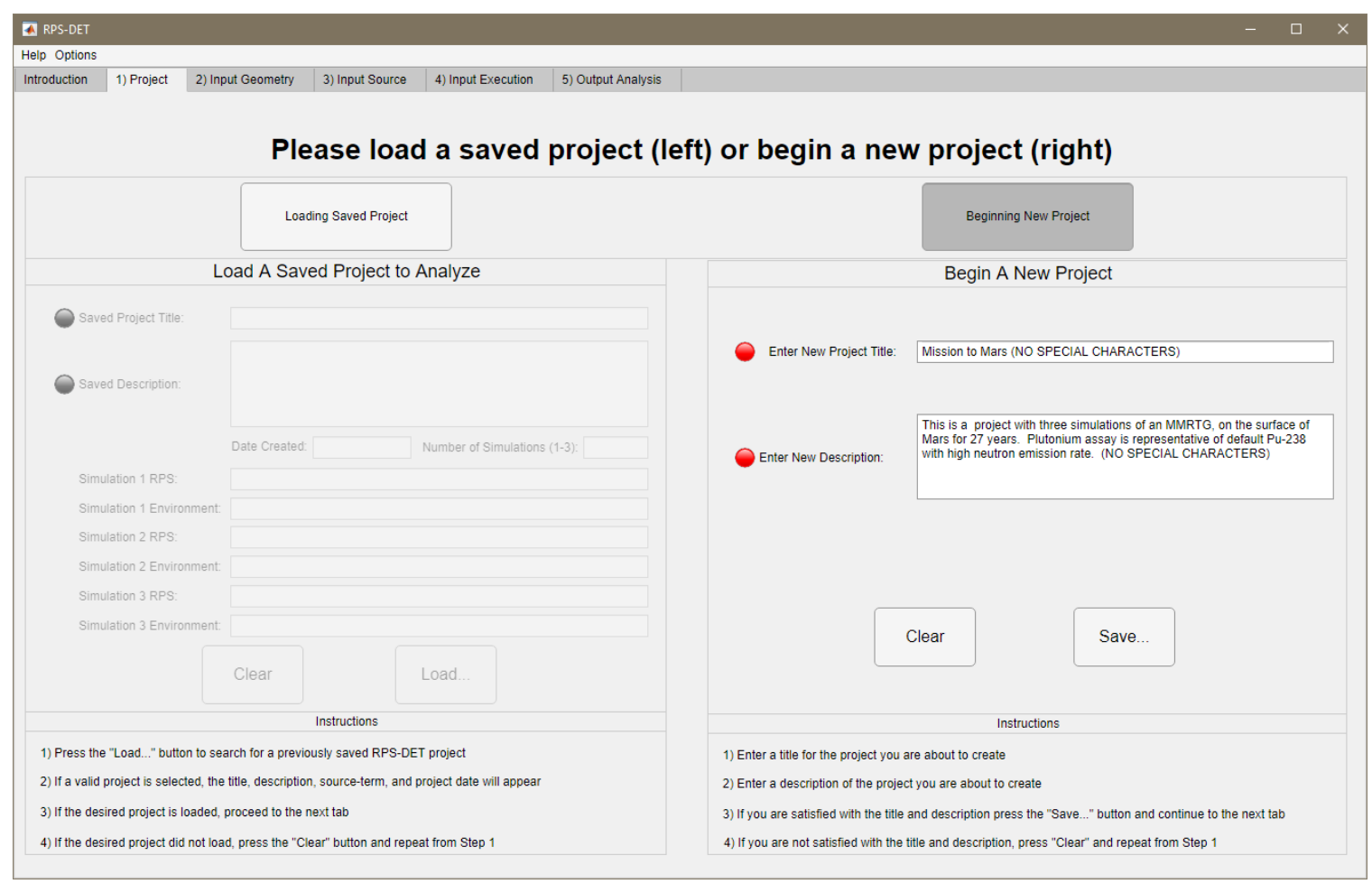

Figure 22. Initial appearance of RPS-DET's Project tab.

The Project tab has a high-level button control that either enables or disables various features of the whole RPS-DET GUI, depending on the selection. The two high-level buttons are Beginning New Project and Loading Saved Project.

\section{- Beginning New Project:}

- By default, this button is selected when the tab is first presented (Figure 23, A). If it is not already selected, then this button should be pressed when beginning a new simulation(s). Selecting Beginning New Project enables all features on the right side of the tab and disables all features on the left side. A title should be typed into the top text field (B), followed by a simulation description (C), prior to pressing the Save button (D). To change a saved title/description press the Clear button [E], re-enter the new title/description, and then save. Upon saving, the indicator lamps will turn green to show that the appropriate directories and RPS-DET ID files have been written/saved (Figure 23). Once the title and description are correct, the Save button is pressed, and the indicator lamps are green, the user can proceed to the next tab. 


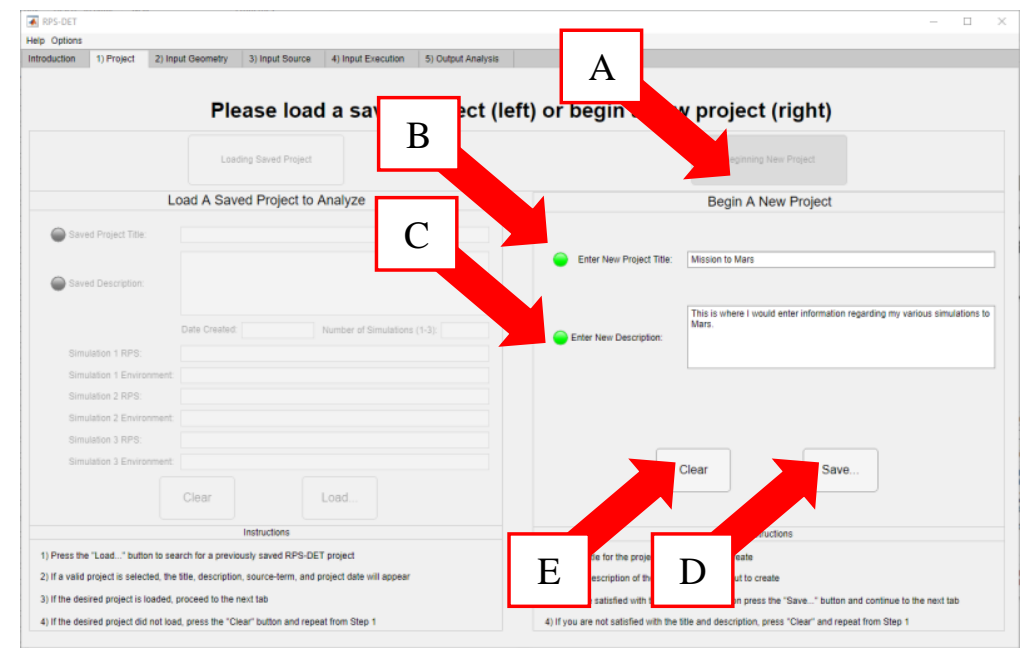

Figure 23. Simulation tab with Beginning New Simulation button selected, and a title and description correctly entered and saved.

\section{- Loading Saved Project}

- If loading a previously saved simulation, press the Loading Saved Simulation button (Figure 24, A). This will enable all features on the left side of the tab and will disable all features on the right side. This selection also disables various features on other tabs throughout the GUI that prevent the user from overwriting portions of the previously saved data and simulation information. Upon pressing the Load button (B), a search window will appear, prompting you to select a file with a .rpsdet suffix (C). Select the desired .rpsdet file (D) and press Open (E). This should load all appropriate information from the .rpsdet file, populate all text fields (if applicable), and turn the indicator lamps green (F). If the selection was incorrect, press the Clear button $(\mathrm{G})$ and start again. 


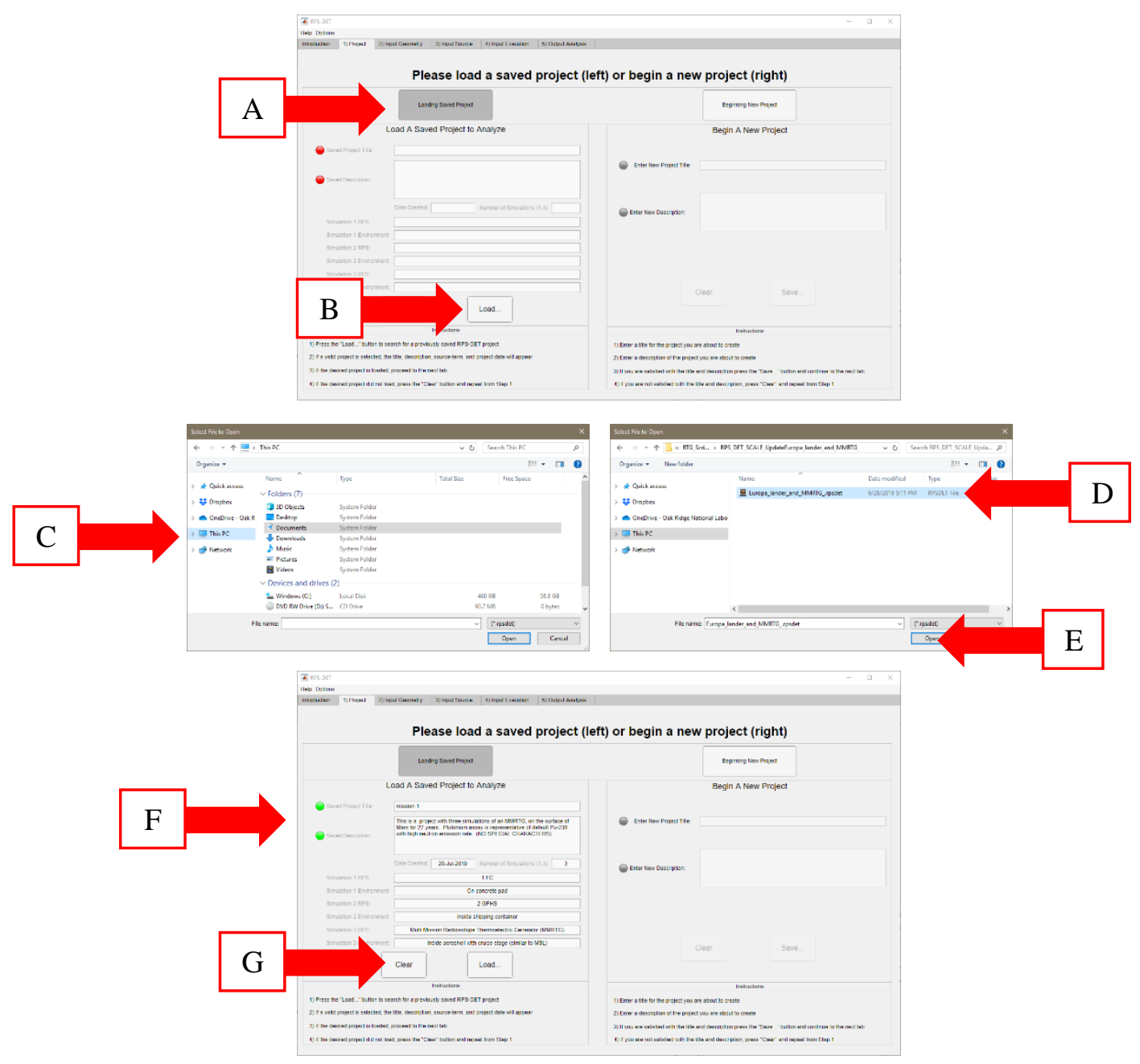

Figure 24. Sequence of events for Loading Saved Simulation button usage.

Once the new simulation is written or the saved simulation is loaded with the respective indicator lamps green, you can progress to the next tab in the RPS-DET GUI. 


\subsection{INPUT GEOMETRY TAB}

On the Input Geometry tab, you can select the geometry for up to three simulations. The structure of the geometry selection is divided into two categories: RPS and Environment selection. The RPS contains the radioisotope fuel (either a complete RPS or subcomponents), which can then be placed in any one of the environments. A complete list of available RPSs is provided in Appendix A, and a list of Environments is provided in Appendix B. The Input Geometry tab appears first, as shown in Figure 25.

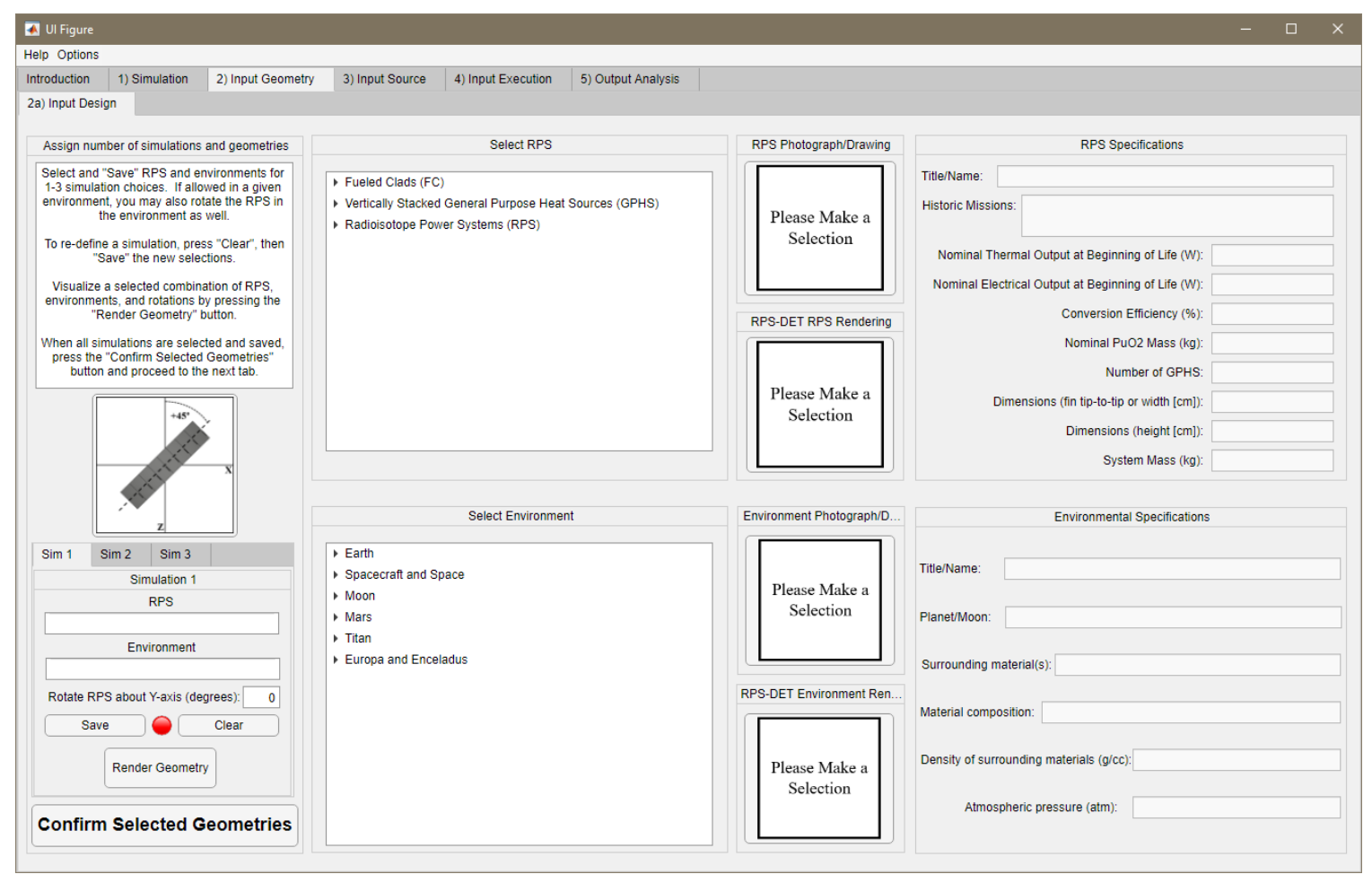

Figure 25. Initial appearance of Input Geometry tab.

There are two separate tree selection panes in this tab, and selecting any one of the elements in either tree pane will display an image, and relevant information about the selection will be displayed in the corresponding text fields next to the RPS (Figure 26, A) and Environment (B) tree panes. Certain geometries allow rotation of the RPS about the Y-axis, and the text field can be updated in degrees to reflect this rotation on this tab (C). The Environments rotation permissions are listed with the Environments provided in Appendix B. Once a combination of geometries is satisfactory, press the Save button (D) to confirm your selection, and the indicator will turn lamp green. The Clear button (E) can be pressed to clear out the RPS, Environment, and rotation selections, allowing you to make a new selection. 

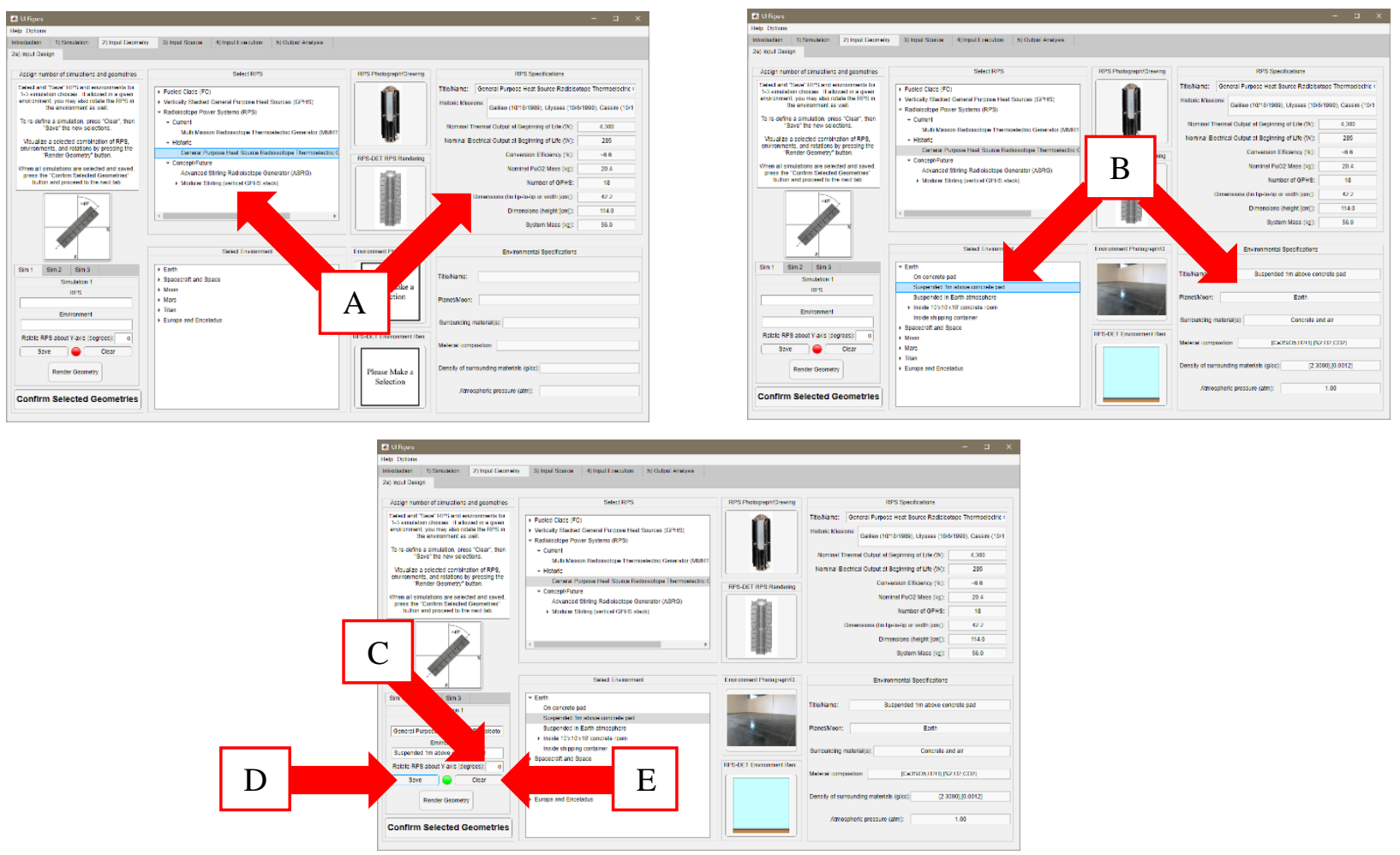

Figure 26. RPS, Environment, and rotation selection process.

At this point, you have various options. You may visualize the current selection of geometries (provided the indicator light is green) by pressing the Render Geometry button (Figure 27, A), which will launch a separate Keno 3D window (Figure 27, B). The ability to render the geometry in Keno 3D is a convenient way to understand the 3D representation of your geometry selections, combinations, and rotations. Note that the Keno 3D rendering will reflect the actual user selection, not necessarily what is pictured below. Please reference the Keno 3D user manual [2] for details on controls and functionality.

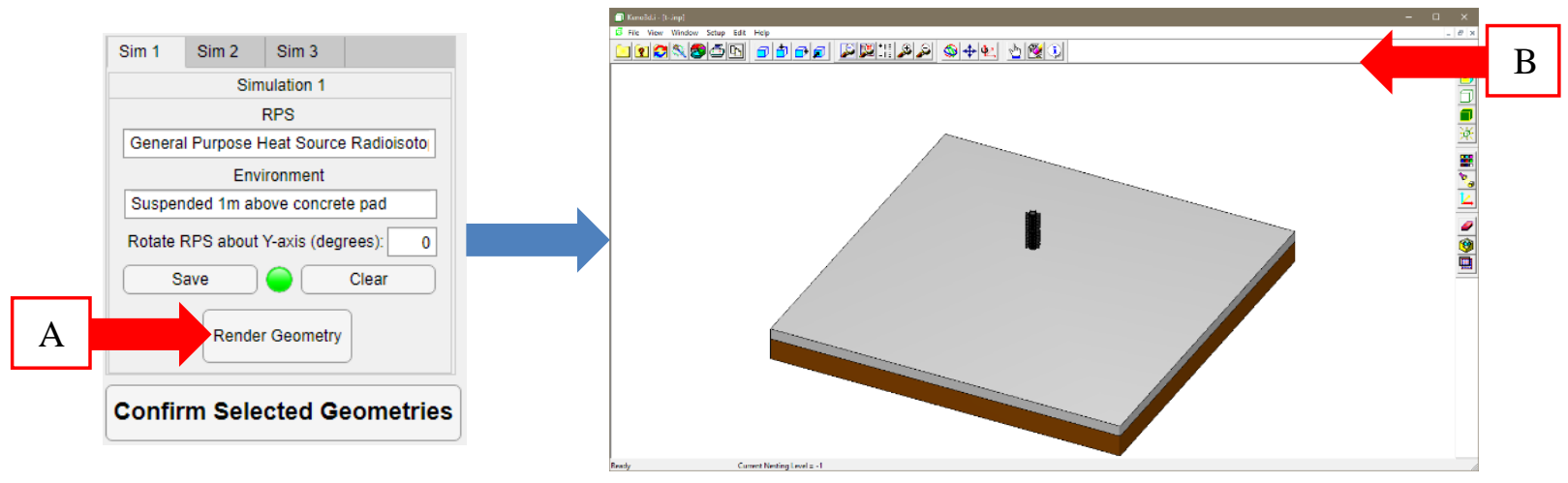

Figure 27. Rendering a geometry selection with Keno 3D application.

While a single geometry may be saved and/or rendered at this point, up to three geometries can be built. Selecting the tabs for $\operatorname{Sim} 1$, $\operatorname{Sim} 2$, or $\operatorname{Sim} 3$ (Figure 28, A, B, or C) will allow you to perform the same operations previously discussed: RPS-selection, Environment-selection, Rotation-selection, Save, Clear, 
Render Geometry, etc. Upon assigning RPSs, Environments, and rotations to each simulation, press the Confirm Selected Geometries button (D) to confirm your selections, and proceed to the next tab. This step must be completed prior to features on the following tab to be enabled.
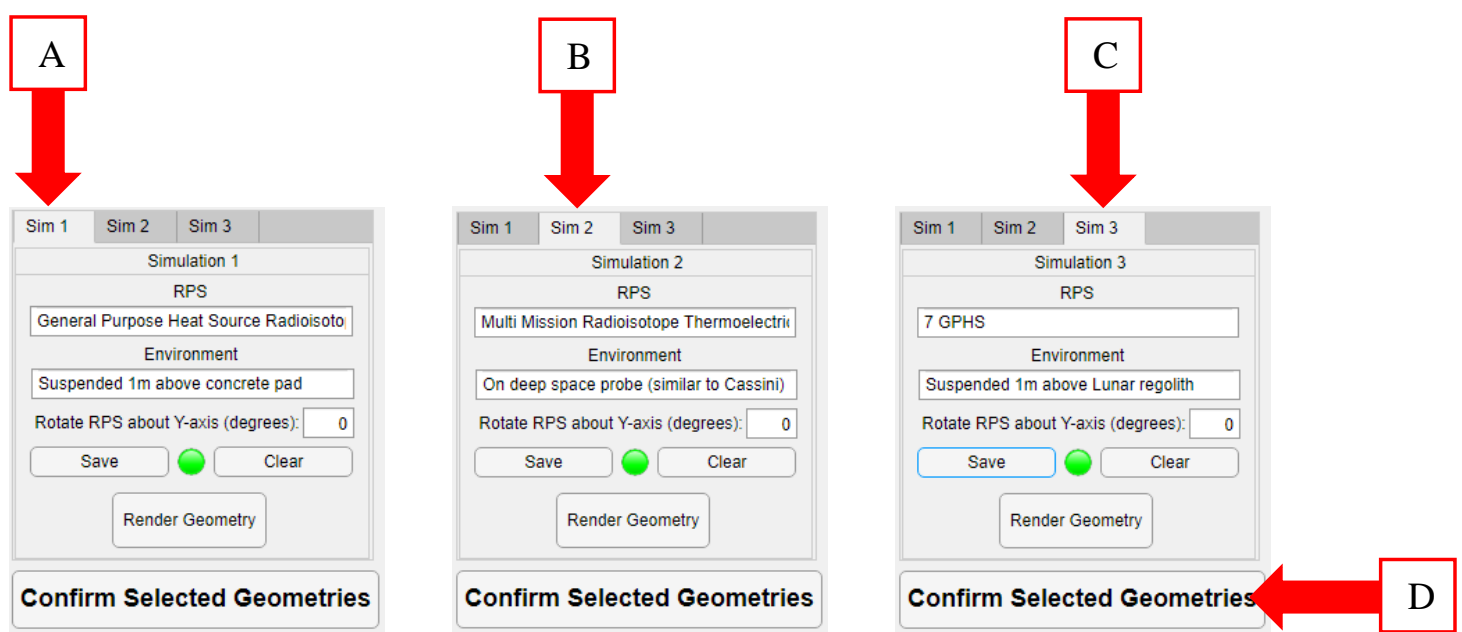

Figure 28. Saving multiple simulations on the Input Geometry tab.

\subsection{INPUT SOURCE TAB}

The Input Source tab is where you select the fuel (and thus neutron and gamma source terms) for all three simulations. While different ages of the same fuel mixture are allowed across three simulations in the same project, only one fuel composition/mixture is allowed for each project. A more complete discussion of fuel settings, recommendations, and rationales for defaults is provided in Section 3.1, "FUEL ASSUMPTIONS." The Input Source tab's initial appearance is shown in Figure 29. 


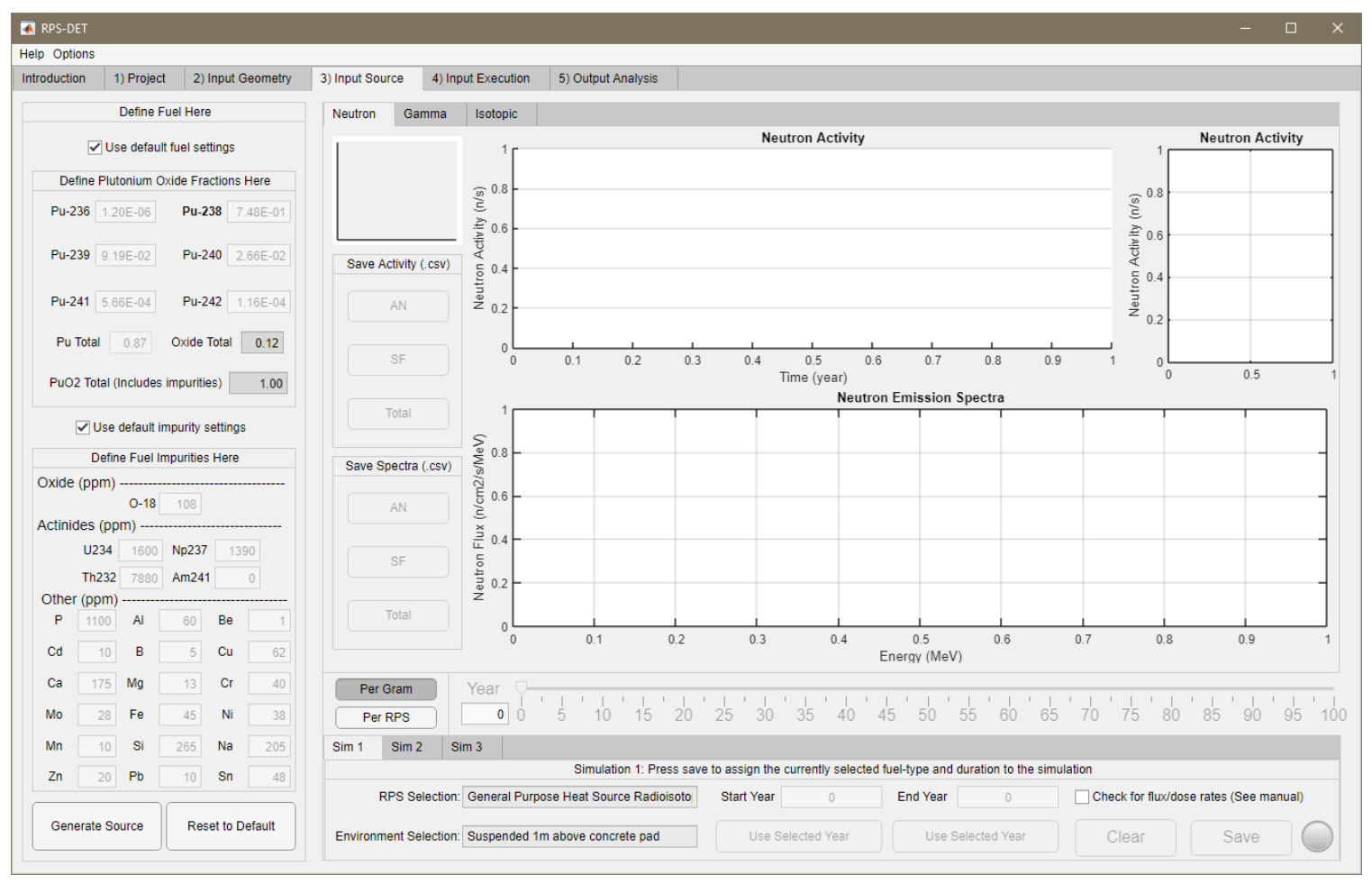

Figure 29. Initial appearance of Input Source tab.

The structure of the fuel selection is divided into four main categories: Fuel Compositions, Fuel Impurities, Fuel Age, and Rate/time-integrated selections. While most users may not be interested in changing the fuel composition or the amount of fuel impurities and will opt to select the default selections for both, the user concerned with the nuances of these effects has the freedom to experiment (within bounds) with these settings. The workflow for the default fuel/impurity selections is discussed first in this section, followed by methods to manipulate/select custom fuel settings.

If default settings are desired for fuel, confirm that the default checkboxes for fuel (Figure 30, A) and fuel impurities (B) are both checked, and then press the Generate Source button (C). This invokes SCALE in the background to perform the ORIGEN calculations for source-term development. A Windows command window may launch at this time. While this command window does not need to be in the foreground of the workspace, it should not be closed prematurely, as it will close automatically upon simulation completion.

The calculation process should take $~ 0.5-1$ minute, depending on computer performance specifications and current running processes. When complete, various plot canvases will populate with data (D), and the tab will be available for user interaction. To erase and run another source calculation, press the Clear button (E) and repeat the steps above. Time-series calculations for 100 years are automatically performed, but you may select various times (in integer years) by either clicking at any point along the year-slider $(\mathrm{F})$ or by clicking and dragging the slider to a desired point. The plots for neutron, gamma, and isotopics will update automatically when the time selection is changed, and you may select which data to observe by switching between the Neutron, Gamma, and Isotopic tabs (G). You may also toggle between the Per Gram and Per RPS buttons (H) to scale the source terms from a \#/gram basis to a \#/RPS basis. 


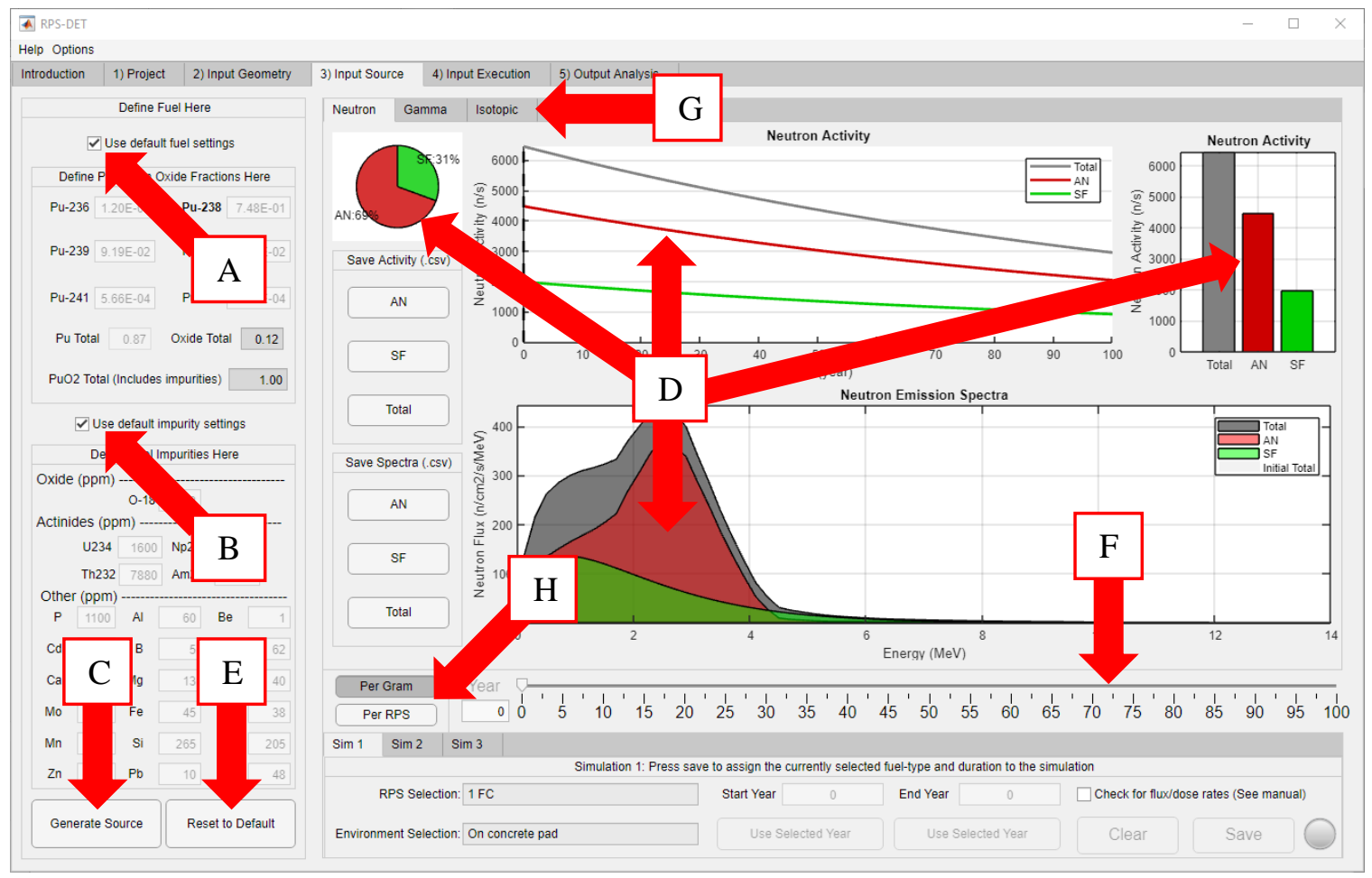

Figure 30. Input Source tab controls.

Multiple options can be used to save comma-separated value (CSV) files for the year selection and the specific source term chosen. Figure 31 through Figure 33 show three separate aspects of the same fuel selection: neutron, gamma, and isotopic, respectively. Data in CSV format can be saved for any/all the selections the user wishes by pressing any one of the Save buttons (A, B, or C) located on the three source tabs. Certain CSVs will reflect the specific year selected, while others will save all years (0-100) into a single CSV. All CSVs will be saved to the relative directory in a path like that shown below:

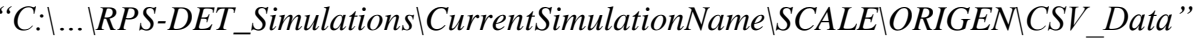

It should be noted that pressing the Generate Source button assumes that you want to change your source definition and will delete all CSV files saved to this directory so as not confuse subsequent simulations.

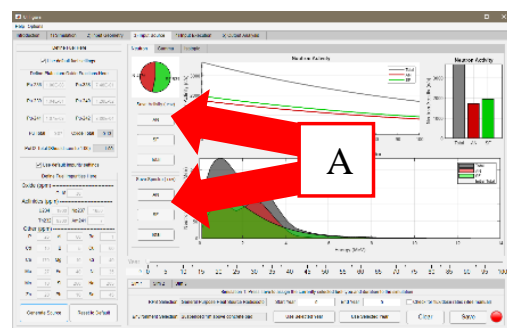

Figure 31. Neutron source information.

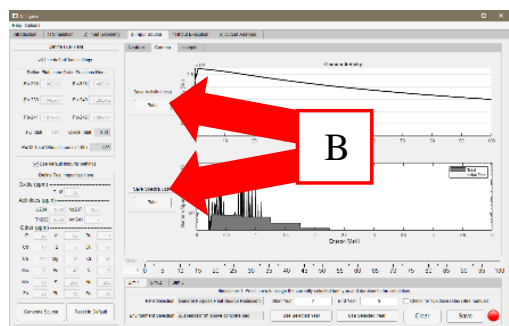

Figure 32. Gamma source information.

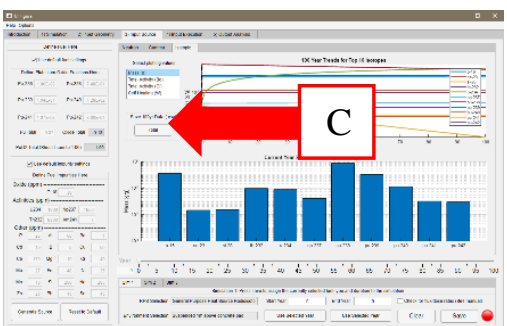

Figure 33. Isotopic source information.

The Input Source tab also allows you to assign different ages of fuel selection for the project to multiple simulations by switching between the simulation year assignment tabs at the bottom right of the screen (Figure 35, A). The concept of three separate simulations stems from the concept of having one simulation for terrestrial settings, one simulation for transit, and one simulation for destination (orbit, 
planet, etc.). By entering/selecting Start Year and End Year values, the calculation will assign an integrated flux value over the span of the years assigned. For example, if Start Year equals " 5 " and End

Year equals "10," then RPS-DET will pull the source strength from the center of the first year and integrate until the center of the last year, making a 5-year integration window (Figure 34). The flux/dose rate results of integrated simulations will ultimately be multiplied by this integrated time window to calculate either total integrated doses/responses (not dose/response rates) or total integrated fluences (not fluxes).

You may also opt to check the Check for flux/dose check box (Figure 35, B), which will disable the ability to assign an End

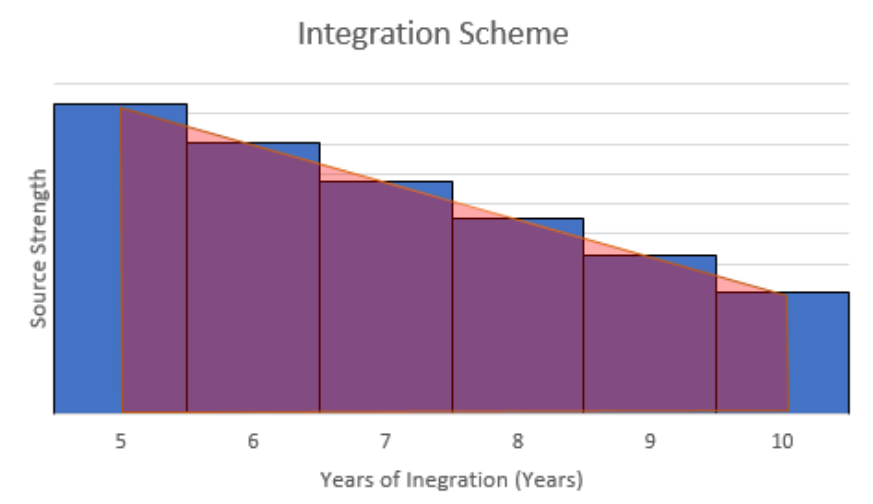

Figure 34. Example of integration scheme for 5-10-year integrated source selections in RPS-DET.

Year and will calculate a flux and/or

dose/response rate at the age of the selected Start Year. Once the selection is made (time-integrated or not) for a given simulation, the Save button (C) should be pressed to officially write the choice into the input file, and the indicator lamp will turn green once your selection is registered. The Clear button (D) will clear all time selections and allow you to reassign new values. Once all time selections have been saved for all desired simulations, you may proceed to the next tab. Details on making changes to the fuel composition are provided below.

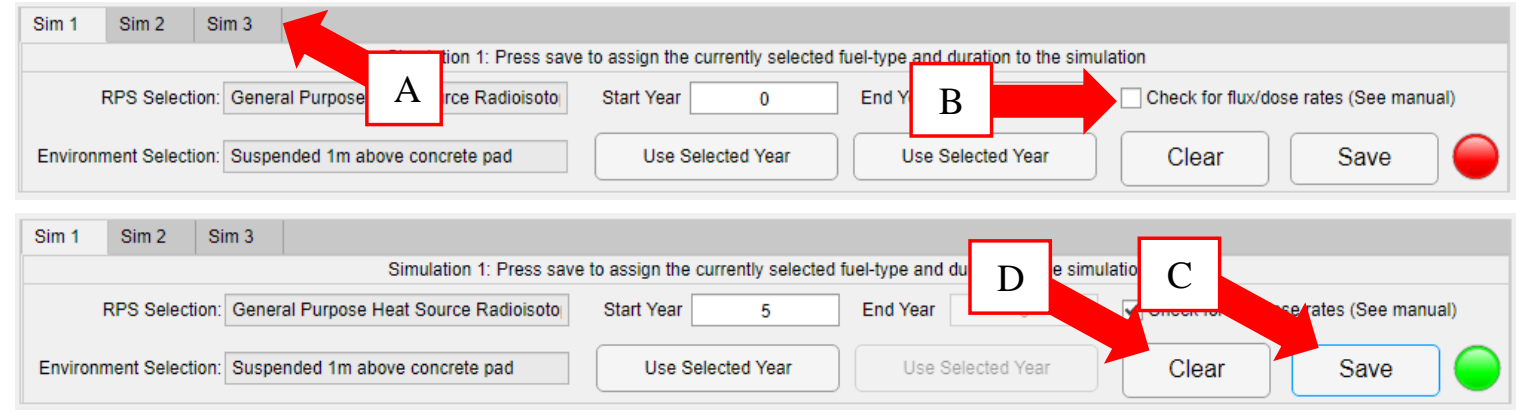

Figure 35. Simulation time assignment for fuel selection.

\subsubsection{Custom Settings for Fuel and Impurity Values}

While most simulations for spaceflight should assume the default selections for fuel—as these values represent reasonable assumptions for flight-specified fuel that would actually be provided for a missioncertain users may desire more freedom in assigning a specific fuel composition for analysis of terrestrial shipping, handling, processing, etc.

To assign custom values to the plutonium oxide and fuel impurities, un-check the Use default fuel settings checkbox (Figure 37, A) and/or the Use default impurity settings (B), and the respective text fields for each will be enabled. While you can enter whatever values of plutonium you wish, if the total sum of all plutonium isotope fractions exceeds 1.0, then the resulting Oxide Total and $\mathrm{PuO}_{2}$ Total text fields will 
turn red (C) to indicate that you cannot proceed. Level the plutonium isotope and the resulting oxide fractions to equal 1.0 prior to proceeding with the source generation. Likewise, the impurity settings are open for alteration from their original default values. However, if an impurity exceeds the fuel specification limits, you are not prevented from proceeding: you are only warned of this when the specific impurity text field turns yellow (D).

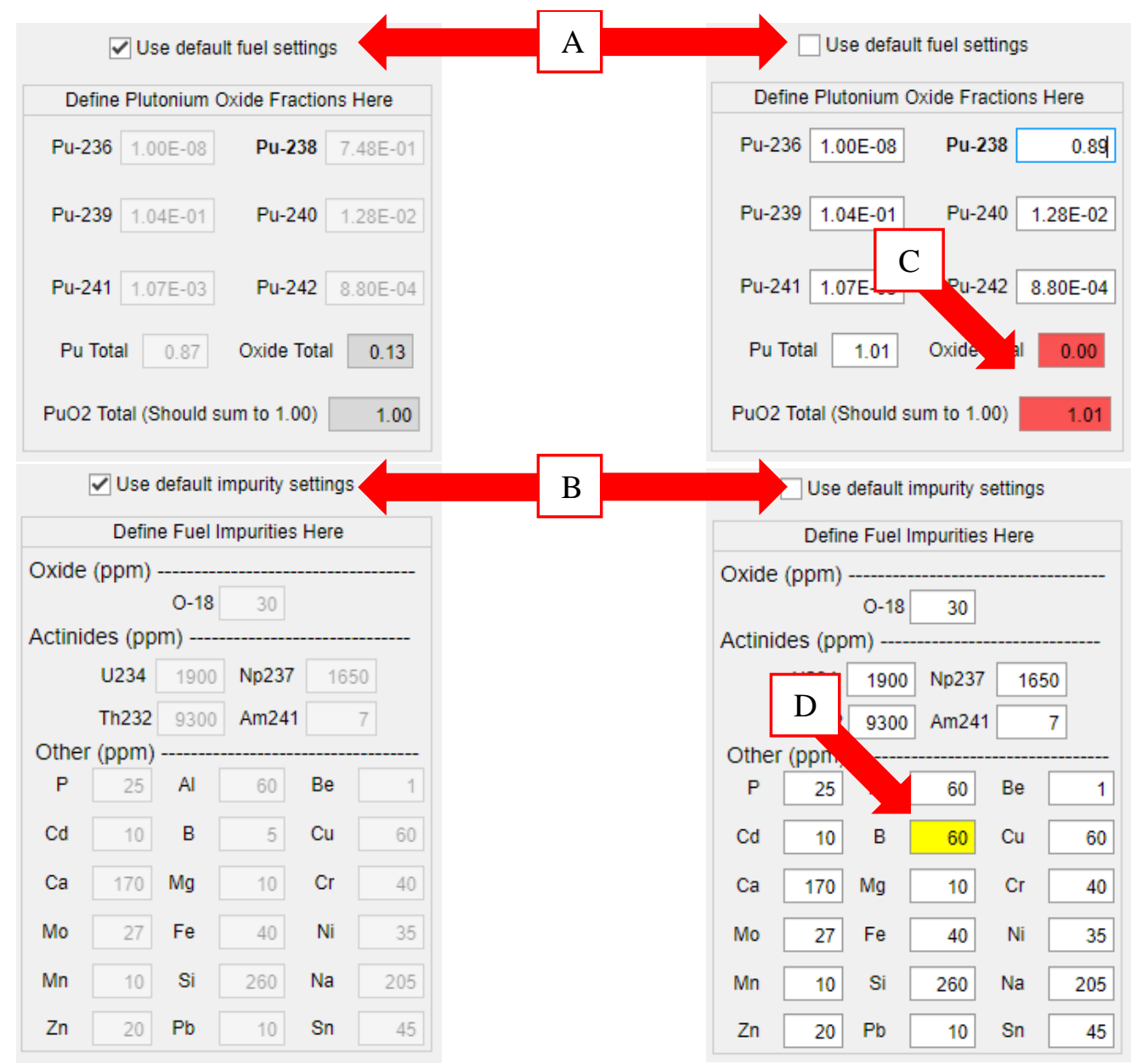

Figure 37. Fuel and impurity defaults and controls.

If fuel and impurity selections are satisfactory, the Generate Source button has effectively created plots, and the simulations have been assigned Start Year and End Year (or a rate selection), then you may proceed to the next tab. The phosphorous impurity will default higher than the specification limits and will thus turn yellow to reflect real-world observations in typical $\mathrm{PuO}_{2}$ fuel characteristics.

\subsection{INPUT EXECUTION TAB}

The Input Execution tab allows you to confirm the selections for your simulations, assign the simulation time or number of particles, and execute the SCALE simulations. This tab also provides dynamic text fields that provide estimated simulation-finish times based on your local system performance, with indicator lamps showing when simulations are complete. Executing runs from the RPS-DET GUI simply invokes the SCALE software through the Windows Command Prompt as a background process. The Input Source tab's initial appearance is shown in Figure 38. 


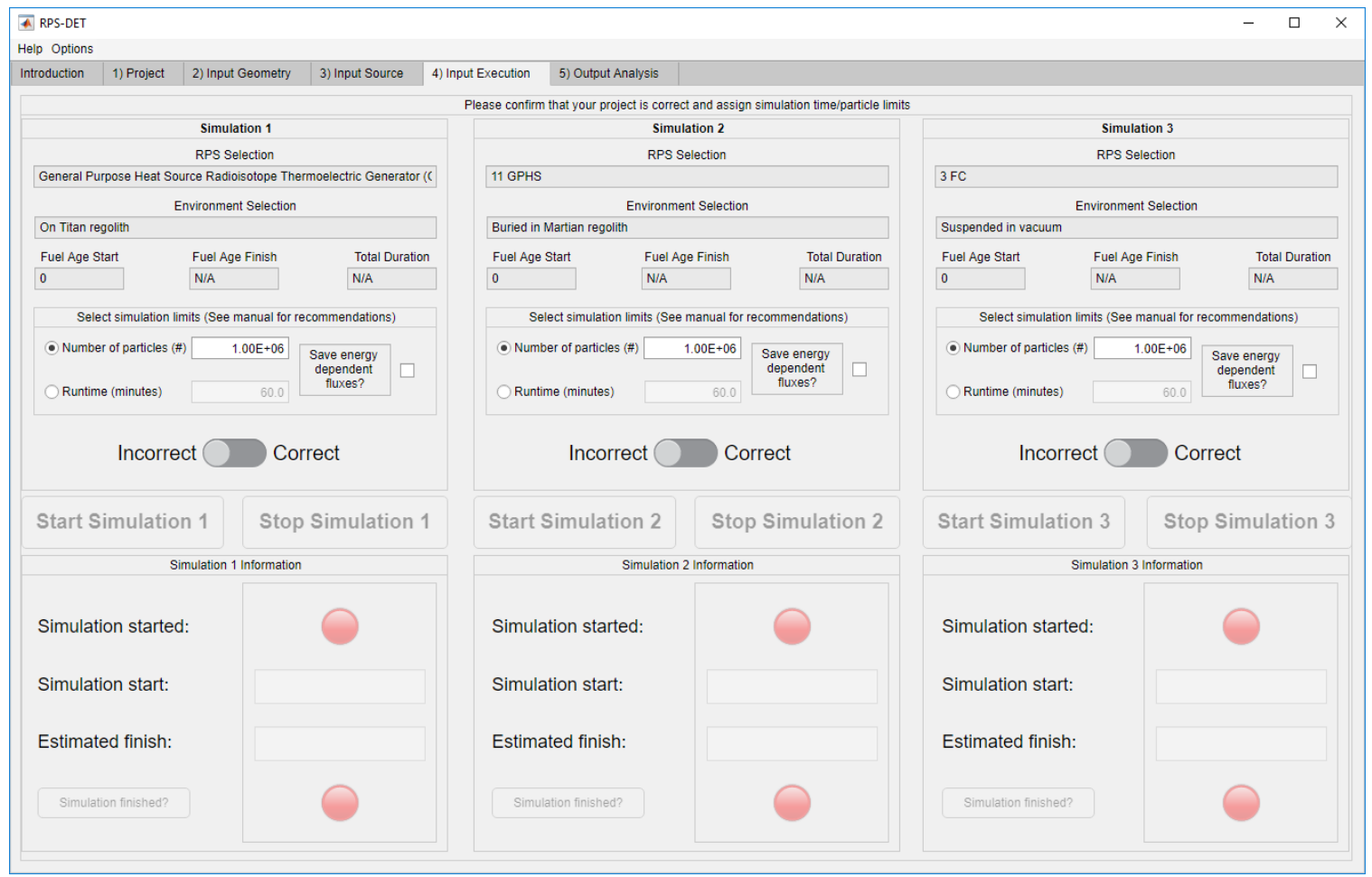

Figure 38. Initial appearance of Input Execution tab.

The Input Execution tab should automatically populate the RPS, Environment, Rotation, Start Year, End Year, and Duration selections in the appropriate text fields for any of the 1-3 simulations that were built for this project. Working from left to right (Simulation 1 through Simulation 3), you should first confirm that your selections for Simulation 1 are correct (Figure 39, A). If these selections are correct, then you must choose either to limit your simulation by the number of particles or by the runtime (CPU time) (Figure 36). These selections are made by toggling between the Number of particles and Runtime radio buttons (B), which enable/disable the corresponding text field for editing. Please see Section 2.6.1 for further discussion on determining ideal settings for these selection options.

There is also an option for selecting to save the energy dependent neutron and photon fluxes during the simulation (C) for each individual voxel of the three-dimensional tally in every simulation. RPS-DET's default settings do not include energy dependent fluxes for photons and neutrons, and instead integrate all flux values (over energy) to a single value for each voxel representing either a flux rate, fluence, response rate, or time-integrated response. Selecting this checkbox (C) will issue a warning notifying you of the added computational consequence of including this option in your simulation. The bulk of the additional computational time is incurred during the post-processing of the tallies, not necessarily during the simulation itself (which is handled by SCALE). A notional $~ 10$ s of minutes may be added to your full simulation time by making this selection depending on computational power of your local machine. It is advised that if energy dependent spectra are not required for your analysis that this option not be selected to save computation time. 


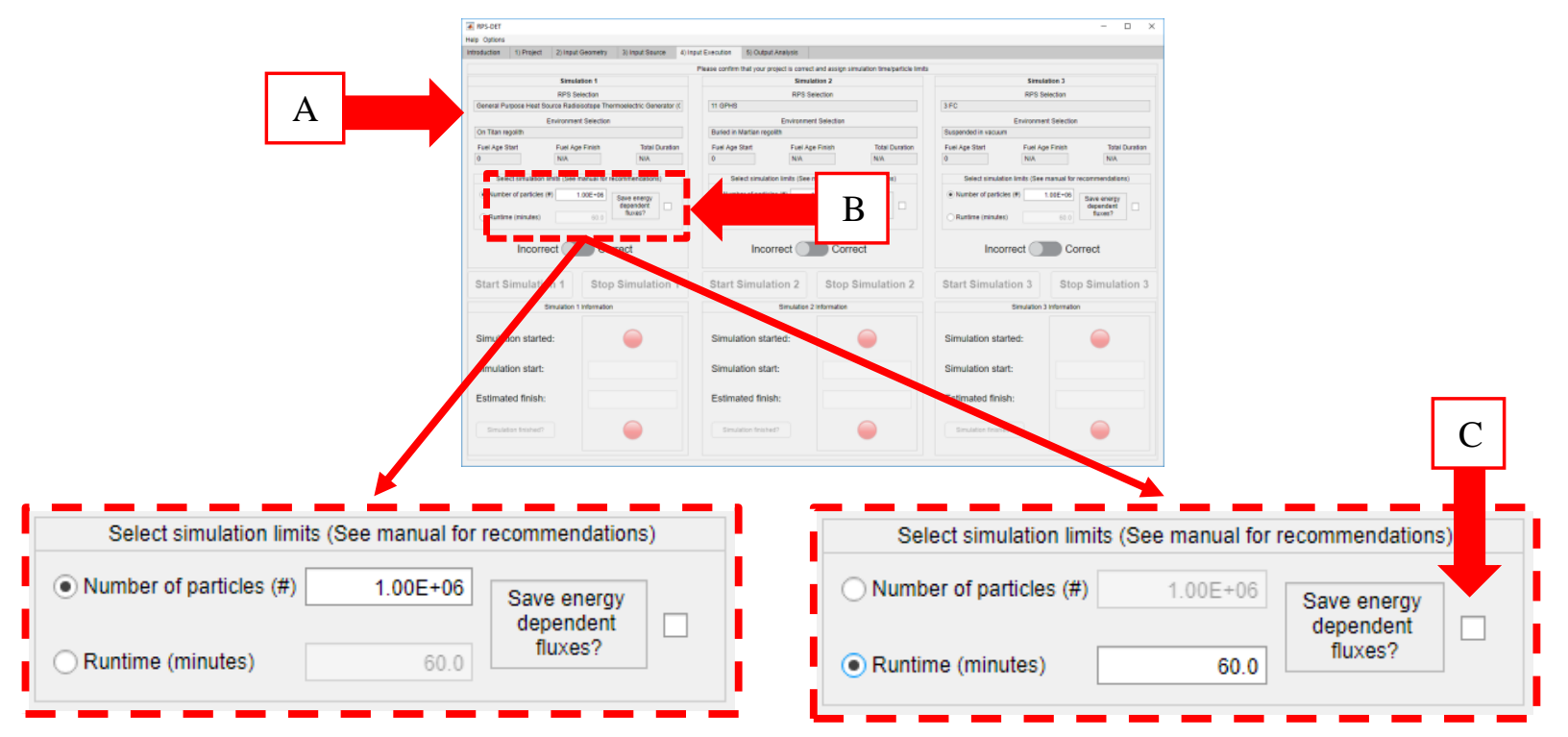

Figure 39. Selection for number of particles or computer runtime.

Once this selection is made, you may toggle the Incorrect switch to the Correct position (Figure 40, A), which enables the Start Simulation button (B) to be pressed. Pressing the Start Simulation will deliberately disable the Start Simulation button (B) and the Stop Simulation button (C) for approximately 1-2 minutes while estimations of the total runtime are made. A wait-bar window (D) will appear during this time to notify you of time remaining, the Simulation start text field will populate with the simulation start date/time, and the indicator lamp will turn green (E). Once the estimated time has been calculated, the Estimated finish text field (G) will present the estimate, and the Simulation Finished? button (F) will also become enabled. Pressing the Simulation Finished? button (F) checks the status of the simulation and updates the Estimated finish text field (G). This may be of interest if long simulations are being performed and you would like an updated estimate on the finish time based on real-time computer performance. The Simulation Finished? button (F) may be pressed as many times as the user requires to satiate curiosity. Allowing the simulation to run its course and finish at its estimated time or prematurely ending it by pressing the Stop Simulation button (C) both have the same effect. When the simulation ends, either by user interruption or natural simulation completion, RPS-DET issues a "kill" command to SCALE, and SCALE begins the process of gracefully ending the simulation and compiling all the current results into their final output formats. This process typically takes 1-5 minutes, depending on computer performance. If the Stop Simulation button (B) is pressed, then RPS-DET will periodically check the local RPS-DET directory for specific output files until they are present and will display a wait-bar window $(\mathrm{H})$ estimating the amount of time required for this to finish. Once these files are present, the simulation is considered complete, and RPS-DET turns the Simulation Finished? indicator lamp green (I), disable the Simulation Finished? button (F), and re-enable the Incorrect/Correct switch (A) if the simulation were stopped to edit something in the simulation and start again. If the simulation runs to natural completion, as indicated by the Estimated Finish date/time being surpassed, you will not be automatically notified. You must press the Simulation Finished? button (F) to confirm completion. If the simulation is complete, then the Simulation Finished? indicator lamp (I) will turn green, the Simulation Finished? button (F) will disable, and you may proceed either to the next simulation or to the next tab. This simulation start/stop process and functionality is identical for simulations $1-3$. 


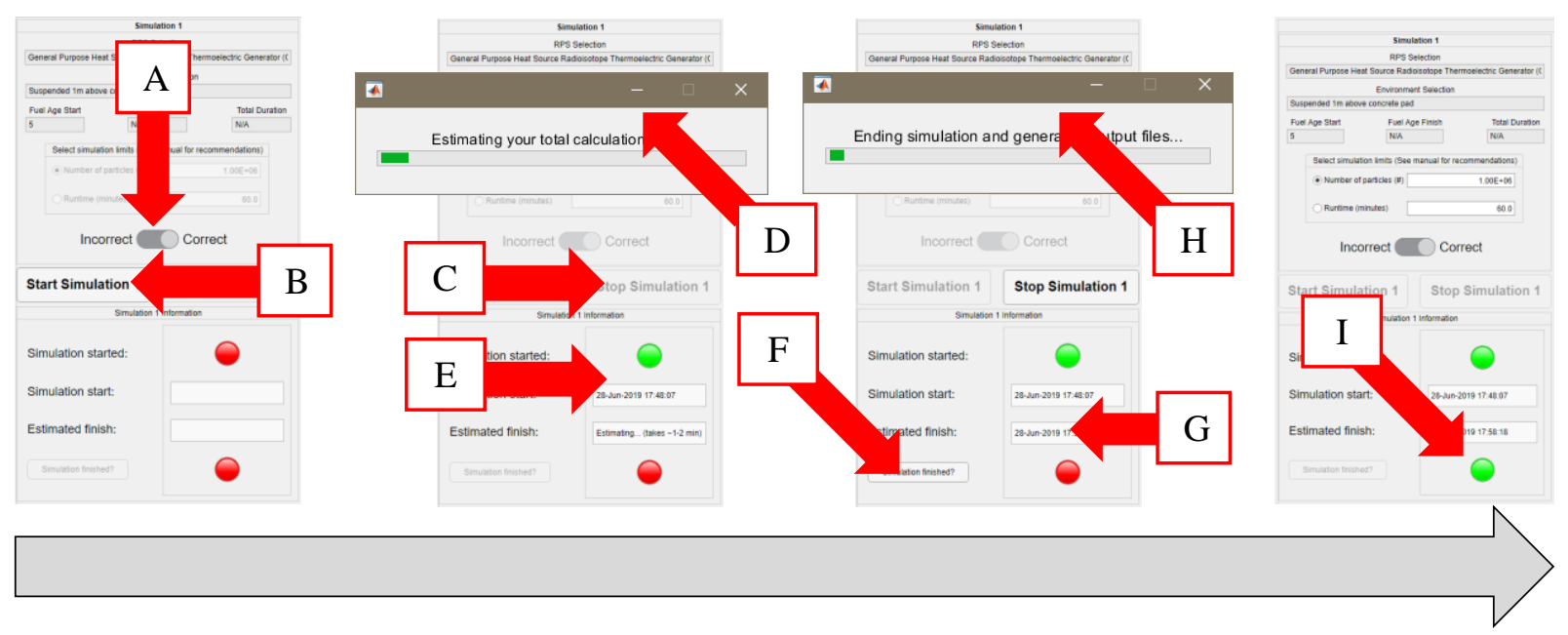

Figure 40. Logic and sequence for starting/stopping simulations with RPS-DET.

\subsubsection{Considerations for Selecting Simulation Runtime and/or Number of Particles}

Many factors affect your local computer performance: the number of ancillary processes running during RPS-DET simulation, the amount of available RAM, the amount of available disk space, solid-state/disk hard drive, etc. A performance example is provided below illustrating the relationship of CPU time to the number of particles simulated. Table 2 provides estimate bounds to start an approximation of your own simulation performance expectations, but it is advised to simply start with 1E6 for your first simulation of RPS-DET, wait 2 minutes while RPS-DET estimates your finish time, and deduce your performance metric for your local computer. While the correlation between simulation time and particle number will likely differ from what is shown in this table, the relationship is expected to be linear after the simulation times exceed one's of minutes. That is, simulation startup time is not as large of a percentage of the total simulation time in longer simulations. With this assumption, a similar trend can easily be deduced for your local computer's performance. It should be noted that each individual execution of SCALE via RPS-DET will occupy only a single processor, so multiple simulations can be executed at the same time. However, depending on your local computer's performance, running multiple RPS-DET simulations at the same time may increase the computation time of each subsequent simulation. You are encouraged to observe the task manager during your first few RPS-DET runs to deduce the performance implications of parallel simulations on your computer's performance and plan accordingly. 
Table 2. Example of single RPS-DET simulation performance.

\begin{tabular}{cc}
\hline Number of particles & $\begin{array}{c}\text { Total CPU simulation time } \\
\text { (HH:MM) }\end{array}$ \\
\hline 1E6 & $00: 04$ \\
5E6 & $00: 18$ \\
1E7 & $00: 35$ \\
5E7 & $02: 55$ \\
1E8 & $05: 50$ \\
5E8 & $29: 12$ \\
1E9 & $58: 18$ \\
\hline
\end{tabular}

Computer specifications:

Intel® Core ${ }^{\mathrm{TM}}$ i7-4790 CPU @ 3.60 GHz, 16 GB RAM

\subsection{OUTPUT ANALYSIS TAB}

RPS-DET simulations may be loaded under the Output Analysis tab, and the results can be inspected through various SCALE visualization applications. This tab will load the current completed simulations (1-3) and will allow the user to inspect aspects of the input and/or results using Meshview, Fulcrum, or Keno 3D. The initial appearance of the Output Analysis tab is shown in Figure 41.

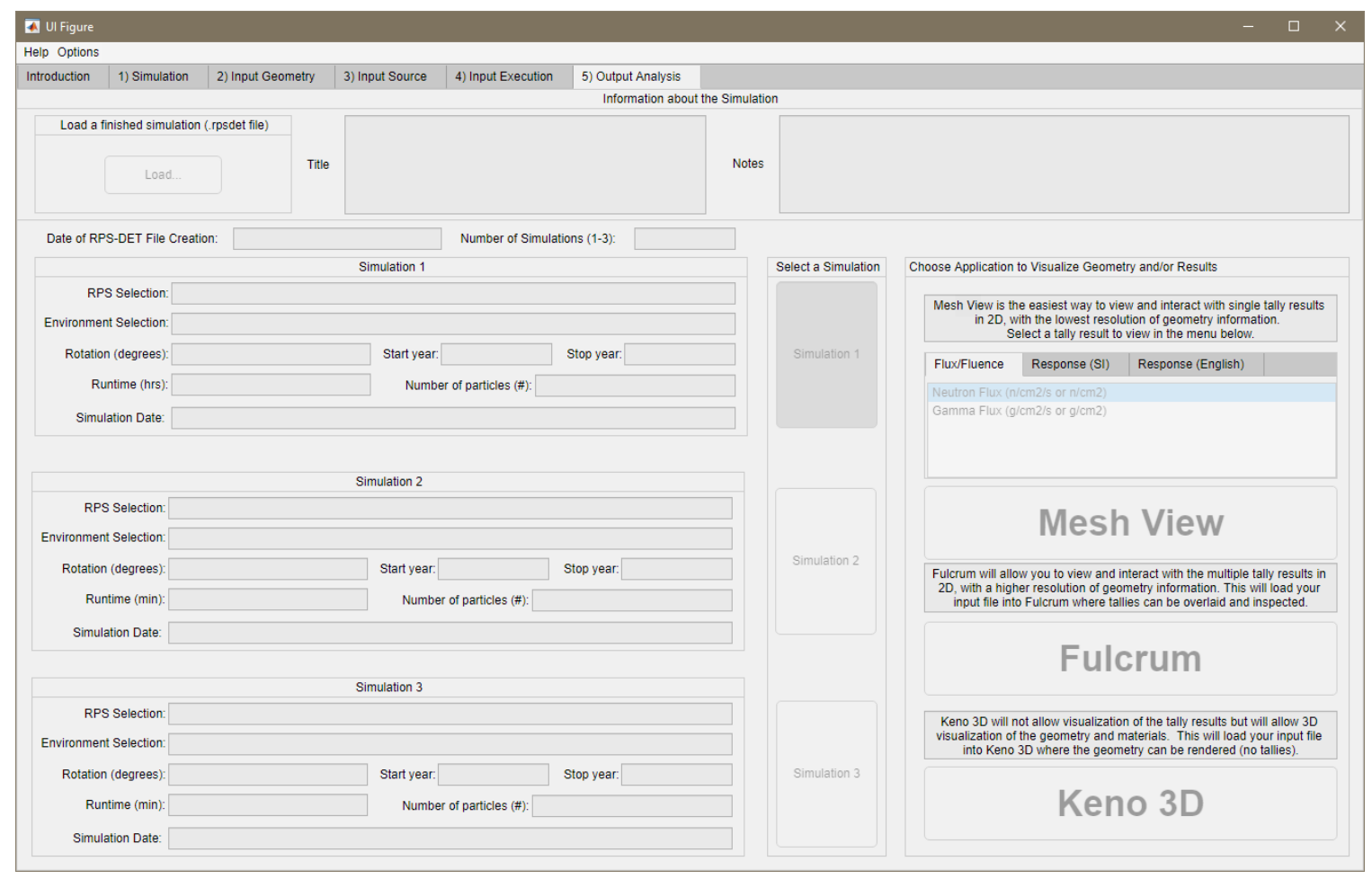

Figure 41. Initial appearance of Output Analysis tab.

If loading a previously saved project or a project or projects simulated in the same session, the information should properly be displayed in the text fields throughout the tab (Figure 42, A). The selections edit fields should reflect the number of simulations in the project, which will display in the 
Number of Simulations text field (B). Correspondingly, the Select a Simulation buttons (C) will only allow selection from these available simulations. Choose a simulation to inspect via the Select a Simulation button (C) and determine what you would like to inspect about this simulation. There are three ways to interact with the simulation inputs/outputs: the Meshview button (D), the Fulcrum button (E), and the Keno $3 D$ button (E). Brief descriptions of the utility of each of these buttons are provided below.

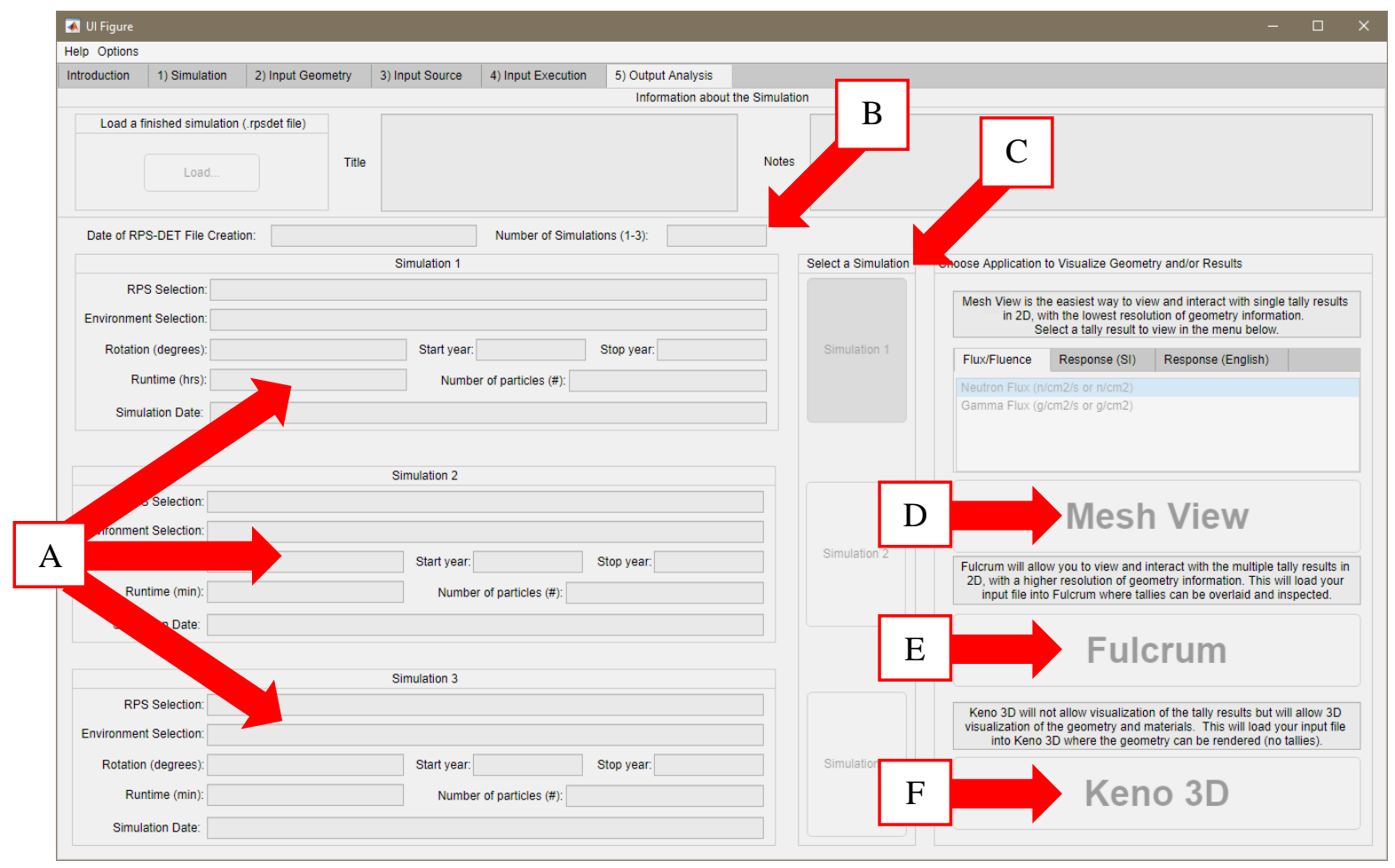

Figure 42. Output Analysis tab, controls, and button logic.

\subsubsection{Meshview}

Meshview is a supplemental SCALE application that allows users to quickly visualize 3D cartesian and cylindrical mesh tallies like those generated by RPS-DET generates on 2D planar slices. It also allows toggling of different materials, geometry units, and boundaries, along with generating radial/axial plots of results. This tool is useful for analytically inspecting your results and generating colorful, informative plots for publications and papers. While a full Meshview User Manual is accessible from the RPS-DET GUI, as discussed in Section 2.2.1.1, a brief introduction to this utility is provided here, as well.

Every simulation input (denoted by a .inp extension) executed by RPS-DET generates multiple mesh tallies (.3dmap extension). These files represent everything from neutron and gamma fluxes (and/or fluences) to particle-separated and/or combined response functions, and Meshview only requires these .3dmap files, not the .inp files. Because of this, the selection of the tally results is made in the RPS-DET GUI to simplify interpreting the naming conventions of the numerous output files. The default tally units are shown in Figure 43 below, where fluxes (Figure 43, A), responses in SI units (B), and responses in English units (C) can be selected. Once a unit selection is made and Meshview is invoked by pressing the Meshview button (D), the corresponding file for the user selection is automatically provided, and the Meshview application window will appear. 


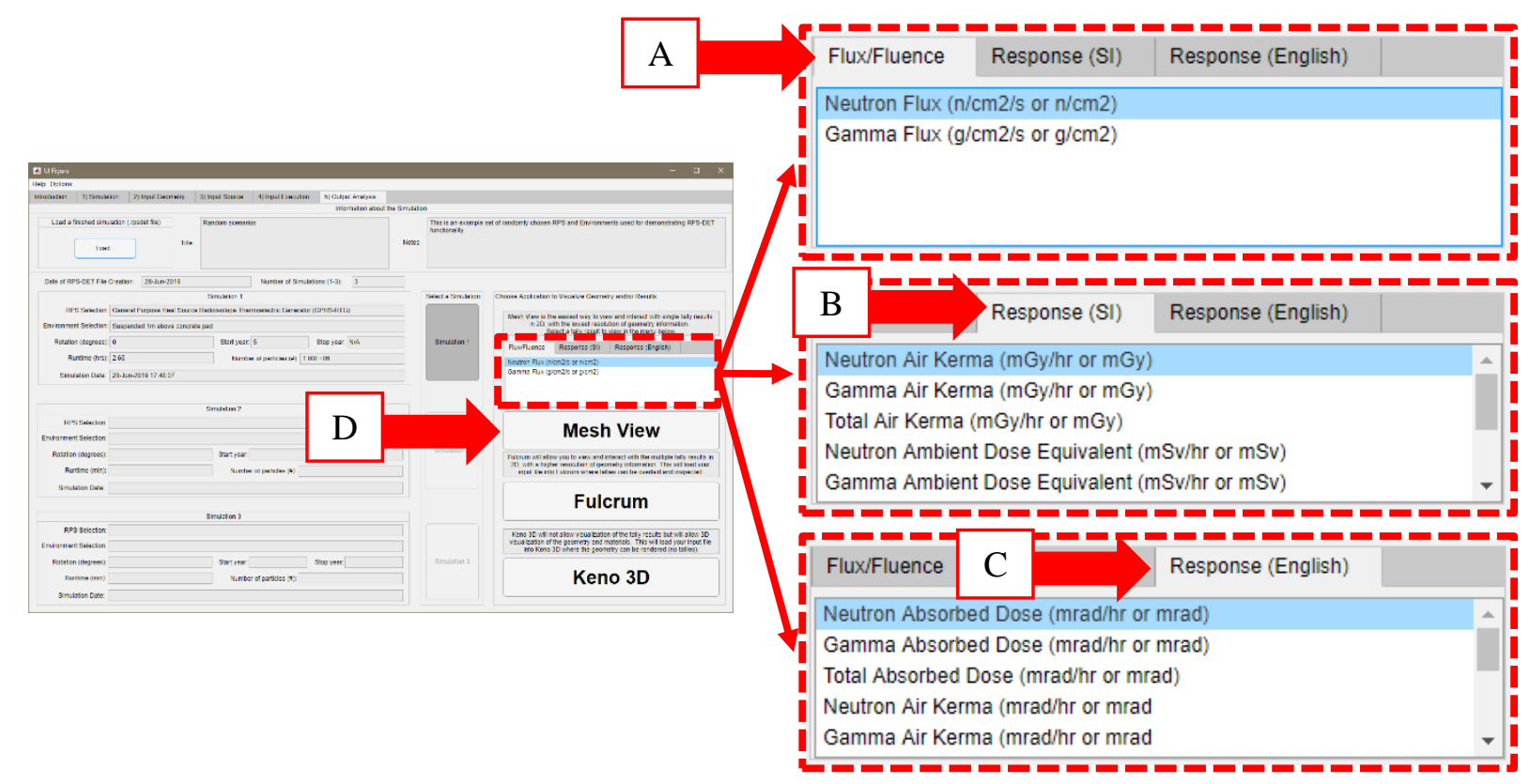

Figure 43. Meshview unit selection.

While the initial appearance of the Meshview data will vary depending on the duration of the simulation and the selected geometries, the controls and features will be the same for any/all Meshview executions, as briefly discussed here. Figure 44 shows a gamma-ray flux result for a Multi-Mission Radioisotope Thermoelectric Generator (MMRTG) on a Cassini-like spacecraft in deep space with 10-year-old fuel visualized in Meshview. A general overview of the Meshview controls is shown in Table 3.

Table 3. Brief descriptions of relevant Meshview controls for inspecting RPS-DET results. All labels in this table reference Figure 44 below.

\begin{tabular}{cl|cl}
\hline Label & \multicolumn{1}{|c|}{ Brief explanation } & Label & \multicolumn{1}{c}{ Brief explanation } \\
\hline A & Meshview pull-down menus & H & Controls location of cross-sectional slice \\
B & File pull-down menu & I & Data inspection information \\
C & Saves current image to file or to clipboard & J & Coordinate at cursor location \\
D & $\begin{array}{l}\text { Scene pull-down menu for general control of the } \\
\text { data display window }\end{array}$ & K & Unit/material/etc. number at cursor location \\
E & Controls cross-sectional slice selection & L & Data value at cursor location \\
F & Allows toggling visualization of various & M & Data absolute uncertainty at cursor location \\
G & features of the geometry & N & Data relative uncertainty at cursor location \\
\hline
\end{tabular}




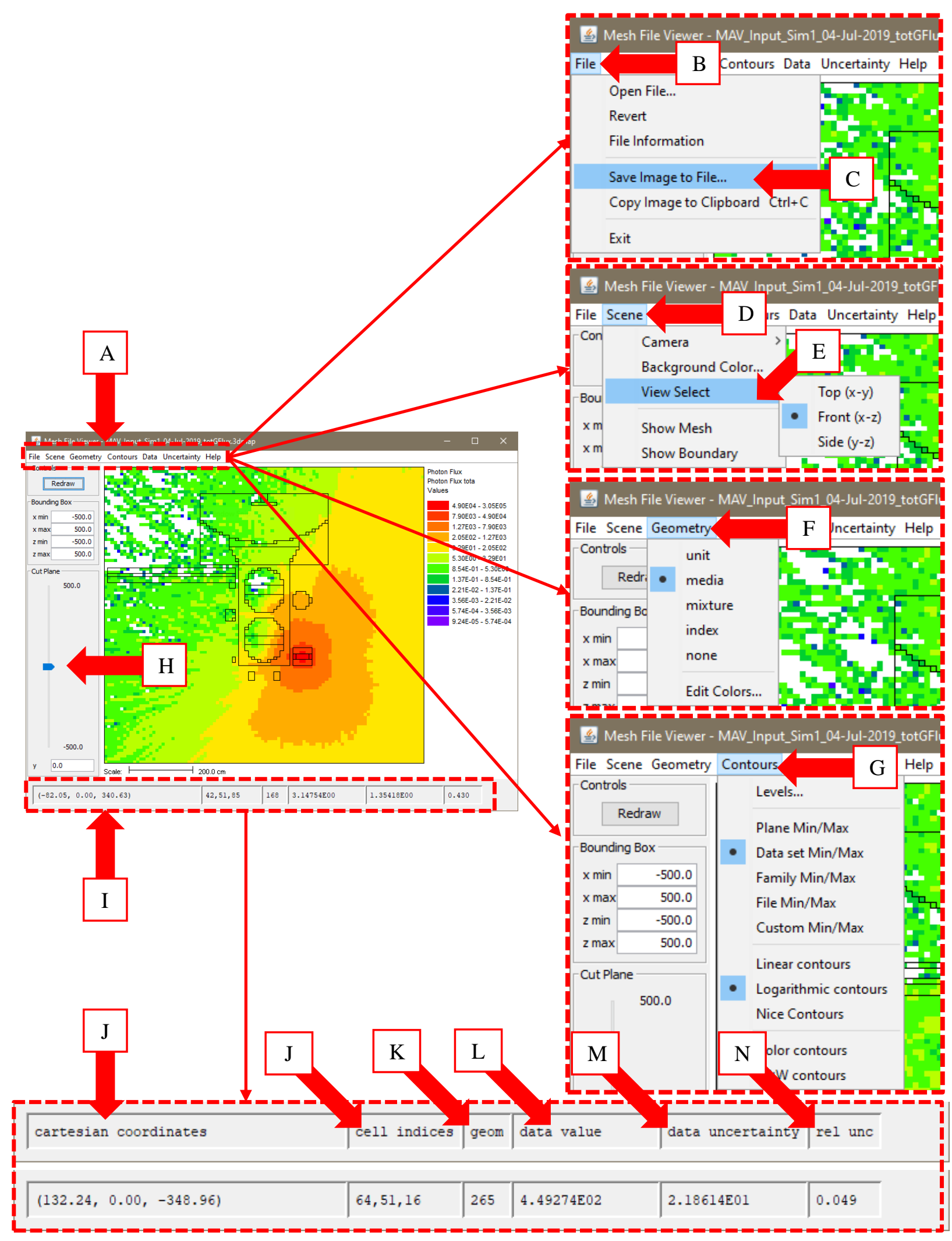

Figure 44. Meshview features and controls. 


\subsubsection{Fulcrum}

Fulcrum is SCALE's flagship GUI that enables control of the entire SCALE software suite. However, the RPS-DET application simply invokes Fulcrum with the desired simulation and allows the user to overlay tally results over high-resolution geometry renderings in $2 \mathrm{D}$ slices of the greater $3 \mathrm{D}$ geometry. The following steps will explain how to use Fulcrum to visualize RPS-DET inputs/results. While the RPS-DET User Manual provides an introductory explanation of Fulcrum capabilities, the user is also encouraged to reference the SCALE User Manual for a detailed explanation of Fulcrum's features [1]. Upon pressing the Fulcrum button (Figure 45, A) in RPS-DET, the Fulcrum window (B) will open with the previously selected input automatically loaded. Selecting the View pulldown menu (C) will allow you to choose the View geometry selection (D), or you can use the keyboard shortcut $C t r l+S h i f t+V$. Once you have made this selection, the geometry of your input will be displayed in the Fulcrum window (E).
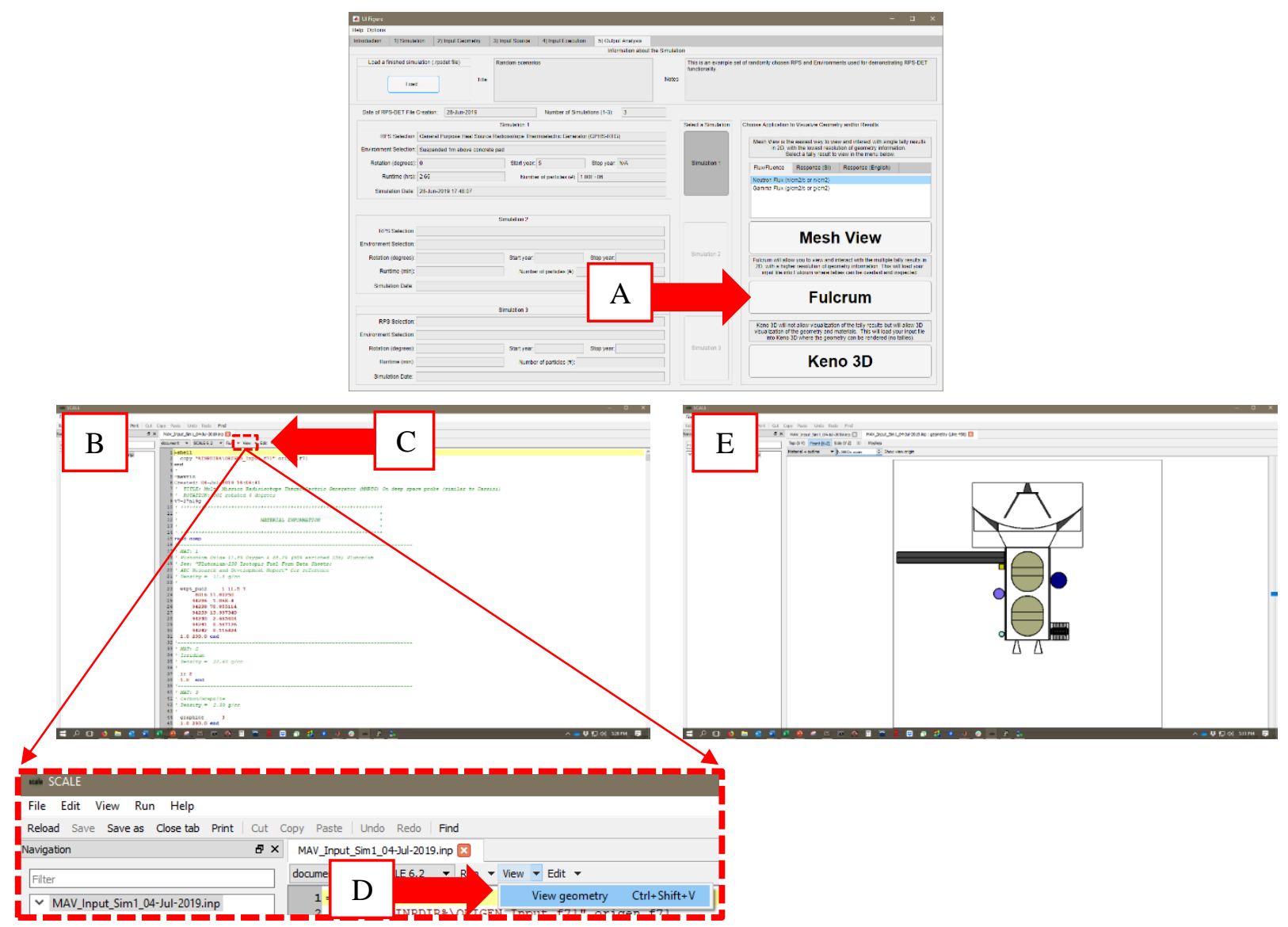

Figure 45. Loading RPS-DET simulation in Fulcrum and visualizing geometry.

While this process does load the simulation's input geometry and allows you to interact with and visualize various cross sectional planes, materials, etc., it does not immediately load and overlay tally results. To visualize tally results in the Fulcrum window, you must navigate to and press the Meshes button near the top (Figure 46, A). A small pane will open below that reads Available meshes (B) and will provide any loaded meshes, none of which should be loaded upon initial launching of Fulcrum. To load meshes, right click anywhere in this window, and a small pulldown menu will appear (C). Select Load mesh file, and a search window will appear (D). Navigate to your working directory and select the desired response to view from the available .3dmap file. This will load the data into the Available meshes window 
(E), and the checkbox for the data to view can be checked (flux, response, uncertainty, etc.). You must then select either Overlay or Overlay+ boundaries $(\mathrm{F})$ to visualize the data over your geometry $(\mathrm{G})$.

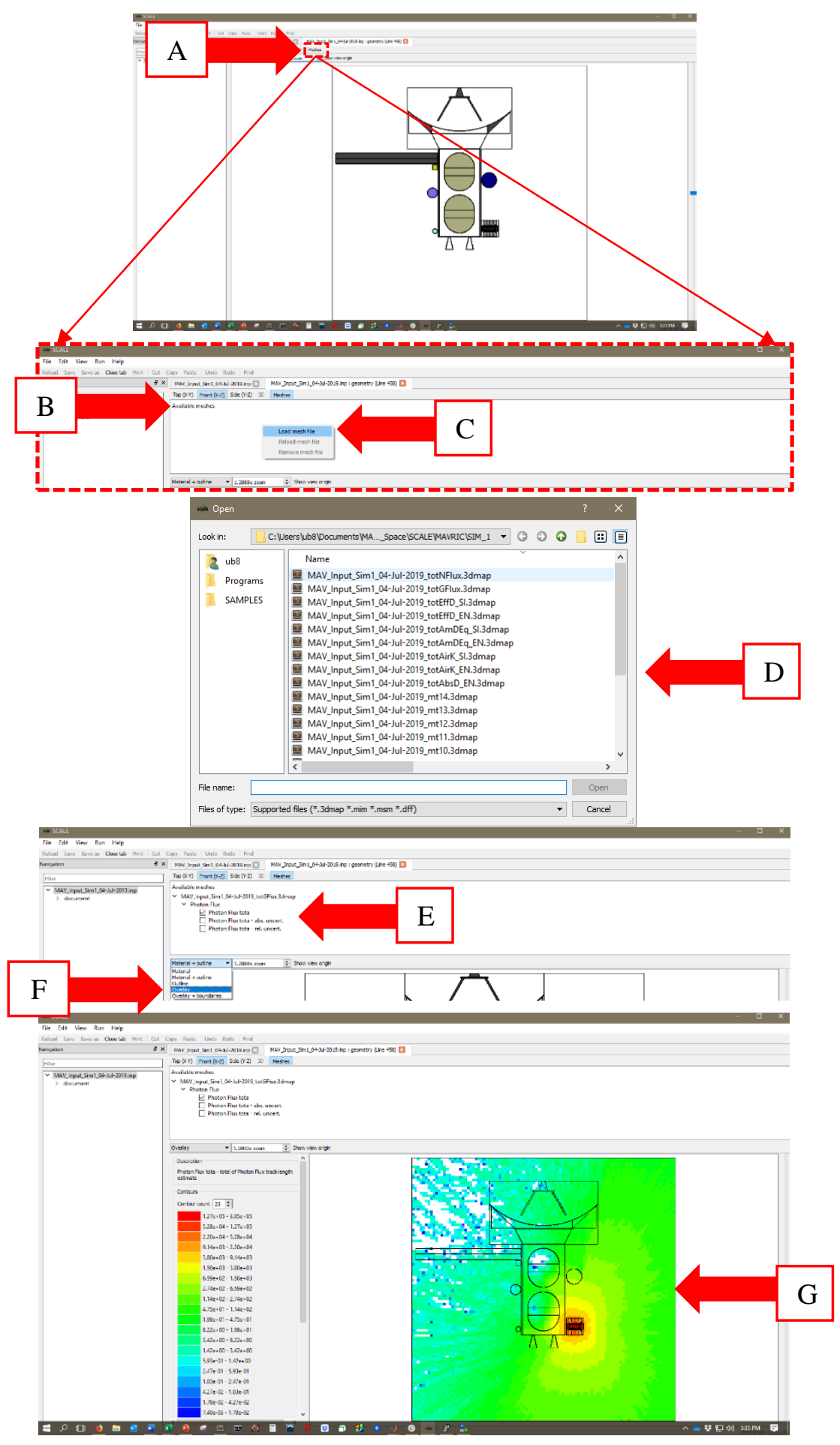

Figure 46. Loading RPS-DET simulation results in Fulcrum and overlaying on geometry. 
Upon successful visualization of the geometry and overlaid data, other high-level controls are available for inspection/interaction. The selection of the viewed cross section can be chosen (Figure 47, A) and all slices of that projection can be made by the incremental slide bar (B) on the right side of the window.

Customization of the colormap for your results can be made in the Contours pane (C), where selections such as number of contours, logarithmic or linear scales, value ranges, etc., can be manipulated to suit your needs. Right clicking at any point on the plot will open a small window allowing you to Change color, Save, Load Concentrations, and Create plot (D). Choosing the Create plot selection will open a window (E). When prompted to choose which axis/value you would like to visualize, make your selection and press $O K$. This will load the axial plot data into the Navigation pane (F), where you can select the bottom tree selection (flux, response, etc.), and the data will be plotted $(\mathrm{G})$. You can then interact with, save, or present the data in tabular format by tabbing over to the Table tab $(\mathrm{H})$. 

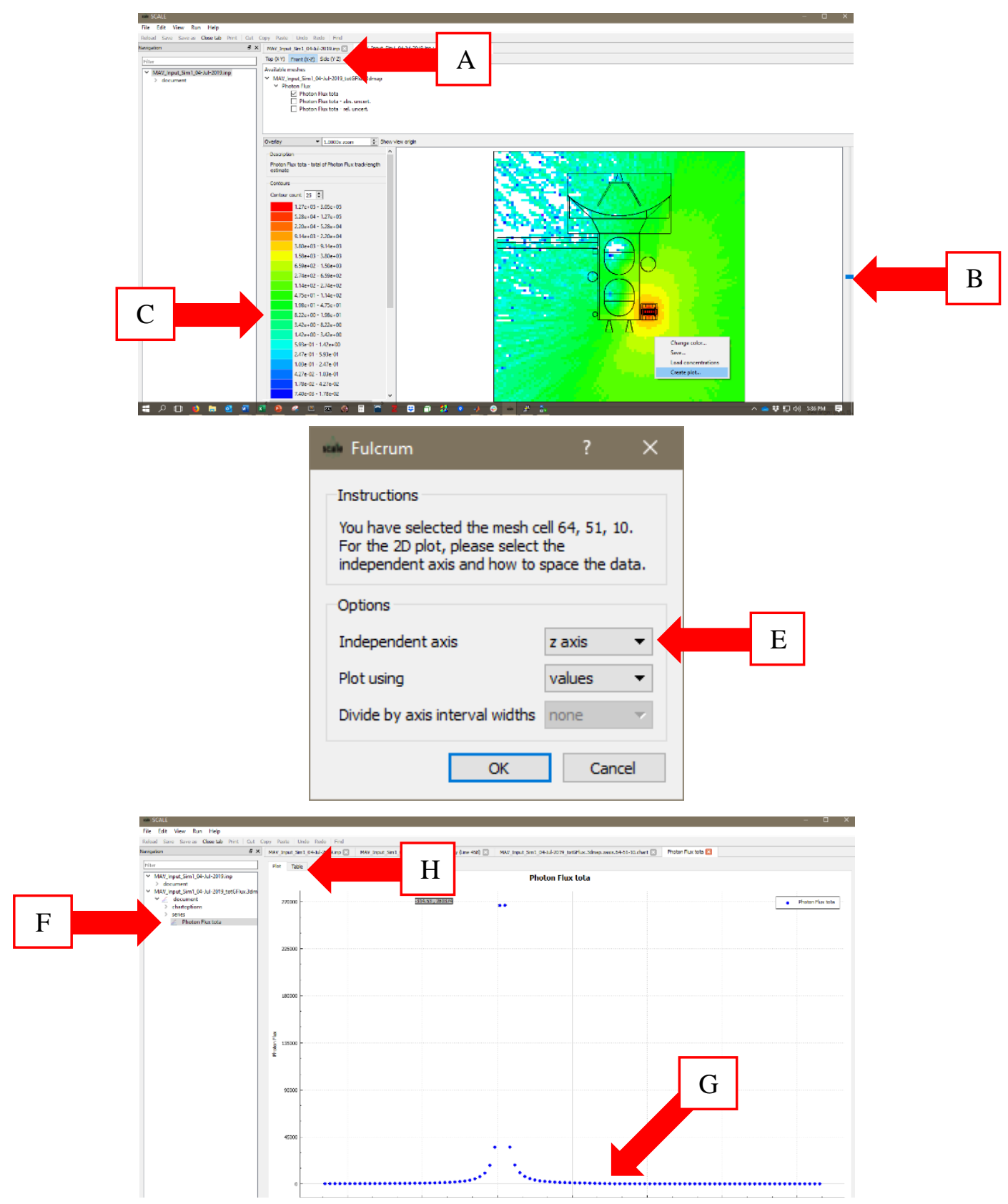

Figure 47. Various features of other Fulcrum data inspection capabilities.

Naming conventions for the various .3dmap files generated in RPS-DET simulations might not be immediately clear for selection in Fulcrum, so Table 4 is provided to assist you in making your selections. All .3dmap files will have the following naming structure:

\section{simulationName_responseName.3dmap}

where the simulationName will typically be structured as MAV_Input_Sim1_01-Jul-2019.inp for simulation \#1 in a project executed on July 1, 2019. Using this same name as the input, a resulting .3dmap file for the total neutron flux would have a responseName of totNFlux resulting in a .3dmap file name of MAV_Input_Sim1_01-Jul-2019_totNFlux.3dmap. Examples for all .3dmap file names in Table 4 will exclude the simulationName. 
Table 4. Description of .3dmap file generated by RPS-DET simulations.

\begin{tabular}{|c|c|c|c|c|}
\hline $\begin{array}{l}\text { Number } \\
\text { of tallies }\end{array}$ & $\begin{array}{c}\text { RPS-DET output } \\
\text {.3dmap File } \\
\text { (responseName) }\end{array}$ & Comments & $\begin{array}{l}\text { Response } \\
\text { source }\end{array}$ & Ref. \# \\
\hline 1 &. $\mathrm{mt101.3dmap}$ & All neutron tallies & N/A & N/A \\
\hline 2 &. $\mathrm{mt} 102.3 \mathrm{dmap}$ & All photon tallies & N/A & N/A \\
\hline 3 & nAbsD_SI.3dmap & Needs to be SI for absorbed dose & Henderson & {$[3]$} \\
\hline 4 & pAbsD_SI.3dmap & Needs to be SI for absorbed dose & Henderson & [3] \\
\hline 5 & tAbsD_SI.3dmap & Total absorbed dose (Gy/hr) & Henderson & [3] \\
\hline 6 & nAbsD_EN.3dmap & Neutron absorbed dose (rad/hr) & Henderson & [3] \\
\hline 7 & pAbsD_EN.3dmap & Photon absorbed dose (rad/hr) & Henderson & [3] \\
\hline 8 & tAbsD_EN.3dmap & Total absorbed dose (rad/hr) & Henderson & [3] \\
\hline 9 & nAirK_SI.3dmap & Neutron Kerma in air $(\mathrm{Gy} / \mathrm{hr})$ & ICRU44 & [4] \\
\hline 10 & pAirK_SI.3dmap & Photon Kerma in air (Gy/hr) & ICRU57 & {$[5]$} \\
\hline 11 & tAirK_SI.3dmap & Total air Kerma (Gy /hr) & ICRU44/57 & {$[4],[5]$} \\
\hline 12 & nAirK_EN.3dmap & Neutron Kerma in air (rad/hr) & ICRU44 & [4] \\
\hline 13 & pAirK_EN.3dmap & Photon Kerma in air (rad/hr) & ICRU57 & {$[5]$} \\
\hline 14 & tAirK_EN.3dmap & Total air Kerma ( $\mathrm{rad} / \mathrm{hr})$ & ICRU44/57 & {$[4],[5]$} \\
\hline 15 & nAmDEq_SI.3dmap & Neutron ambient dose equivalent (Sv/hr) & ICRU57 & [5] \\
\hline 16 & pAmDEq_SI.3dmap & Photon ambient dose equivalent (Sv/hr) & ICRU57 & [5] \\
\hline 17 & tAmDEq_SI.3dmap & Total ambient dose equivalent $(\mathrm{Sv} / \mathrm{hr})$ & ICRU57 & [5] \\
\hline 18 & nAmDEq_EN.3dmap & Neutron ambient dose equivalent ( $\mathrm{rad} / \mathrm{hr})$ & ICRU57 & [5] \\
\hline 19 & pAmDEq_EN.3dmap & Photon ambient dose equivalent ( $\mathrm{rad} / \mathrm{hr}$ ) & ICRU57 & [5] \\
\hline 20 & tAmDEq_EN.3dmap & Total ambient dose equivalent (Rem/hr) & ICRU57 & [5] \\
\hline 21 & nEffD_SI.3dmap & Neutron effective dose (Sv/hr) & ICRU57 & [5] \\
\hline 22 & pEffD_SI.3dmap & Photon effective dose (Sv/hr) & ICRU57 & [5] \\
\hline 23 & tEffD_SI.3dmap & Total effective dose $(\mathrm{Sv} / \mathrm{hr})$ & ICRU57 & [5] \\
\hline 24 & nEffD_EN.3dmap & Neutron effective dose (Rem $/ \mathrm{hr})$ & ICRU57 & [5] \\
\hline 25 & pEffD_EN.3dmap & Photon effective dose (Rem/hr) & ICRU57 & {$[5]$} \\
\hline 26 & tEffD_EN.3dmap & Total effective dose (Rem/hr) & ICRU57 & {$[5]$} \\
\hline 27 & nFlux.3dmap & Neutron flux $\left(\mathrm{n} / \mathrm{s} / \mathrm{cm}^{2}\right)$ & N/A & N/A \\
\hline 28 & pFlux.3dmap & Photon flux $\left(\mathrm{p} / \mathrm{s} / \mathrm{cm}^{2}\right)$ & N/A & N/A \\
\hline $29 *$ & pAirExposure.3dmap & Photon exposure in air (R/hr) & NIST & {$[6],[7]$} \\
\hline $30 *$ & nSiKerma.3dmap & Neutron Kerma in silicon $(\mathrm{rad} / \mathrm{hr})$ & Rogers & [8] \\
\hline
\end{tabular}

*Custom responses are included in the customResponse.txt file of the RPS-DET distribution. These responses may be edited, added, or omitted by the user at any time. See customResponse.txt, included in the RPS-DET main directory, for more information on adding, using, and analyzing custom responses, and/or contact rpsdethelp@ornl.gov for further instructions on how to appropriately implement your own custom responses.

ICRU = International Commission on Radiation Units

\subsubsection{Keno 3D}

Keno 3D is a three-dimensional geometry visualization tool that is useful for studying the simulation geometry and for generating images for documentation, reports, and papers, but it does not provide 
visualization capabilities of simulation results. On the Output Analysis tab of RPS-DET, the selected simulation can be visualized in Keno 3D by pressing the Keno $3 D$ button (A). The initial appearance of the Keno 3D application will appear automatically with the geometry loaded (B). While many features are available in Keno 3D, only some high-level discussion is provided here.

The user may save, rename, reload, print, copy, etc., the images (C), choose default perspectives (D), zoom in and out in various ways (E), pan, rotate, tilt, etc. (F), mask, expose, or select certain materials $(\mathrm{G})$, visualize as filled, wire framed, lined, etc. $(\mathrm{H})$, change material colors, lighting, and axis appearance (I), and cut slices of the geometry (J). While this is a quick overview of Keno 3D's capabilities, the user is

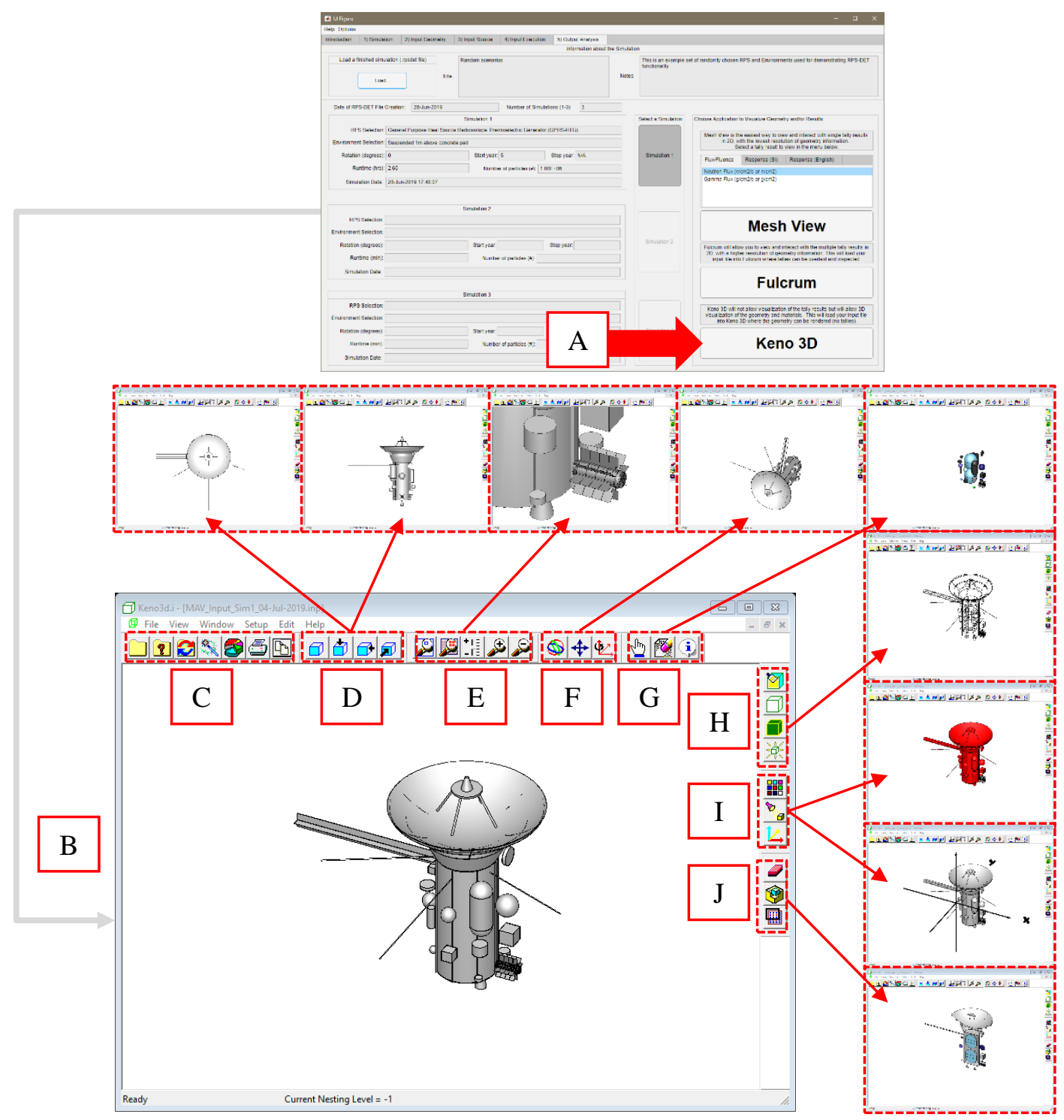

Figure 48. Controls and appearance of Keno 3D application for RPS-DET geometries.

encouraged to reference the Keno 3D User Manual for detailed explanations of all Keno 3D's features [2]. 


\section{ASSUMPTIONS, THEORY, AND METHODOLOGY}

The RPS-DET application builds, simulates, and analyzes SCALE calculations, making many assumptions that the development team wants to make the user aware of at this point. This section describes the high-level assumptions that should be considered during building, simulating, analyzing, and ultimately interpreting an RPS-DET simulation. The user is encouraged to contact the RPS-DET development team via email (rpsdethelp@ornl.gov) with any needs, further clarification, or questions regarding the assumptions therein. Many of the RPS-DET spacecraft and transportation vessel geometries are much higher detail but generalize specific dimensions for proprietary reasons or for reasons of specific export control concerns regarding International Traffic in Arms Regulations (ITAR) restrictions.

\subsection{FUEL ASSUMPTIONS}

The plutonium oxide $\left(\mathrm{PuO}_{2}\right)$ fuel for NASA's RPS program is developed by the US Department of Energy (DOE) per explicit specifications based on power output, occupational dose limits, and transportation considerations. While the RPS-DET user has the freedom to develop custom fuel compositions, the defaults provided represent a best-assumption for future average fuel compositions based on simulation comparisons to recent mission measurements (Appendix D).

\subsubsection{Fuel Composition and Impurities}

While operational fuel specifications are not available for open distribution, the general guidelines for plutonium assay and impurity levels are available in the public format [9] and are thus used as a baseline for user input defaults in RPS-DET. The ORIGEN sequence in the SCALE software suite performs the isotopic decay calculations based on these starting fuel compositions. Keeping those solution methods in mind, the following high-level assumptions are made:

- Every RPS-DET simulation automatically generates a 0-100-year simulation in time steps of 1 year to calculate the time-dependent isotopic compositions, thermal output, and photon/gamma and neutron emissions. This means the source information has a resolution of 1 year. Any deductions based on time increments of less than 1 year are not advised.

- Each ORIGEN calculation is based on a $1 \mathrm{~g}$ fuel mass, and these calculations are scaled on this per-gram basis to meet the total mass of each respective simulation.

- $\quad$ Each RPS-DET simulation assumes that the selected fuel composition is identically and uniformly distributed through the entire RPS.

- The material composition used to develop the source terms and the actual material in the geometry representing the fuel may not necessarily be identical. The default composition of fuel is physically or virtually present in the simulations, but it does not dynamically update based on the user's selection of source term. When simulating reasonable RPS fuel compositions, the isotopic variations (within reason) do not significantly affect the shielding aspects of radiation transport for these circumstances. If a user decides to simulate extremely unusual fuel compositions such as those that are well outside specification limits or that significantly deviate from default settings, then there is no guarantee of relevance or accuracy in the results.

- Secondary fissions are not simulated for the fuel mass. This consideration was tested, and when assessed, it accounted for statistically insignificant effects in the final tallies and created 
significant computational overhead. For these reasons, this feature was disabled for all RPS-DET simulations.

\subsubsection{Photon Spectra}

The time-dependent photon spectra are provided by ORIGEN calculations based on half-life, timedependent activities, emission probabilities, and branching ratios. The following high-level assumptions are made regarding the photon spectra provided in RPS-DET simulations:

- Natural photons emitted from $\mathrm{PuO}_{2}$ fuel-decay cover energies ranging from approximately $\sim 1 \mathrm{eV}$ to $5 \mathrm{MeV}$, yet calculations (described in Appendix C) have shown that photons $\leq 200 \mathrm{keV}$ contribute only $\sim 1 \%$ of final flux/dose tallies, but they represent the vast majority of the probability of photon emission. From a Monte Carlo particle transport perspective, this implies that the natural photon emission spectra would cause most of the calculation time for particle transport calculations to be devoted to particles that would rarely contribute to the final simulation result. For these reasons, the natural photon emission spectra are truncated to $200 \mathrm{keV}$ to $5 \mathrm{MeV}$ for RPS-DET simulations, and ORIGEN weights the resulting source strength accordingly. See Appendix $\mathrm{C}$ for further explanation.

- Photon spectra resolutions are 2.0E5 eV to 5.0E6, binned linearly into 1,000 bins, each of which is $4.8 \mathrm{E} 3 \mathrm{eV}$ wide.

- Given that the finest resolution time step in RPS-DET calculations is 1 year, all source strengths represent a single source strength for an entire year, when there may be changes of interest within the bounds of a single year. For example, during the first 1-3 years of fuel aging, there are significant changes in the fuel's radiation signatures and isotopic compositions, more so than at subsequent ages. Therefore, higher uncertainty in exact fuel characteristics, specifically isotope composition, and gamma spectrum should be assumed for flux/response-rate calculations earlier in the fuel's life.

- The photon source is sampled equally through any/all regions of $\mathrm{PuO}_{2}$ fuel in the RPS-DET geometry.

\subsubsection{Neutron Spectra}

The time-dependent neutron spectra are provided by ORIGEN calculations based on half-life, timedependent activities, spontaneous fission probabilities, and $\alpha-n$ reaction probabilities. The following highlevel assumptions are made regarding the neutron spectra provided in RPS-DET simulations:

- The default neutron spectra are based on spontaneous fission neutrons and $\alpha-n$ for default fuel compositions.

- Neutron spectra resolutions are 1.0E-3 eV through 2.0E7, binned linearly into 100 bins, each of which is $\sim 2.0 \mathrm{E} 5 \mathrm{eV}$ wide.

- The neutron source is sampled equally through any/all regions of $\mathrm{PuO}_{2}$ fuel in the RPS-DET geometry. 


\subsection{RPS ASSUMPTIONS}

While accuracy for material properties and geometry dimensions was of the utmost importance for RPS included in RPS-DET simulations, many generalizations and assumptions were made. Every simulation for RPS-DET is rooted in the base-unit of the fueled clad (FC). Each FC in RPS-DET has $151 \mathrm{~g}$ of $\mathrm{PuO}_{2}$ (Figure 49), and each general purpose heat source (GPHS) encases four FCs (Figure 50). Every RPS-DET simulation includes some combination of these two components, so it is important to disclose the details of their geometries. All FCs include an iridium outermost cladding and are assumed to be filled completely by $\mathrm{PuO}_{2}$. While displaying nuance about geometric features, all GPHSs are simply uniform carbon materials with FCs superimposed inside them (Figure 49 and Figure 50).
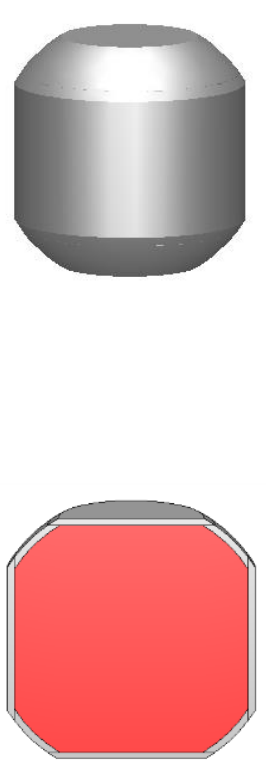

Figure 49. Fueled clad (FC) geometry: full example (top) and cutaway (bottom).
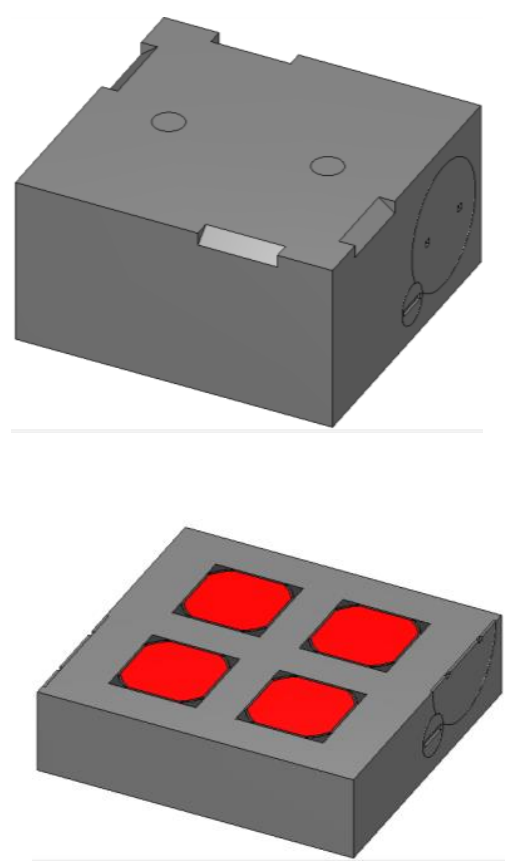

Figure 50. GPHS geometry: full example (top) and cutaway (bottom).

\subsubsection{RPS Geometries}

While the FC and GPHS geometries are the fundamental building blocks of all RPS-DET geometries and actual RPSs for NASA, many of the RPS geometries included here generalize specific dimensions for proprietary reasons or for reasons of specific export control concerns regarding ITAR restrictions. The following assumption was made regarding the geometries of various RPS in the RPS-DET application:

- While bulk RPS-DET geometries and dimensions for RPSs are accurate for shielding-level calculations, they are not precise to as-built drawings for reasons of proprietary and export control concerns. We believe the RPS-DET models for RPSs to be accurate and relevant for radiation shielding calculations. 


\subsubsection{RPS Materials}

Many of the RPS materials included in RPS-DET generalize specific materials for proprietary reasons or for reasons of specific export control concerns regarding ITAR restrictions. The following assumptions were made regarding the geometries of various RPS in the RPS-DET application:

- Thermoelectric materials for all thermoelectric RPS in the RPS-DET library are bulk generalizations of actual material distributions, compositions, and orientations with simplified and convolved materials accurate for shielding calculations but deliberately imprecise to dimension and specific material composition for proprietary and export control considerations.

- Many detailed materials determined to be irrelevant for particle transport/shielding considerations are omitted from the geometries: electronics, bolts, gaskets, etc.

\subsection{ENVIRONMENT ASSUMPTIONS}

The RPS-DET environments contain various geometries and materials that come with their own suites of assumptions, which are discussed here.

\subsubsection{Environment Geometries}

The following assumptions were made regarding the geometries of various environments in the RPS-DET application:

- Planetary surface environments are composed of perfect planes and thus may not necessarily be accurate for simulations investigating external particle scattering in certain scenarios. The user is encouraged to determine the applicability of perfect planetary surfaces for their specific simulations. The largest discrepancies (if any) of perfect or unreal vs. imperfect or real particle scattering will be evidenced in the tally regions closest to the perfect/imperfect surface in question. Regions farther from the surface will be less affected by these concerns.

- While bulk RPS-DET geometries and dimensions for environments are accurate for shieldinglevel calculations, they are not precise to as-built drawings for reasons of proprietary and export control concerns. We believe the RPS-DET models for spacecraft and transportation vessels to be accurate and relevant for radiation shielding calculations.

- For spacecraft environments, the location, orientation, and distribution of external instruments are strictly notional and should not be considered representative of actual instrumentation locations on actual spacecraft. If the user is interested in introducing a new instrument, material, or component into an RPS-DET geometry, then the user is encouraged to contact the RPS-DET design team (rpsdethelp@ornl.gov) for insight on how to include this properly.

\subsubsection{Environment Materials}

The following assumptions were made regarding the materials of various environments in the RPS-DET application:

- Thermoelectric, insulation, and electronic materials in RPS-DET geometries are deliberately convolved to avoid proprietary and/or export control concerns. The generalized bulk material compositions for these features are believed to be accurate for the purposes of radiation transport calculations. 
- Most RPS-DET spacecraft hull and structural materials are assumed to be aerospace-grade aluminum (Al-6061).

- Most instruments placed around spacecraft environments have Al-6061 hulls and are filled with various mixtures of gas-helium, argon, etc.-or silicon. Large spheres in spacecraft environments are filled with hydrazine materials.

- All planetary regolith and atmosphere assumptions (with respective references) are assumed to be homogenous mixtures and are listed in Table 5.

Table 5. Material information and assumptions regarding planetary regolith and atmospheric assumptions.

\begin{tabular}{|c|c|c|c|c|}
\hline Material & General atomic/chemical composition & $\begin{array}{l}\text { Bulk density } \\
(\mathrm{g} / \mathrm{cc})\end{array}$ & Comments & References \\
\hline Earth atmosphere & $\mathrm{N} 2+\mathrm{O}_{2}+\mathrm{CO}_{2}$ & 0.0012 & $\begin{array}{l}\text { Assumed at Earth } \\
\text { sea-level }\end{array}$ & {$[10]$} \\
\hline Earth regolith & $\mathrm{SiO} 2+\mathrm{Al} 2 \mathrm{O} 3+\mathrm{H} 2 \mathrm{O}$ & 1.5200 & Average US soil & {$[10]$} \\
\hline Earth concrete & $\mathrm{Ca}_{3} \mathrm{SiO}_{5}+\mathrm{H}_{2} \mathrm{O}$ & 2.3000 & "Ordinary" concrete & {$[10]$} \\
\hline Lunar regolith & $\mathrm{SiO}_{2}+\mathrm{FeO}+\mathrm{Al}_{2} \mathrm{O}_{3}+\mathrm{CaO}+\mathrm{MgO}+\mathrm{TiO}_{2}$ & 1.5000 & Average values & {$[11]$} \\
\hline Martian regolith & $\mathrm{SiO}_{2}+\mathrm{Fe}_{2} \mathrm{O}_{3}+\mathrm{Al}_{2} \mathrm{CaK}_{2} \mathrm{MgNa}_{2} \mathrm{O}_{7}+\mathrm{H}_{2} \mathrm{O}$ & 1.7000 & $\begin{array}{l}\text { Assuming in } \\
\text { regions of } \\
\text { hydrogenous } \\
\text { regolith }\end{array}$ & [12], [13] \\
\hline $\begin{array}{l}\text { Martian atmosphere } \\
\text { (Gale Crater) }\end{array}$ & $\mathrm{CO}_{2}$ & $1.80 \mathrm{E}-5$ & $\begin{array}{l}\text { Assumed at Gale } \\
\text { Crater }(\sim-4 \mathrm{~km})\end{array}$ & [12], [14] \\
\hline $\begin{array}{l}\text { Martian atmosphere } \\
\text { (Olympus Mons) }\end{array}$ & $\mathrm{CO}_{2}$ & $1.70 \mathrm{E}-6$ & $\begin{array}{l}\text { Assumed at } \\
\text { Olympus Mons } \\
(\sim+22 \mathrm{~km})\end{array}$ & [12], [14] \\
\hline Titan regolith & $\mathrm{H}_{2} \mathrm{O}$ (solid) & 0.9200 & $\begin{array}{l}\text { Assumed as water- } \\
\text { ice }\end{array}$ & {$[15]$} \\
\hline Titan atmosphere & $\mathrm{N}_{2}$ & 0.0050 & $\begin{array}{l}\text { Assumed at Titan } \\
\text { sea-level }\end{array}$ & {$[16]$} \\
\hline Titan methane & $\mathrm{CH}_{4}$ (liquid) & 0.4410 & $\begin{array}{l}\text { Assumed in liquid } \\
\text { form }\end{array}$ & {$[17]$} \\
\hline Titan ethane & $\mathrm{C}_{2} \mathrm{H}_{6}$ (liquid) & 0.5480 & $\begin{array}{l}\text { Assumed in liquid } \\
\text { form }\end{array}$ & [18] \\
\hline $\begin{array}{l}\text { Enceladus/Europa } \\
\text { regolith }\end{array}$ & $\mathrm{H}_{2} \mathrm{O}$ (solid) & 0.9200 & $\begin{array}{l}\text { Assuming pure } \\
\text { water-ice }\end{array}$ & [19], [20] \\
\hline
\end{tabular}

\subsubsection{Tally Assumptions}

All tallies in RPS-DET outputs are constructed from 3D cartesian mesh tallies, and every simulation will have the same size tally. Each RPS-DET simulation is bounded by a $10 \mathrm{~m}$ cuboid that is further subdivided into 100 segments in each spatial axis, making a 3D matrix of one million evenly distributed $10 \mathrm{~cm}$ volumetric pixels (or voxels).

Estimates of the flux $\phi$ (neutron and photon separately) are made for each voxel using path-length tallies. The flux-per-unit source is the average path length of the particle in a region divided by the region 
volume, so the Monte Carlo code simulates $N$ source particles (histories) and accumulates a sum of all the path-lengths $l_{i}$ from each history $i$ through a given voxel. For a source strength $S$, the flux is then computed using Eq. (1):

$$
\phi=S \frac{1}{V}\left(\frac{1}{N} \sum_{i=1}^{N} l_{i}\right)
$$

If the source strength is a rate (particles/s), then the flux has units of particles $/ \mathrm{s} / \mathrm{cm}^{2}$. If the source strength is a total number of particles (a source integrated over a given time), then $\phi$ is a fluence with units of particles $/ \mathrm{cm}^{2}$.

Note that an estimate for the statistical uncertainty for the flux or fluence is also made by SCALE. The statistical uncertainty falls with the square root of the number of histories sampled; quadrupling the number of histories will reduce the statistical uncertainty of the flux estimates in half.

\subsubsection{Flux and Dose Rates}

The source strength for each RPS-DET simulation starts with the initial project's ORIGEN calculation, which determines the specific source strength $\left(S_{\mathrm{g}}\right.$ in particles/s/g) at a given time for the $\mathrm{PuO}_{2}$ composition selected for the simulation. When the user selects an RPS, there is a prescribed $\mathrm{PuO}_{2}$ mass ( $M$ in $\mathrm{g}$ ) for each RPS selection that is multiplied against the specific source strength to obtain the total RPS source strength $S$ for the simulation, as shown in Eq. (2). Reference Appendix A for prescribed $\mathrm{PuO}_{2}$ masses for RPS selections.

$$
S=M S_{\mathrm{g}}
$$

For computing fluxes, the Monte Carlo code uses this source strength in Eq. (1).

Furthermore, when calculating a response, these energy-dependent flux values can be multiplied by various dose-per-fluence-conversion coefficients to estimate what the dose rate would be in a given voxel. As an example, consider using the effective dose per fluence conversion coefficients $f(E)$ in $(\mathrm{mSv} / \mathrm{hr}) /\left(\right.$ particles $\left./ \mathrm{s} / \mathrm{cm}^{2}\right)$ from the International Commission on Radiation Units (ICRU) 57 report as the response function. The effective dose rate $\dot{D}$, in units of $\mathrm{mSv} / \mathrm{hr}$, is then computed as

$$
\dot{D}=\int \phi(E) f(E) d E
$$

\subsubsection{Time-Integrated Fluence and Doses}

The time-integrated fluence and doses follow the same methodology as the flux and dose rates described in Section 3.3.4, but they use a source strength $S$ that is the total number of particles emitted over the time interval considered. In RPS-DET, ORIGEN is used to compute the instantaneous source strengths (particle/s/g) of the fuel just after chemical separation (time 0), then 1 year later, then 2 years later, etc., for a total of 100 years. When computing the fluence and time-integrated doses over a year, the source strength is computed as the average of the rates at the start and end of that year, multiplied by the length of a year $(C=31,556,952 \mathrm{~s})$. For the period spanning $t_{i}$ to $t_{j}$ (in years), the total source strength $S$ (number of particles) is then 


$$
S=M C \sum_{k=i}^{j-1} \frac{1}{2}\left(S_{g}^{k}+S_{g}^{k+1}\right)=M C\left[\frac{1}{2} S_{g}^{i}+\left(\sum_{k=i+1}^{j-1} S_{g}^{k}\right)+\frac{1}{2} S_{g}^{j}\right]
$$

The fluence computed has units of particles $/ \mathrm{cm}^{2}$, and the ICRU 57 report's effective dose, for example, would have units of Sv·s/hr. RPS-DET then applies a multiplier of $(1 \mathrm{hr} / 3,600 \mathrm{~s})$ to get the effective dose in Sv. While the ICRU 57 response was used as an example, this same process is applied to all responses included in RPS-DET.

Figure 51 presents an example for obtaining the total dose over a mission lasting from 5-10 years after the fuel was made. In this case, the instantons' source strengths for years 5-10 were used to compute the total number of particles emitted as

$$
S=M C\left[\frac{1}{2} S_{g}^{5 y r}+S_{g}^{6 y r}+S_{g}^{7 y r}+S_{g}^{8 y r}+S_{g}^{9 y r}+\frac{1}{2} S_{g}^{10 y r}\right]
$$

\section{Integration Scheme}

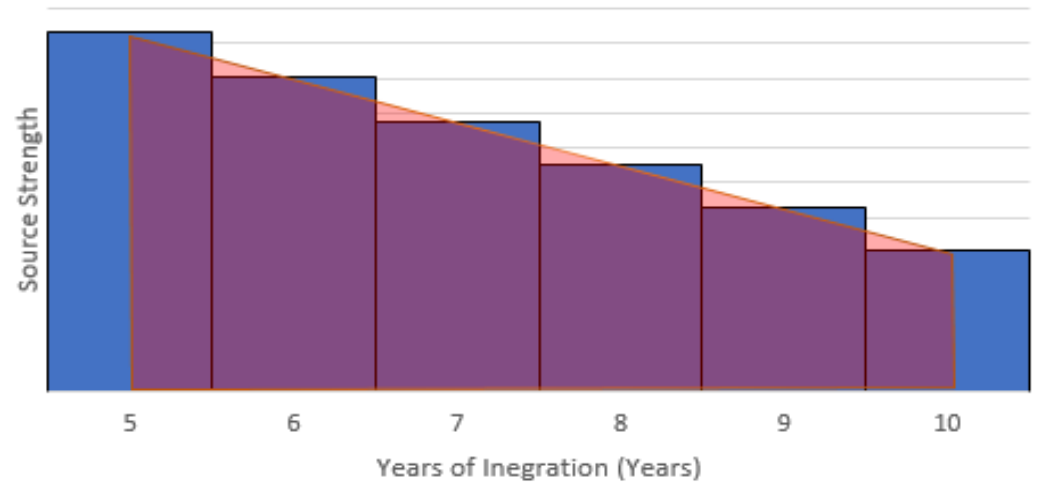

Figure 51. Integration scheme for RPS-DET source strength.

\section{ACKNOWLEDGMENTS}

The authors would like to thank multiple people from multiple institutions for their support and input during the development of RPS-DET.

- NASA Glenn Research Center

- June Zakrajsek and Paul Schmitz for their support and insight on many bureaucratic and technical details involved in the development of this software (too numerous to list)

- Sal Oriti for his insight and perspective on export control designations with regards to NASA technologies

- Oak Ridge National Laboratory

○ Lou Qualls for his many technical insights on RPS technologies

- Mark Baird for his support with RSICC's preparation and release

- Sam Howard, Tim Busch, and Judah Wilkins for their exhaustive guidance and management of the export control evaluation and determination

- Steve Sherman for his support and insight into $\mathrm{PuO}_{2}$ material characteristics 
- George Ulrich for his support and insight in RPS materials

- Rob Howard for his help with validation and verification and the software quality assurance processes

- Idaho National Laboratory

- Steve Johnson and Kelly Lively for their support with occupational dose measurements of previous RPS and other RPS-related information

- Los Alamos National Laboratory

$\circ \quad$ Elizabeth Bluhm for her insights on $\mathrm{PuO}_{2}$ fuel characteristics

- Aerojet Rocketdyne

$\circ \quad$ Bill Otting for his support with MMRTG materials and geometries 


\section{BIBLIOGRAPHY}

[1] B. Rearden and M. Jessee, "SCALE Code System," Oak Ridge National Laboratory (ORNL), Technical Report ORNL/TM-2005/39, Aug. 2016.

[2] J. E. Horwedel and S. M. Bowman, "KENO3D Visualization Tool for KENO Va and KENO-VI Geometry Models," Oak Ridge National Lab., TN (US), 2000.

[3] B. J. Henderson, "Conversion of Neutron or Gamma Ray Flux to Absorbed Dose Rate," Oak Ridge National Laboratory (ORNL), XDC-59-8-179, Aug. 1959.

[4] "Tissue Substitutes in Radiation Dosimetry and Measurement," International Commission of Radiation Units and Measurements (ICRU), Bethesda, MD, ICRU Report 44, 1989.

[5] "Conversion Coefficients for use in Radiological Protection Against External Radiation," International Commission of Radiation Units and Measurements (ICRU), Bethesda, MD, ICRU Report 57, Aug. 1998.

[6] K. J. Shultis and R. E. Faw, Radiation Shielding. Prentice Hall Inc., Upper Saddle River, NJ, 1996.

[7] J. H. Hubbell and S. M. Seltzer, "NIST Standard Reference Database 126."

[8] V. C. Rogers, L. Harris, D. K. Steinman, and D. E. Bryan, "Silicon ionization and displacement kerma for neutrons from thermal to $20 \mathrm{MeV}$," IEEE Trans. Nucl. Sci., vol. 22, no. 6, pp. 2326-2329, 1975.

[9] A. S. Wong, "Chemical analysis of plutonium-238 for space applications," in AIP Conference Proceedings, 2001, vol. 552, pp. 753-757.

[10]R. G. Williams, C. J. Gesh, and R. T. Pagh, "Compendium of Material Composition Data for Radiation Transport Modeling," Pacific Northwest National Laboratory (PNNL), Richland, WA (US), 2006.

[11]S. Schreiner, J. Dominguez, L. Sibille, and J. Hoffman, "Thermophysical Property Models for Lunar Regolith,” Adv. Space Res., Jun. 2015.

[12]C. G. Justus and R. D. Braun, "Atmospheric Environments for Entry, Descent and Landing (EDL)," 2007.

[13]C. C. Allen et al., "Martian Regolith Simulant JSC MARS-1," Lunar Planet. Sci., vol. XXIX, no. 1690, 1998.

[14]P. R. Mahaffy et al., "Abundance and isotopic composition of gases in the martian atmosphere from the Curiosity rover," Science, vol. 341, no. 6143, p. 263, 2013.

[15]C. Griffith, Owen, T. Gaballe, J. Rayner, and P. Rannou, "Evidence for the Exposure of Water Ice on Titan's Surface," Science, vol. 300.5619, p. 628, Apr. 2003.

[16]D. Gautier et al., "The Composition of Titan's Lower Atmosphere and Simple Surface Volatiles as Measured by the Cassini-Huygens Probe Gas Chromatograph Mass Spectrometer Experiment," 2010.

[17]W. F. Zimmerman, J. Lunine, and R. Lorenz, "A surface science paradigm for a post-Huygens Titan Mission," 2005.

[18]P. A. Dalba et al., "Low-latitude ethane rain on Titan," 2012.

[19]E. Wang and A. Lee, "Estimation of Enceladus Plume Density Using Cassini Flight Data," in AIAA Guidance, Navigation, and Control Conference, 2012, pp. 13-16.

[20]D. D. Blankenship and D. L. Morse, "Earth's ice sheets and ice shelves as an analog for Europa's icy shell," in Workshop on Europa's Icy Shell: Past, Present, and Future, 2004. 
RPS BDET 
APPENDICES 



\section{APPENDIX A. RPS GEOMETRY SELECTIONS}

\begin{tabular}{|c|c|c|c|}
\hline RPS \# & $\begin{array}{l}\text { RPS label in } \\
\text { menu }\end{array}$ & $\begin{array}{c}\mathrm{PuO}_{2} \text { mass } \\
(\mathrm{g}[\mathrm{kg}])\end{array}$ & Comments \\
\hline \multicolumn{4}{|c|}{ Fueled clads (FCs) } \\
\hline 1 & $1 \mathrm{FC}$ & $151[0.151]$ & $\begin{array}{l}\text { Single iridium fueled clad oriented } \\
\text { vertically from flat face }\end{array}$ \\
\hline 2 & $2 \mathrm{FC}$ & $302[0.302]$ & $\begin{array}{l}\text { Two iridium fueled clads oriented } \\
\text { vertically from flat face and distributed in } \\
\text { two of four quadrants on } 4 \mathrm{~cm} \text { centers }\end{array}$ \\
\hline 3 & $3 \mathrm{FC}$ & $453[0.453]$ & $\begin{array}{l}\text { Three iridium fueled clads oriented } \\
\text { vertically from flat face and distributed in } \\
\text { three of four quadrants on } 4 \mathrm{~cm} \text { centers }\end{array}$ \\
\hline 4 & $4 \mathrm{FC}$ & 604 [0.604] & $\begin{array}{l}\text { Four iridium fueled clads oriented } \\
\text { vertically from flat face and distributed in } \\
\text { four of four quadrants on } 4 \mathrm{~cm} \text { centers }\end{array}$ \\
\hline \multicolumn{4}{|c|}{ Vertically stacked general purpose heat sources (GPHSs) } \\
\hline 5 & $1 \mathrm{GPHS}$ & $604[0.604]$ & Single GPHS \\
\hline 6 & 2 GPHS & $1,208[1.208]$ & Two vertically stacked GPHSs \\
\hline 7 & 3 GPHS & $1,812[1.812]$ & Three vertically stacked GPHSs \\
\hline 8 & 4 GPHS & $2,416[2.416]$ & Four vertically stacked GPHSs \\
\hline 9 & 5 GPHS & $3,020[3.020]$ & Five vertically stacked GPHSs \\
\hline 10 & 6 GPHS & $3,624[3.624]$ & Six vertically stacked GPHSs \\
\hline 11 & 7 GPHS & $4,228[4.228]$ & Seven vertically stacked GPHSs \\
\hline 12 & 8 GPHS & $4,832[4.832]$ & Eight vertically stacked GPHSs \\
\hline 13 & 9 GPHS & $5,436[5.436]$ & Nine vertically stacked GPHSs \\
\hline 14 & $10 \mathrm{GPHS}$ & $6,040[6.040]$ & Ten vertically stacked GPHSs \\
\hline 15 & $11 \mathrm{GPHS}$ & $6,644[6.644]$ & Eleven vertically stacked GPHSs \\
\hline 16 & 12 GPHS & $7,248[7.248]$ & Twelve vertically stacked GPHSs \\
\hline 17 & 13 GPHS & $7,852[7.852]$ & Thirteen vertically stacked GPHSs \\
\hline 18 & 14 GPHS & $8,456[8.456]$ & Fourteen vertically stacked GPHSs \\
\hline 19 & 15 GPHS & $9,060[9.060]$ & Fifteen vertically stacked GPHSs \\
\hline 20 & 16 GPHS & $9,664[9.664]$ & Sixteen vertically stacked GPHSs \\
\hline 21 & 17 GPHS & $10,268[10.268]$ & Seventeen vertically stacked GPHSs \\
\hline 22 & 18 GPHS & $10,872[10.872]$ & Eighteen vertically stacked GPHSs \\
\hline
\end{tabular}




\begin{tabular}{|c|c|c|c|}
\hline RPS \# & RPS label in menu & $\begin{array}{c}\mathrm{PuO}_{2} \text { mass } \\
(\mathrm{g}[\mathrm{kg}])\end{array}$ & Comments \\
\hline \multicolumn{4}{|c|}{ Radioisotope power systems (RPSs) } \\
\hline \multicolumn{4}{|c|}{ Current } \\
\hline 23 & $\begin{array}{l}\text { Multi Mission } \\
\text { Radioisotope } \\
\text { Thermoelectric Generator } \\
\text { (MMRTG) }\end{array}$ & $4,832[4.832]$ & $\begin{array}{l}\text { Fully assembled MMRTG containing } 8 \\
\text { GPHSs; default orientation is vertical axes } \\
\text { parallel to Z-axis }\end{array}$ \\
\hline \multicolumn{4}{|c|}{ Historic } \\
\hline 25 & $\begin{array}{l}\text { General Purpose Heat } \\
\text { Source Radioisotope } \\
\text { Thermoelectric Generator } \\
\text { (GPHS-RTG) }\end{array}$ & $10,872[10.872]$ & $\begin{array}{l}\text { Fully assembled GPHS-RTG containing } 18 \\
\text { GPHSs; default orientation is vertical axes } \\
\text { parallel to Z-axis }\end{array}$ \\
\hline \multicolumn{4}{|c|}{ Concept/future } \\
\hline 26 & $\begin{array}{l}\text { Advanced Stirling } \\
\text { Radioisotope Generator } \\
\text { (ASRG) }\end{array}$ & $1,208[1.208]$ & $\begin{array}{l}\text { Fully assembled ASRG containing } 2 \\
\text { GPHSs; default orientation is vertical axes } \\
\text { parallel to Z-axis }\end{array}$ \\
\hline \multicolumn{4}{|c|}{ Modular Stirling (vertical GPHS stack) } \\
\hline 27 & 4 GPHS Modular Stirling & $2,416[2.416]$ & $\begin{array}{l}\text { Concept of a Modular Stirling RPS } \\
\text { containing } 4 \text { GPHSs; default orientation is } \\
\text { vertical axes parallel to Z-axis }\end{array}$ \\
\hline 28 & 8 GPHS Modular Stirling & $4,832[4.832]$ & $\begin{array}{l}\text { Concept of a Modular Stirling RPS } \\
\text { containing } 8 \text { GPHSs; default orientation is } \\
\text { vertical axes parallel to Z-axis }\end{array}$ \\
\hline 29 & 12 GPHS Modular Stirling & $7,248[7.248]$ & $\begin{array}{l}\text { Concept of a Modular Stirling RPS } \\
\text { containing } 12 \text { GPHSs; default orientation } \\
\text { is vertical axes parallel to Z-axis }\end{array}$ \\
\hline 30 & 16 GPHS Modular Stirling & $9,664[9.664]$ & $\begin{array}{l}\text { Concept of a Modular Stirling RPS } \\
\text { containing } 16 \text { GPHSs; default orientation } \\
\text { is vertical axes parallel to Z-axis }\end{array}$ \\
\hline
\end{tabular}




\begin{tabular}{|c|c|c|c|c|c|}
\hline RPS \# & $\begin{array}{l}\text { RPS-DET render } \\
\text { (not to scale) }\end{array}$ & RPS \# & $\begin{array}{l}\text { RPS-DET render } \\
\text { (not to scale) }\end{array}$ & RPS \# & $\begin{array}{l}\text { RPS-DET render } \\
\text { (not to scale) }\end{array}$ \\
\hline 1 & & 7 & & 13 & \\
\hline 2 & & 8 & & 14 & 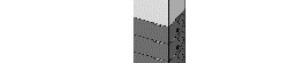 \\
\hline 3 & & 9 & & 15 & \\
\hline 4 & & 10 & & 16 & \\
\hline 5 & & 11 & & 17 & \\
\hline 6 & & 12 & & 18 & \\
\hline
\end{tabular}




\begin{tabular}{|c|c|c|c|c|c|}
\hline RPS \# & $\begin{array}{l}\text { RPS-DET render } \\
\text { (not to scale) }\end{array}$ & RPS \# & $\begin{array}{l}\text { RPS-DET render } \\
\text { (not to scale) }\end{array}$ & RPS \# & $\begin{array}{l}\text { RPS-DET render } \\
\text { (not to scale) }\end{array}$ \\
\hline 19 & & 24 & & 28 & \\
\hline 20 & & 25 & & 29 & \\
\hline 22 & & 26 & & & \\
\hline 23 & & 27 & & & \\
\hline
\end{tabular}




\section{APPENDIX B. ENVIRONMENT GEOMETRY SELECTIONS}

\begin{tabular}{|c|c|c|c|}
\hline Env \# & $\begin{array}{l}\text { Environment label } \\
\text { in menu }\end{array}$ & $\begin{array}{l}\text { Rotation } \\
\text { allowed? }\end{array}$ & Comments \\
\hline \multicolumn{4}{|c|}{ Earth } \\
\hline 1 & On concrete pad & No & $\begin{array}{l}\text { RPS is oriented vertically on the surface of the } \\
\text { concrete pad }\end{array}$ \\
\hline 2 & $\begin{array}{l}\text { Suspended } 1 \mathrm{~m} \text { above } \\
\text { concrete pad }\end{array}$ & Yes & $\begin{array}{l}\text { RPS is located } 1 \mathrm{~m} \text { above concrete pad in earth } \\
\text { atmosphere (air) }\end{array}$ \\
\hline 3 & $\begin{array}{l}\text { Suspended in Earth's } \\
\text { atmosphere }\end{array}$ & Yes & RPS is suspended in Earth's atmosphere \\
\hline \multicolumn{4}{|c|}{ Inside $10 \times 10 \times 10$-foot concrete room } \\
\hline 4 & $\begin{array}{l}\text { In center of room, on } \\
\text { the floor }\end{array}$ & No & $\begin{array}{l}\text { RPS is oriented vertically on the surface of a } \\
\text { concrete floor in the center of a concrete room }\end{array}$ \\
\hline 5 & $\begin{array}{l}\text { In center of room, } \\
\text { suspended } 1 \mathrm{~m} \text { above } \\
\text { the floor }\end{array}$ & Yes & $\begin{array}{l}\text { RPS is } 1 \mathrm{~m} \text { above the surface of a concrete floor } \\
\text { in the center of a concrete room }\end{array}$ \\
\hline 6 & Next to wall, on the floor & No & $\begin{array}{l}\text { RPS is oriented vertically on the surface of a } \\
\text { concrete floor near a wall of a concrete room }\end{array}$ \\
\hline 7 & $\begin{array}{l}\text { Next to wall, suspended } \\
1 \mathrm{~m} \text { above the floor }\end{array}$ & Yes & $\begin{array}{l}\text { RPS is } 1 \mathrm{~m} \text { above the surface of a concrete floor } \\
\text { near a wall of a concrete room }\end{array}$ \\
\hline 8 & $\begin{array}{l}\text { In corner of concrete room, } \\
\text { on the floor }\end{array}$ & No & $\begin{array}{l}\text { RPS is oriented vertically on the surface of a } \\
\text { concrete floor in a } 90^{\circ} \text { corner of a concrete room }\end{array}$ \\
\hline 9 & $\begin{array}{l}\text { In corner of concrete room } \\
\text { suspended } 1 \mathrm{~m} \text { above } \\
\text { the floor }\end{array}$ & Yes & $\begin{array}{l}\text { RPS is } 1 \mathrm{~m} \text { above the surface of a concrete floor } \\
\text { in a } 90^{\circ} \text { corner of a concrete room }\end{array}$ \\
\hline 10 & Inside shipping container & No & $\begin{array}{l}\text { RPS is oriented vertically on a mounting plate, } \\
\text { inside a 9904-like shipping container }\end{array}$ \\
\hline \multicolumn{4}{|c|}{ Spacecraft and space } \\
\hline 11 & Suspended in vacuum & Yes & RPS is surrounded by void \\
\hline 12 & $\begin{array}{l}\text { Inside aeroshell with } \\
\text { cruise-stage (similar to } \\
\text { MSL) }\end{array}$ & No & $\begin{array}{l}\text { RPS is located inside an entry-descent-landing } \\
\text { vehicle that includes bulk materials to simulate } \\
\text { lander/rover/rotorcraft and hydrazine tanks }\end{array}$ \\
\hline 13 & $\begin{array}{l}\text { On deep space probe } \\
\text { (similar to Cassini) }\end{array}$ & No & $\begin{array}{l}\text { RPS is located at base of large planetary orbiter } \\
\text { vehicle that includes various proxy instruments } \\
\text { and hydrazine tanks and is comparable in shape } \\
\text { and size to Cassini spacecraft }\end{array}$ \\
\hline 14 & $\begin{array}{l}\text { On deep space probe } \\
\text { (similar to New Horizons) }\end{array}$ & No & $\begin{array}{l}\text { RPS is located on center-face of deep space } \\
\text { vehicle that includes various proxy instruments } \\
\text { and hydrazine tanks and is comparable in shape } \\
\text { and size to New Horizons spacecraft }\end{array}$ \\
\hline 15 & $\begin{array}{l}\text { On Deep space probe } \\
\text { (similar to Voyager) }\end{array}$ & No & $\begin{array}{l}\text { RPS is located on extended boom of interstellar } \\
\text { vehicle that includes various proxy instruments } \\
\text { and hydrazine tanks and is comparable in shape } \\
\text { and size to Voyager I \& II spacecraft }\end{array}$ \\
\hline
\end{tabular}




\begin{tabular}{|c|c|c|c|}
\hline Env \# & $\begin{array}{l}\text { Environment label } \\
\text { in menu }\end{array}$ & $\begin{array}{l}\text { Rotation } \\
\text { allowed? }\end{array}$ & Comments \\
\hline \multicolumn{4}{|c|}{ Moon } \\
\hline 16 & On Lunar regolith & No & $\begin{array}{l}\text { RPS is oriented vertically on the surface of } \\
\text { Lunar regolith }\end{array}$ \\
\hline 17 & $\begin{array}{l}\text { Suspended } 1 \mathrm{~m} \text { above } \\
\text { Lunar regolith }\end{array}$ & Yes & RPS is $1 \mathrm{~m}$ above the surface of Lunar regolith \\
\hline 18 & Buried in Lunar regolith & Yes & RPS is suspended in Lunar regolith \\
\hline \multicolumn{4}{|c|}{ Mars } \\
\hline \multicolumn{4}{|c|}{ On Martian regolith } \\
\hline 19 & $\begin{array}{l}\text { On Martian regolith in } \\
\text { Gale Crater }\end{array}$ & No & $\begin{array}{l}\text { RPS is oriented vertically on the surface of } \\
\text { Martian regolith; surrounding } \mathrm{CO}_{2} \text { atmosphere } \\
\text { corresponds to mean Gale Crater densities } \\
\left(1.80 \mathrm{E}-5 \mathrm{~g} / \mathrm{cm}^{3}\right)\end{array}$ \\
\hline 20 & $\begin{array}{l}\text { On Martian regolith on } \\
\text { Olympus Mons }\end{array}$ & No & $\begin{array}{l}\text { RPS is oriented vertically on the surface of } \\
\text { Martian regolith; surrounding } \mathrm{CO}_{2} \text { atmosphere } \\
\text { corresponds to mean Olympus } \mathrm{Mons} \text { densities } \\
\left(1.70 \mathrm{E}-6 \mathrm{~g} / \mathrm{cm}^{3}\right)\end{array}$ \\
\hline \multicolumn{4}{|c|}{ Suspended $1 \mathrm{~m}$ above Martian regolith } \\
\hline 21 & $\begin{array}{l}\text { Suspended } 1 \mathrm{~m} \text { above } \\
\text { Martian regolith in Gale } \\
\text { Crater }\end{array}$ & Yes & $\begin{array}{l}\text { RPS is } 1 \mathrm{~m} \text { above the surface of Martian } \\
\text { regolith; surrounding } \mathrm{CO}_{2} \text { atmosphere } \\
\text { corresponds to mean Gale Crater densities } \\
\left(1.80 \mathrm{E}-5 \mathrm{~g} / \mathrm{cm}^{3}\right)\end{array}$ \\
\hline 22 & $\begin{array}{l}\text { Suspended } 1 \mathrm{~m} \text { above } \\
\text { Martian regolith on } \\
\text { Olympus Mons }\end{array}$ & Yes & $\begin{array}{l}\text { RPS is } 1 \mathrm{~m} \text { above the surface of Martian } \\
\text { regolith; surrounding } \mathrm{CO}_{2} \text { atmosphere } \\
\text { corresponds to mean Olympus Mons densities } \\
\left(1.70 \mathrm{E}-6 \mathrm{~g} / \mathrm{cm}^{3}\right)\end{array}$ \\
\hline \multicolumn{4}{|c|}{ Suspended in Martian atmosphere } \\
\hline 23 & $\begin{array}{l}\text { Suspended in Martian } \\
\text { atmosphere in Gale Crater }\end{array}$ & Yes & $\begin{array}{l}\text { RPS is suspended in } \mathrm{CO}_{2} \text { atmosphere } \\
\text { corresponding to mean Gale Crater densities } \\
\left(1.80 \mathrm{E}-5 \mathrm{~g} / \mathrm{cm}^{3}\right)\end{array}$ \\
\hline 24 & $\begin{array}{l}\text { Suspended in Martian } \\
\text { atmosphere on Olympus } \\
\text { Mons }\end{array}$ & Yes & $\begin{array}{l}\text { RPS is suspended in } \mathrm{CO}_{2} \text { atmosphere } \\
\text { corresponding to mean Olympus Mons densities } \\
\left(1.70 \mathrm{E}-6 \mathrm{~g} / \mathrm{cm}^{3}\right)\end{array}$ \\
\hline 25 & Buried in Martian regolith & Yes & RPS is suspended in Martian regolith \\
\hline
\end{tabular}




\begin{tabular}{|c|c|c|c|}
\hline Env \# & $\begin{array}{l}\text { Environment label } \\
\text { in menu }\end{array}$ & $\begin{array}{l}\text { Rotation } \\
\text { allowed? }\end{array}$ & Comments \\
\hline \multicolumn{4}{|c|}{ Titan } \\
\hline 26 & On Titan regolith & No & $\begin{array}{l}\text { RPS is oriented vertically on the surface of Titan } \\
\text { regolith (water ice) }\end{array}$ \\
\hline 27 & $\begin{array}{l}\text { Suspended } 1 \mathrm{~m} \text { above } \\
\text { Titan regolith }\end{array}$ & Yes & $\begin{array}{l}\text { RPS is } 1 \mathrm{~m} \text { above the surface of Titan regolith } \\
\text { (water ice) }\end{array}$ \\
\hline 28 & $\begin{array}{l}\text { Suspended in Titan } \\
\text { atmosphere }\end{array}$ & Yes & RPS is suspended in Titan's atmosphere \\
\hline 29 & Buried in Titan regolith & Yes & $\begin{array}{l}\text { RPS is suspended in Titan regolith } \\
\text { (water ice) }\end{array}$ \\
\hline \multicolumn{4}{|c|}{ Liquid methane } \\
\hline 30 & On surface of methane & No & $\begin{array}{l}\text { RPS is oriented vertically on the surface of } \\
\text { liquid methane }\end{array}$ \\
\hline 31 & $\begin{array}{l}\text { Suspended } 1 \mathrm{~m} \text { above } \\
\text { methane }\end{array}$ & Yes & RPS is $1 \mathrm{~m}$ above the surface of liquid methane \\
\hline 32 & Submerged in methane & Yes & RPS is suspended in liquid methane \\
\hline \multicolumn{4}{|c|}{ Liquid ethane } \\
\hline 33 & On surface of ethane & No & $\begin{array}{l}\text { RPS is oriented vertically on the surface of } \\
\text { liquid ethane }\end{array}$ \\
\hline 34 & $\begin{array}{l}\text { Suspended } 1 \mathrm{~m} \text { above } \\
\text { ethane }\end{array}$ & Yes & RPS is $1 \mathrm{~m}$ above the surface of liquid ethane \\
\hline 35 & Submerged in ethane & Yes & RPS is suspended in liquid ethane \\
\hline \multicolumn{4}{|c|}{ Europa and Enceladus } \\
\hline 36 & $\begin{array}{l}\text { On surface of ice } \\
\text { (in vacuum) }\end{array}$ & No & $\begin{array}{l}\text { RPS is oriented vertically on the surface of } \\
\text { water-ice and in vacuum }\end{array}$ \\
\hline 37 & $\begin{array}{l}\text { Suspended } 1 \mathrm{~m} \text { above ice } \\
\text { (in vacuum) }\end{array}$ & Yes & $\begin{array}{l}\text { RPS is } 1 \mathrm{~m} \text { above the surface of water-ice and in } \\
\text { vacuum }\end{array}$ \\
\hline 38 & Suspended in ice & Yes & RPS is suspended in solid water ice \\
\hline 39 & $\begin{array}{l}\text { Submerged in column of } \\
\text { freshwater surrounded } \\
\text { by ice }\end{array}$ & Yes & $\begin{array}{l}\text { RPS is suspended in } 1.5 \mathrm{~m} \text { diameter liquid fresh } \\
\text { water and surrounded by solid water-ice }\end{array}$ \\
\hline 40 & $\begin{array}{l}\text { Submerged in liquid } \\
\text { freshwater }\end{array}$ & Yes & RPS is suspended in liquid fresh water \\
\hline 41 & $\begin{array}{l}\text { Submerged in column of } \\
\text { salt-water surrounded } \\
\text { by ice }\end{array}$ & Yes & $\begin{array}{l}\text { RPS is suspended in } 1.5 \mathrm{~m} \text { diameter liquid } \\
\text { saltwater and surrounded by solid water-ice }\end{array}$ \\
\hline 42 & $\begin{array}{l}\text { Submerged in liquid } \\
\text { salt-water }\end{array}$ & Yes & RPS is suspended in liquid saltwater \\
\hline
\end{tabular}




\begin{tabular}{|c|c|c|c|c|c|}
\hline ENV \# & $\begin{array}{c}\text { RPS-DET render } \\
\text { (not to scale) }\end{array}$ & ENV \# & $\begin{array}{c}\text { RPS-DET render } \\
\text { (not to scale) }\end{array}$ & ENV \# & $\begin{array}{l}\text { RPS-DET render } \\
\text { (not to scale) }\end{array}$ \\
\hline 1 & & 7 & & 13 & \\
\hline 2 & & 8 & & 14 & \\
\hline 3 & & 9 & & 15 & \\
\hline 4 & & 10 & & 16 & \\
\hline 5 & & 11 & & 17 & \\
\hline 6 & & 12 & & 18 & \\
\hline 19 & & 28 & & 36 & \\
\hline
\end{tabular}




\begin{tabular}{|c|c|c|c|c|c|}
\hline ENV \# & $\begin{array}{l}\text { RPS-DET render } \\
\text { (not to scale) }\end{array}$ & ENV \# & $\begin{array}{l}\text { RPS-DET render } \\
\text { (not to scale) }\end{array}$ & ENV \# & $\begin{array}{l}\text { RPS-DET render } \\
\text { (not to scale) }\end{array}$ \\
\hline 20 & & 29 & & 37 & \\
\hline 22 & & 30 & & 38 & \\
\hline 23 & & 31 & & 39 & \\
\hline 24 & & 32 & & 40 & \\
\hline 25 & & 33 & & 41 & \\
\hline 26 & & 34 & & 42 & \\
\hline 27 & & 35 & & & \\
\hline
\end{tabular}





\section{APPENDIX C. LOWER ENERGY PHOTON THRESHOLD}

While SCALE provides advanced deterministic methods for decreasing computational time required for Monte-Carlo calculations, there are simple methods to vet a source term that were exercised for RPS-DET. For probabilistic calculations (Monte-Carlo), particle energy regimes of high activity but with low contribution to the final tallied result (i.e., external flux and/or dose) contribute little to convergence on an accurate answer, but they consume large amounts of computational time. For these reasons, hard thresholds for low-consequence and high-probability photons were investigated to reduce the amount of computational time required for RPS-DET simulations.

The source photon energy distribution computed by ORIGEN contains a large number of low-energy photons. The distribution for an age of 25 years is shown below.

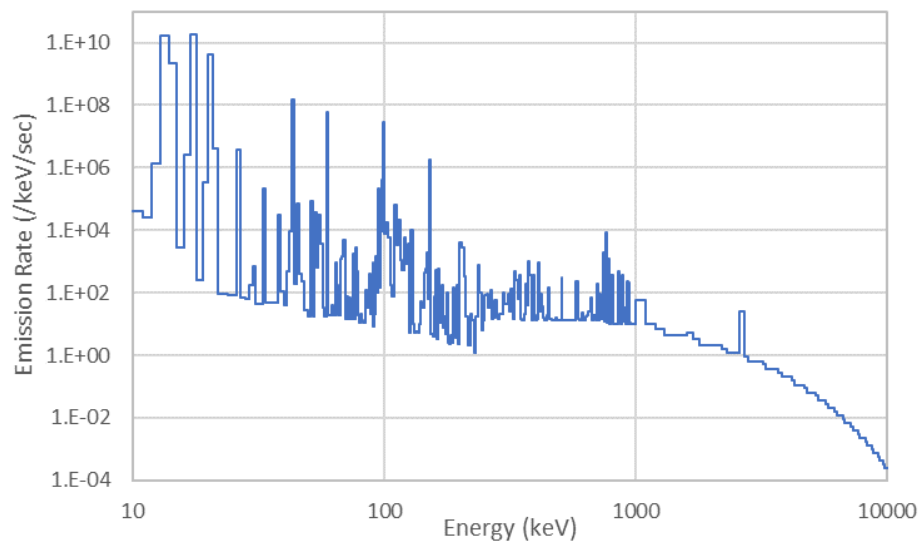

Figure 52: Photon spectrum emitted by RPS-DET default fuel at 25-years-old.

For an age of 25 years, ORIGEN computes that $4.29 \times 10^{10}$ photons $/ \mathrm{g} / \mathrm{sec}$ and $3.89 \times 10^{3}$ neutrons/g/sec are released. This large disparity between the numbers of photons and neutrons can lead to sampling issues in analog Monte Carlo dose rate calculations. For the photons, $99.7862 \%$ are less than $50 \mathrm{keV}$, and $99.9995 \%$ are less than $200 \mathrm{keV}$ (at an age of 25 years). (Note, one fueled clad [FC] contains $141.15 \mathrm{~g}$ of $\mathrm{PuO}_{2}$ ).

The iridium shell (thickness of $0.07575 \mathrm{~cm}$ and density of $22.42 \mathrm{~g} / \mathrm{cm}^{3}$ ) that covers the $\mathrm{PuO}_{2}$ material attenuates low-energy photons very well. The attenuation factor based only on the photoelectric effect for different energy photons is shown below, with the source energy distribution for a time of 25 years. 


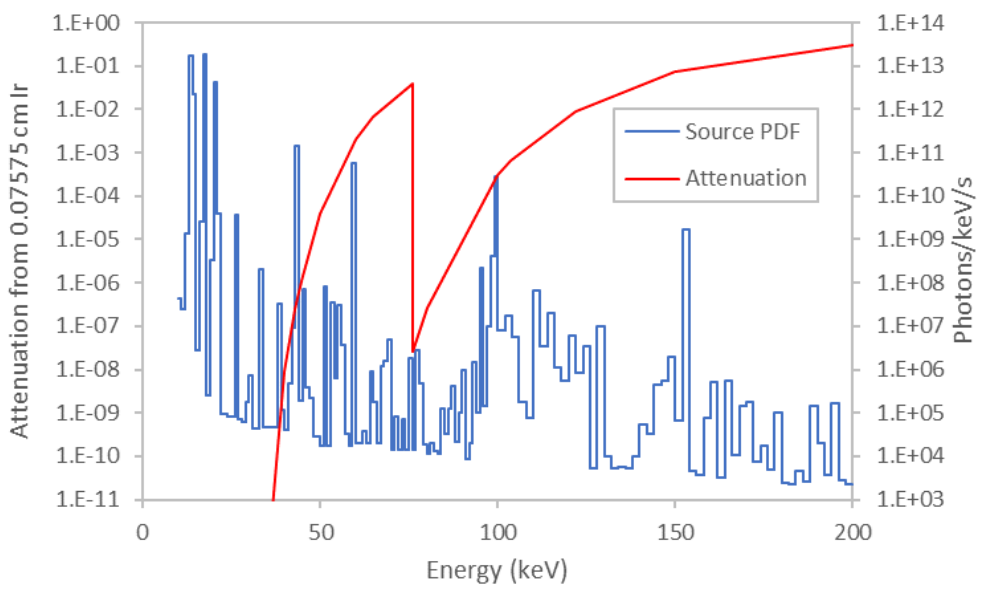

Figure 53: Photon spectrum with overlaid attenuation factor for low energy regime of 25-year-old fuel.

This indicates that photons below $40 \mathrm{keV}$ can safely be left out of the source distribution without having any impact on the energy-dependent photon flux outside the iridium.

The plutonium oxide fuel (density $11.52 \mathrm{~g} / \mathrm{cm}^{3}$ ) is also a good attenuator. Low-energy photons born more than a few millimeters inside the outer edge will be severely attenuated by the combination of the $\mathrm{PuO}_{2}$ and iridium materials. What really matters is the contribution of the low-energy photons to the dose rate outside of the FC body.

Detailed simulations were implemented to compute the photon dose rate just outside a bare FC. The dose rate $(2.43 \mathrm{mrem} / \mathrm{hr} / \mathrm{g})$ is dominated by photons in the range of $500-1,000 \mathrm{keV}$. (Ignoring photons under $200 \mathrm{keV}$, the majority of the source photons are between 500-1,000 keV.)
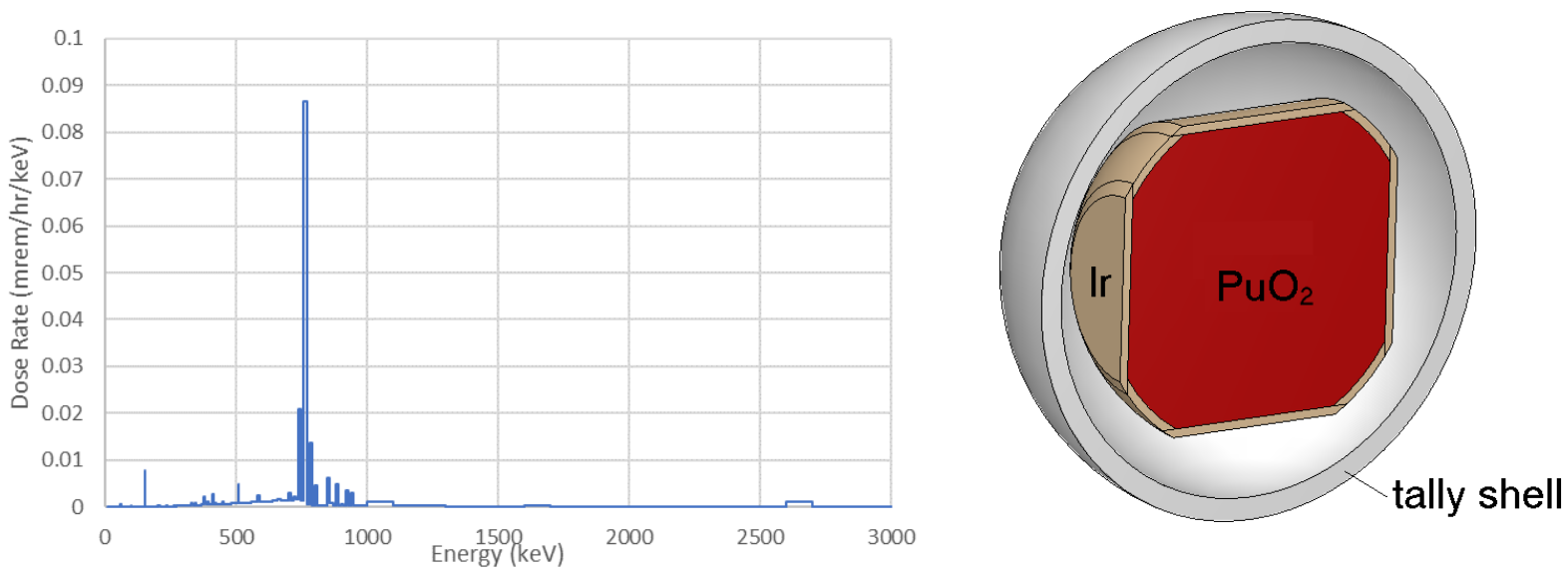
The table below shows the cumulative fraction of the photon dose rate.

\begin{tabular}{rc}
\hline \multicolumn{2}{c}{ Percent of total dose rate from different photon energy regimes. } \\
\hline Below (keV) & Percent \\
\hline 50 & $0.000 \%$ \\
100 & $0.041 \%$ \\
200 & $0.754 \%$ \\
250 & $0.982 \%$ \\
300 & $1.338 \%$ \\
500 & $6.842 \%$ \\
1,000 & $81.759 \%$ \\
2,000 & $92.659 \%$ \\
3,000 & $99.011 \%$ \\
11,000 & $100.000 \%$ \\
\hline
\end{tabular}

This table shows that photons with an energy of $50 \mathrm{keV}$ or less can be left out of the source energy distribution without impacting the dose rate at all. If photons below $200 \mathrm{keV}$ are ignored, then the dose rate outside the $\mathrm{FC}$ is underestimated by less than $1 \%$.

With more materials around the FC (e.g., general purpose heat source, thermoelectrics, insulation, housing bodies, spacecraft, planetary atmospheres/materials), the contribution of the low-energy photons to dose rates will be even smaller than the amounts listed in the table above $(\ll 1 \%)$. Also note that the photon dose rate outside the FC are about $20 \%$ of the total dose rate. As more materials are added around the FC, the fraction of dose rate from the primary photons should decrease.

For the reasons outlined above, the natural photon/gamma spectrum of $\mathrm{PuO}_{2}$ fuels is truncated at a lower limit of $200 \mathrm{keV}$ to provide the user with a faster, more efficient, more accurate convergence on a useful answer.

If any questions or concerns with this methodology arise, please contact the RPS-DET development team at rpsdethelp@ornl.gov . 



\section{APPENDIX D. RPS-DET SIMULATION COMPARISONS TO MMRTG MEASUREMENT}

Mars Science Laboratory (MSL) used a Multi-Mission Radioisotope Thermoelectric Generator (MMRTG) for a primary power system and was surveyed for occupational concerns regarding radiation emissions. Measurements of MMRTG (for MSL) were conducted at The Idaho National Laboratory (INL), and these measurements serve as a benchmark of RPS-DET's simulation accuracy. While detailed information about individual FC placement, FC isotopic composition, fuel impurity levels, and fuel composition with respect to GPHS location in the RPS were unknown for this comparison, the general assumptions for RPS-DET geometry for MMRTG - a concrete room and the RPS-DET "default" fuel assay and impurity settings — were selected with a fuel age of 3 years old.

Given these assumptions, and the systematic uncertainties involved in the benchmark data, there is agreement within uncertainties between RPS-DET and MMRTG neutron/gamma measurements for the MSL mission. Future missions will use fuel similar to these comparisons (and thus the RPS-DET default fuel), but the user is cautioned to consider the fact that fuel that is "within specification" can vary significantly (up to $\sim 30 \%$ ) with consideration to the emitted spectrum and resulting responses. 


\section{Neutron Response}

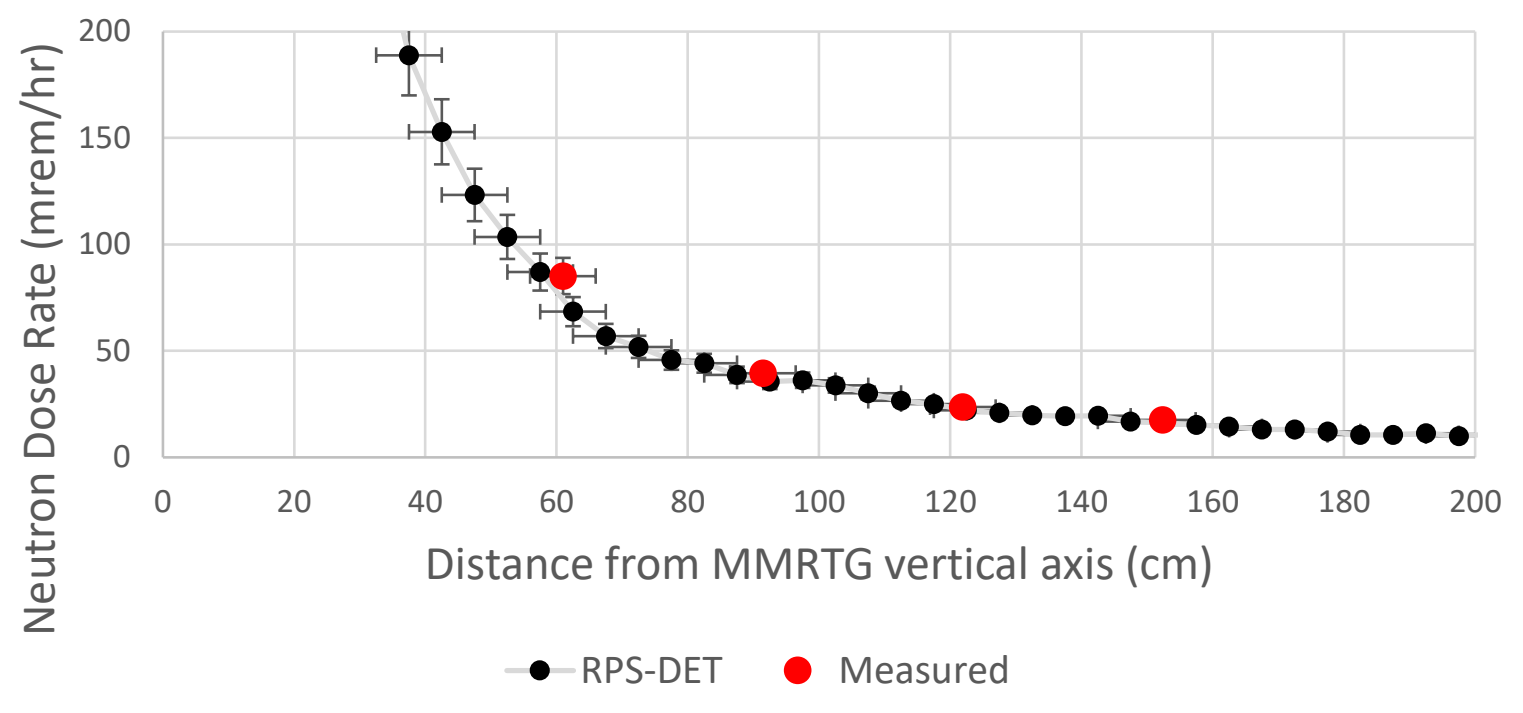

Figure 54: RPS-DET neutron dose rate simulations (black) compared to occupational dose measurements (red).

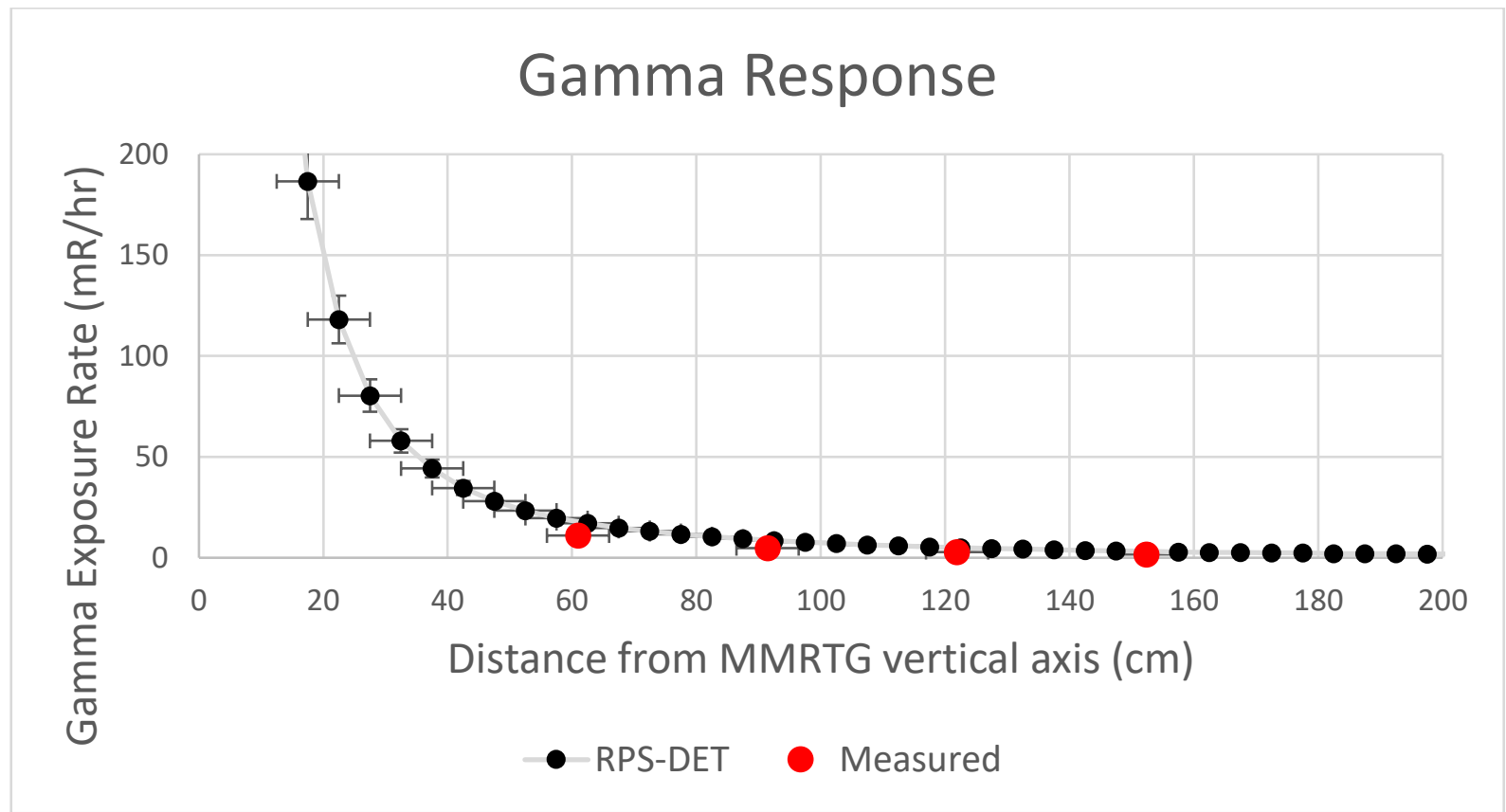

Figure 55: RPS-DET photon exposure rate simulations (black) compared to occupational dose measurements (red). 